\title{
ASSOCIATION BETWEEN CHRONIC RHINOSINUSITIS AND HEALTH-RELATED QUALITY OF LIFE IN ADULTS WITH CYSTIC FIBROSIS
}

\author{
by \\ Al-Rahim Habib \\ B.Sc., Simon Fraser University, 2011 \\ A THESIS SUMBITTED IN PARTIAL FULFILLMENT OF THE REQUIREMENTS \\ FOR THE DEGREE OF \\ MASTER OF SCIENCE \\ in \\ THE FACULTY OF GRADUATE AND POSTDOCTORAL STUDIES \\ (Population and Public Health) \\ THE UNIVERSITY OF BRITISH COLUMBIA \\ (Vancouver) \\ September 2014 \\ (C) Al-Rahim Habib, 2014
}




\section{ABSTRACT}

\section{Objectives:}

In the past four decades, the median age of survival has nearly doubled for individuals with cystic fibrosis (CF), where over half the population is now adults. The prevalence of chronic diseases such as chronic rhinosinusitis (CRS) has increased with older age. In the non-CF population, CRS is associated with reduced health-related quality of life (HRQoL). Our objectives were to determine the prevalence of CRS among adults with CF and evaluate its impact on their HRQoL.

\section{Methods:}

One hundred sixty individuals from an academic teaching hospital in Vancouver, Canada were eligible to participate in this cross-sectional study. Included subjects were above the age of 18 years, had a confirmed diagnosis of CF and attended the CF clinic between September 2013 and April 2014. Participants completed a CF-specific HRQoL questionnaire (i.e. CFQ-R 14+), and underwent symptom and endoscopic assessment to diagnose CRS. Medical charts were reviewed for potential confounders that included socio-demographic (age, gender and body-mass index) and clinical factors (age of CF diagnosis, type of CF mutation, lung function and chronic Pseudomonas aeruginosa infection). Multivariable linear regression was used to model the relationship between CRS and HRQoL, adjusted for potential confounders.

\section{Results:}

One hundred twenty-one individuals were contacted prior to clinic visits of which, $113(93.4 \%)$ consented to participate. The prevalence of CRS was found to be $64.2 \%$. Socio-demographic and clinical factors were similarly distributed between CRS-positive and negative groups, except age of CF diagnosis. CRS-positive individuals were diagnosed with $\mathrm{CF}$ at younger age than non-CRS 
counterparts, although this finding was not significant (mean difference: 6.5 years, $p=0.13$ ). In unadjusted analysis, those with CRS reported worse HRQoL on 10 of 12 domains of the CFQ-R 14+. These findings remained despite adjustment for potential confounders. Individuals with CRS reported significantly worse HRQoL on Respiratory symptoms (adjusted regression coefficient: -13.33, $\mathrm{p}=0.001$ ) and Digestion (adjusted regression coefficient: $-8.71, \mathrm{p}=0.03$ ) domains, than non-CRS counterparts.

\section{Conclusion:}

The majority of adults with CF suffer from concomitant CRS. CRS is associated with worse HRQoL based on multiple domains of the CFQ-R 14+. CRS should be diagnosed and managed to optimize the HRQoL for adults with CF. 


\section{PREFACE}

This thesis involves primary analysis of data collected from a sample of participants recruited from a large group of individuals, currently enrolled at the St. Paul's Cystic Fibrosis Clinic. Study design, recruitment, data collection, statistical analysis and a systematic review of relevant literature are all counted towards this thesis and were led by Al-Rahim Habib with guidance from Dr. Jane A. Buxton, Dr. Amin R. Javer, Dr. Bradley S. Quon, Dr. Pearce G. Wilcox and Dr. Joel Singer.

All work presented henceforth were conducted at the St. Paul's Cystic Fibrosis Clinic and St. Paul's Sinus Centre, located in the St. Paul's Hospital, Vancouver Canada.

Ethics approval for this thesis was provided the University of British Columbia Clinical Research Ethics Board (approval number: H13-01848).

Findings from this thesis were presented at the 2014 North American Cystic Fibrosis Conference in Atlanta, Georgia. 


\section{TABLE OF CONTENTS}

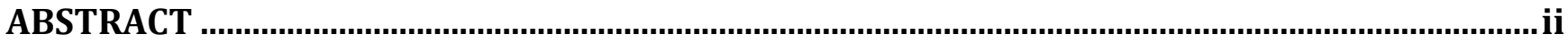

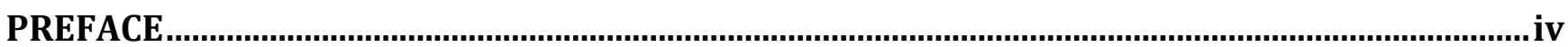

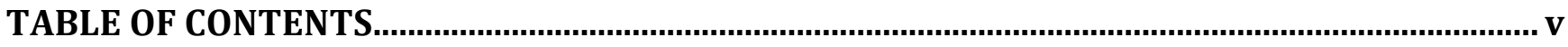

LIST OF TABLES

LIST OF FIGURES

LIST OF ABBREVIATIONS ….................................................................................................

ACKNOWLEDGEMENTS ….................................................................................................... xii

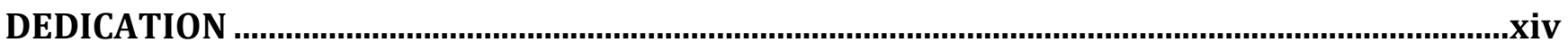

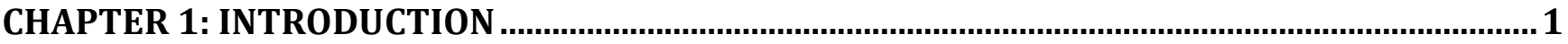

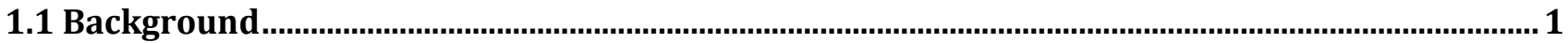

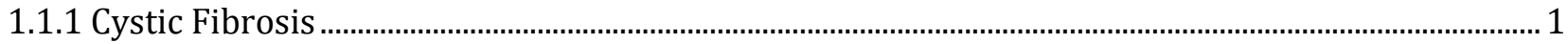

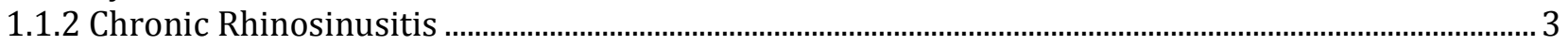

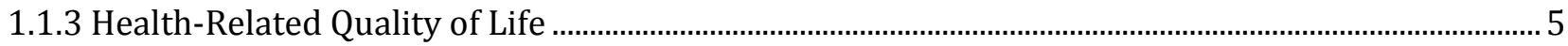

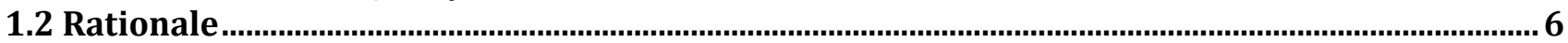

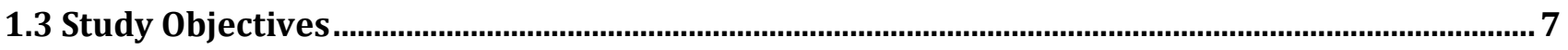

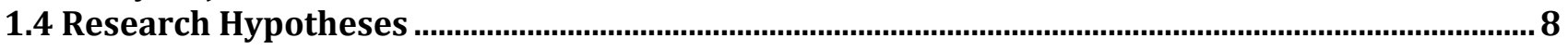

CHAPTER 2: SYSTEMATIC REVIEW

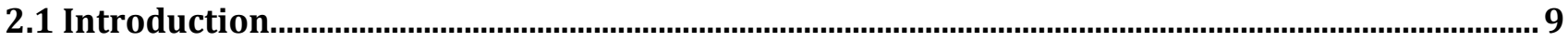

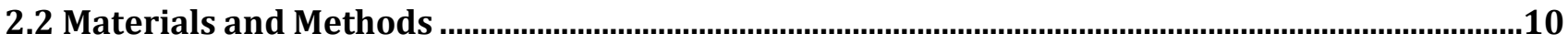

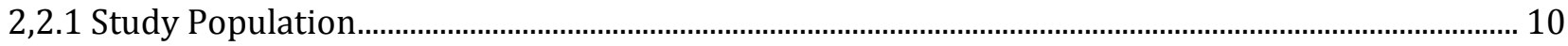

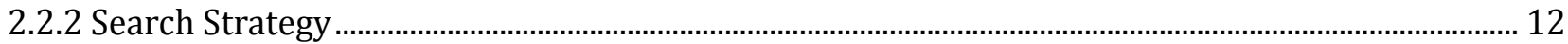

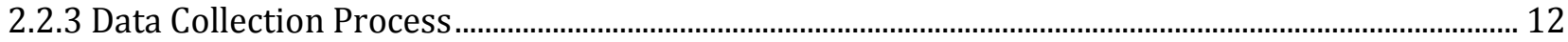

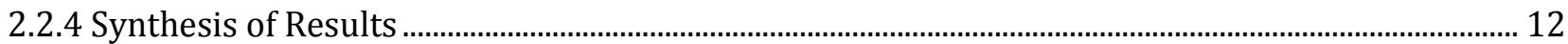

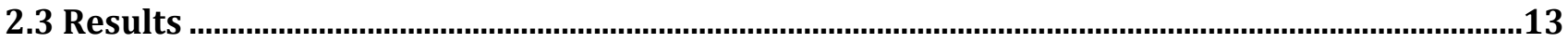

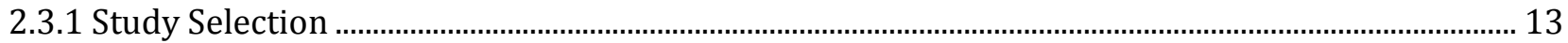

2.3.2 Summary of Risk of Bias, Study Design and Subject Characteristics..................................................... 15

2.3.3 Association Between Socio-Demographic and Clinical Factors With the CFQ-R 14+ ...................... 16

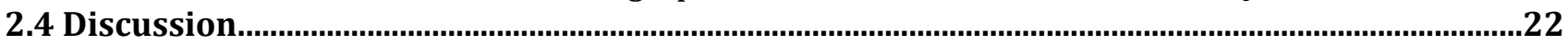

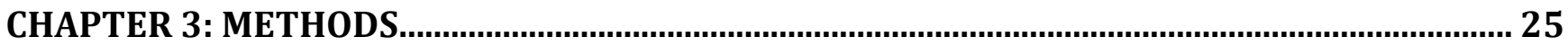

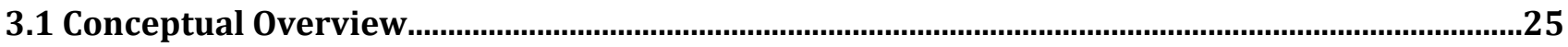

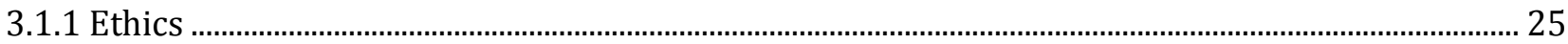

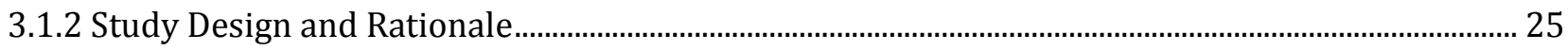

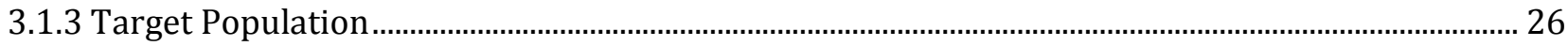

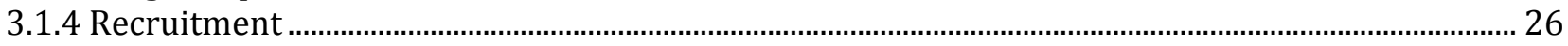

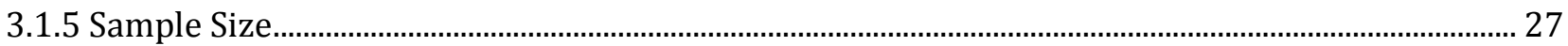

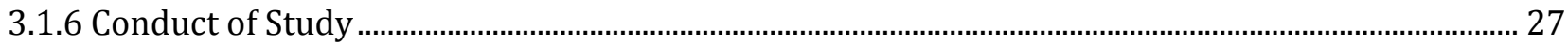

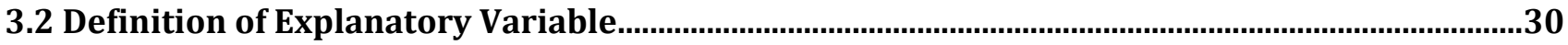

3.2.1 Chronic Rhinosinusitis ............................................................................................................................ 30

3.3 Health-Related Quality of Life Outcomes ......................................................................................32

3.3.1 Cystic Fibrosis Questionnaire-Revised .......................................................................................... 32

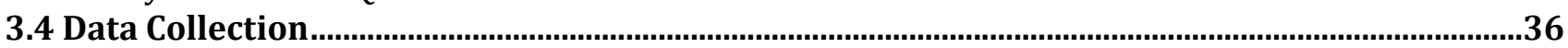

3.5 Coding of Outcome and Explanatory Variables ………..................................................................37

3.5.1 CFQ-R 14+ Domain Scores ....................................................................................................................... 37

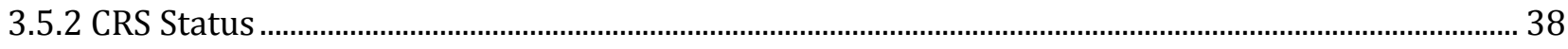




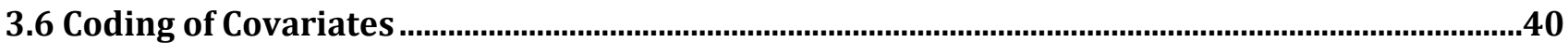

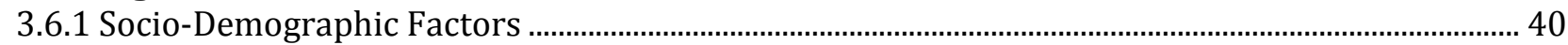

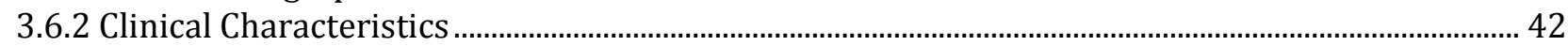

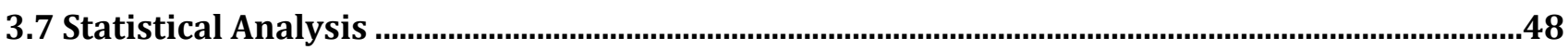

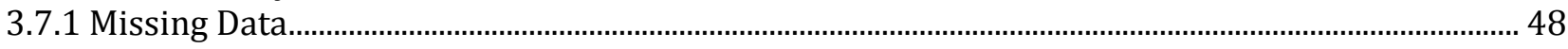

3.7.2 Methods to Assess Representativeness of Study Sample................................................................. 50

3.7.3 Methods to Analyze Socio-Demographic Factors and Clinical Characteristics by CRS status ...... 50

3.7.4 Methods to Analyze CRS Status and CFQ-R 14+ Domain Scores........................................................... 51

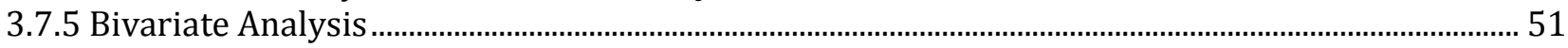

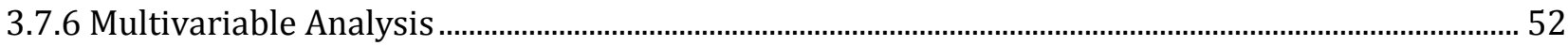

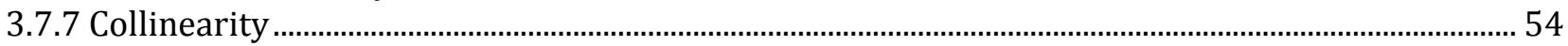

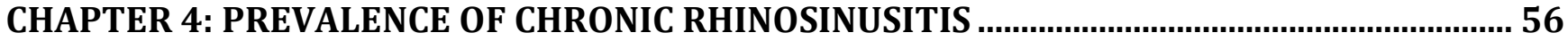

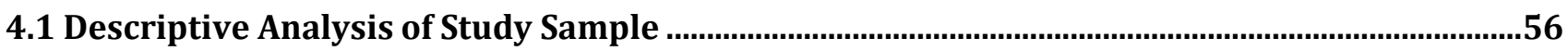

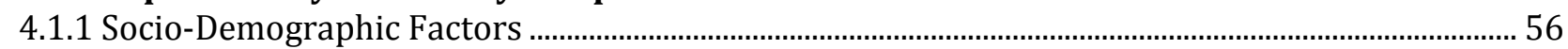

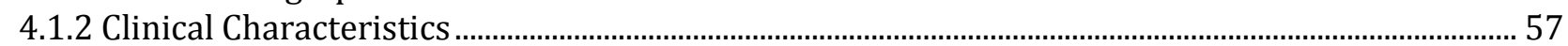

4.1.3 Comparison With Clinic Population.................................................................................................. 58

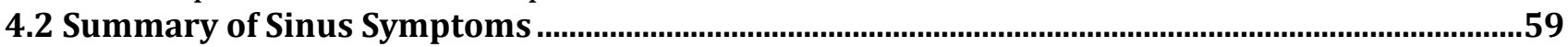

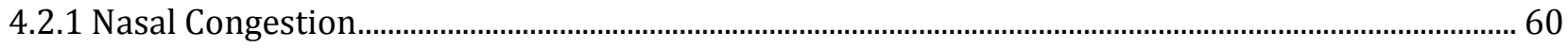

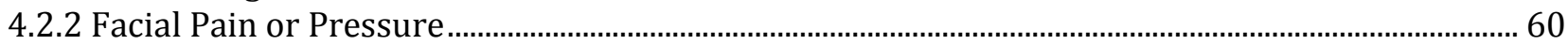

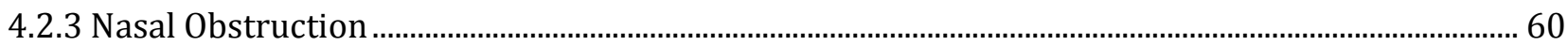

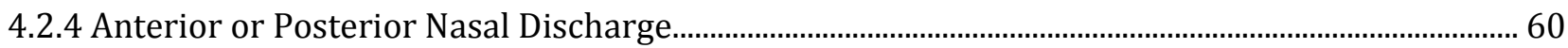

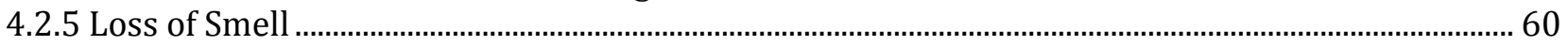

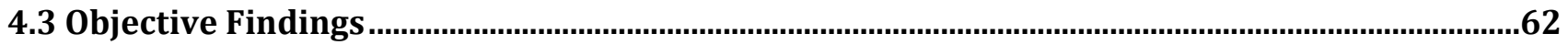

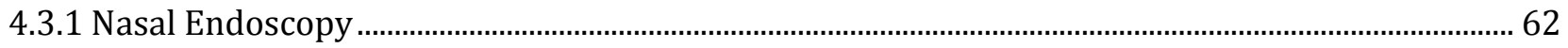

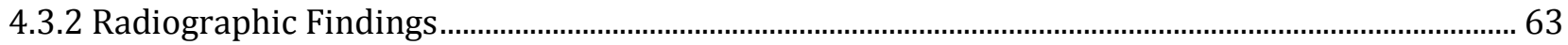

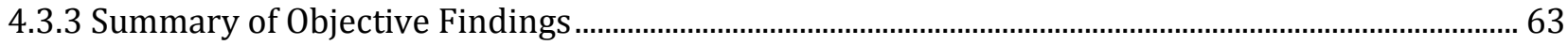

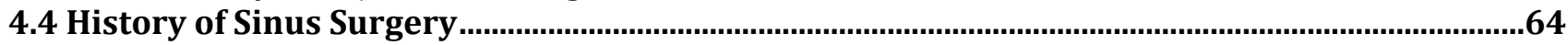

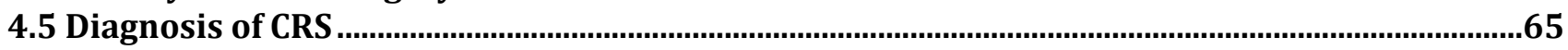

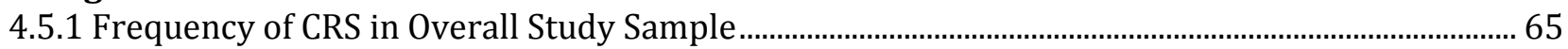

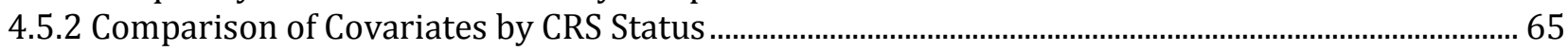

4.5.3 Participants Stratified by Receiving or Refusing Nasal Endoscopy ..................................................... 67

CHAPTER 5: EFFECT OF CRS ON CFQ-R 14+ DOMAIN SCORES.................................................... 70

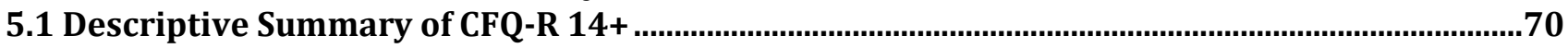

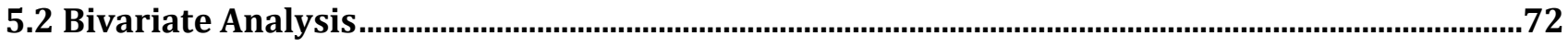

5.2.1 Summary of CFQ-R 14+ Domain Scores by CRS Status ........................................................................ 72

5.2.2 Summary of CFQ-R 14+ Domain Scores by Covariates ......................................................................... 73

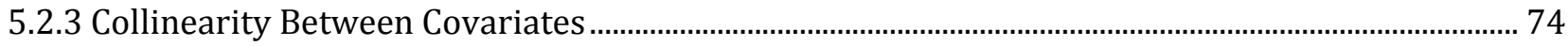

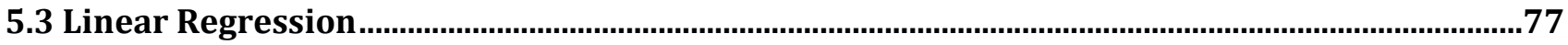

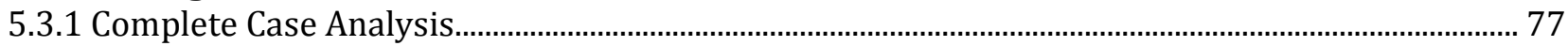

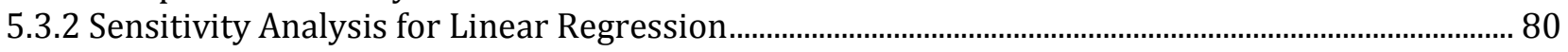

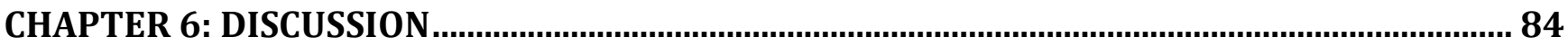

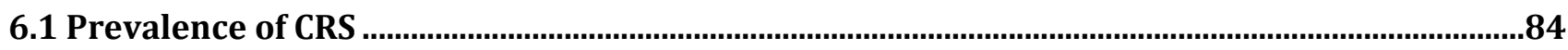

6.2 Socio-Demographic and Clinical Factors Associated with CRS Status ........................................86

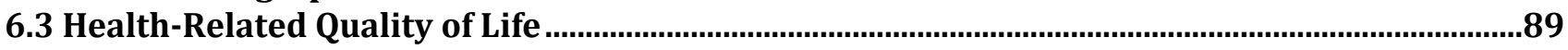

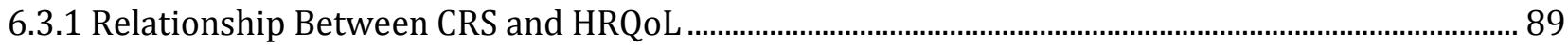

6.3.2 Significant CFQ-R 14+ Domains ......................................................................................................... 91

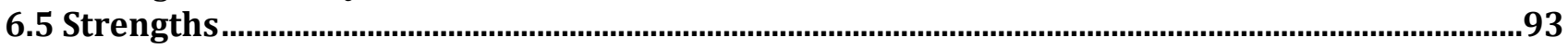

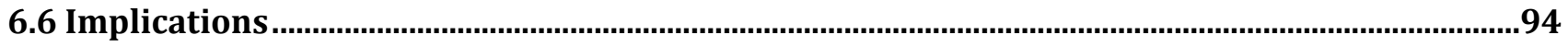

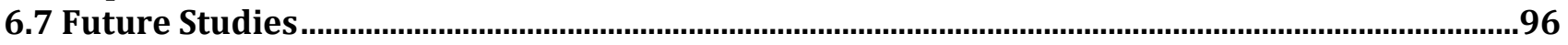

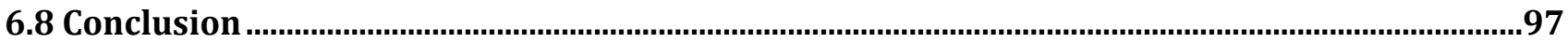




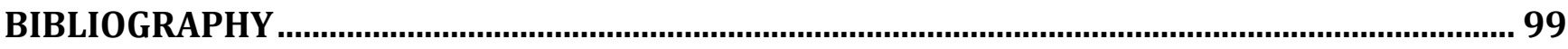

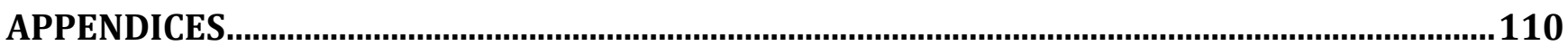

Appendix A: Additional Tables for Chapter 2: Systematic Review..................................................110

Appendix B: Data Collection Form for Sinus Symptoms and Nasal Endoscopy ................................115

Appendix C: Comparing Participants With or Without Missing Data .................................................116

Appendix D: Associations Between Covariates and CFQ-R 14+ Domains...........................................118

Appendix E: Directed Acyclic Graphs Illustrating the Relationship Between CRS and CFQ-R 14+

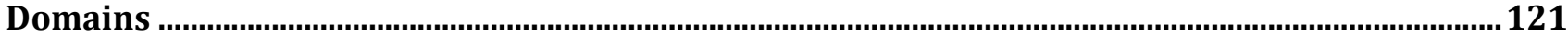




\section{LIST OF TABLES}

Table 2.1- Description of a priori chosen socio-demographic and clinical factors potentially associated with health-related quality of life in adults with cystic fibrosis

Table 2.2- Characteristics of the 28 articles meeting the inclusion/exclusion criteria

Table 3.1- Summary of methods used to diagnosis CRS.

Table 3.2- Number of items and items numbers used in the scoring of each CFQ-R 14+ domain .38

Table 3.3- Summary of outcome variable, explanatory variable and covariates captured in crosssectional evaluation of the impact of CRS on the HRQoL of adults with CF

Table 3.4- Frequency of missing data for outcome variable, explanatory variable and covariates

Table 4.1- Descriptive summary of socio-demographic factors for final study sample..... .56

Table 4.2- Descriptive summary of clinical characteristics for final study sample

Table 4.3- Descriptive summary of socio-demographic factors and clinical characteristics to compare total clinic population and study sample recruited.

Table 4.4- Descriptive summary of sinus symptoms for overall study sample

Table 4.5- Summary of objective findings for CRS among individuals electing to receive nasal endoscopy.

Table 4.6- Comparison of socio-demographic factors and clinical characteristics between CRS positive and negative individuals.

Table 4.7- Comparison of socio-demographic factors and clinical characteristics between participants receiving and refusing nasal endoscopy.

Table 5.1- Descriptive summary of domain scores for study sample completing the CFQ-R 14+ .......71

Table 5.2- Comparison of CFQ-R 14+ domains scores between participants positive versus negative for CRS .

Table 5.3- Summary of covariates significantly associated with CFQ-R 14+ domain scores from bivariate analysis of total study sample and from systematic review in Chapter 2 ........................... 76

Table 5.4- Unadjusted and adjusted linear regression using complete case data .79

Table 5.5- Sensitivity analysis of unadjusted and adjusted linear regression 
Table A.1- Description of search strategy for systematic review identifying socio-demographic factors and clinical characteristics that are associated with health-related quality of life in adults with cystic fibrosis

Table A.2- Description of data collection form for systematic review identifying socio-demographic and clinical factors potentially associated with health-related quality of life in adults with cystic fibrosis

Table A.3- Gender, age and lung function of subjects included in the final collection of 28 articles for systematic review identifying socio-demographic factors and clinical characteristics that are associated with health-related quality of life in adults with cystic fibrosis.

Table A.4- Proportion of studies reporting statistically significant bivariable associations between candidate factors and individual CFQ-R 14+ domains ....

Table A.5- Proportion of studies reporting statistically significant multivariable associations between candidate factors and domains of the CFQ-R 14+

Table C.1- Comparison of participants with or without missing data regarding CRS status

Table C.2- Comparison of sinus-related characteristics, socio-demographics and clinical characteristics between participants with or without missing CFQ-R 14+ domain scores 118

Table D.1- Bivariate associations between socio-demographic factors and CFQ-R 14+ domains

Table D.2- Bivariate associations between continuous clinical characteristics and CFQ-R 14+ domains

Table D.3- Bivariate associations between categorical clinical characteristics and CFQ-R 14+ domains 


\section{LIST OF FIGURES}

Figure 2.1- PRISMA (Preferred Reporting Items for Systematic Reviews and Meta-Analyses) flow diagram depicting search results and eligible articles.

Figure 3.1- Schematic describing the frequency and proportion of individuals eligible, approached, participating, refusing and completing study questionnaires and nasal endoscopy....

Figure 4.1- Venn diagram showing distribution of objective findings

Figure 5.1- Schematic illustrating primary relationship studied between CRS and CFQ-R 14+ and collinearity among covariates

Figure 5.2- Comparison of unadjusted linear regression estimates between complete case analysis and sensitivity analysis using multiple imputations

Figure 5.3- Comparison of adjusted linear regression estimates between complete case analysis and sensitivity analysis using multiple imputations

Figure E.1- Schematic illustrating the relationship between CRS and CFQ-R 14+ Physical Functioning

Figure E.2- Schematic illustrating the relationship between CRS and CFQ-R 14+ Energy ..............123

Figure E.3- Schematic illustrating the relationship between CRS and CFQ-R 14+ Emotion

Figure E.4- Schematic illustrating the relationship between CRS and CFQ-R 14+ Social Functioning

Figure E.5- Schematic illustrating the relationship between CRS and CFQ-R 14+ Role Functioning 125 Figure E.6- Schematic illustrating the relationship between CRS and CFQ-R 14+ Eating Disturbances

Figure E.7- Schematic illustrating the relationship between CRS and CFQ-R 14+ Body Image ........ 126

Figure E.8- Schematic illustrating the relationship between CRS and CFQ-R 14+ Treatment Burden127

Figure E.9- Schematic illustrating the relationship between CRS and CFQ-R 14+ Health Perception128

Figure E.10- Schematic illustrating the relationship between CRS and CFQ-R 14+ Respiratory

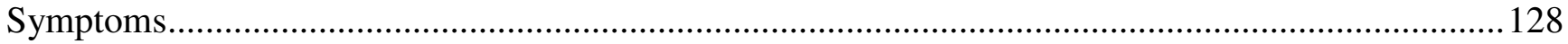

Figure E.11- Schematic illustrating the relationship between CRS and CFQ-R 14+ Digestion ..........129

Figure E.12- Schematic illustrating the relationship between CRS and CFQ-R 14+ Weight 


\section{LIST OF ABBREVIATIONS}

2012-EPOS - 2012 European Position Paper on Rhinosinusitis and Nasal Polyps

B. cepacia - Burholderia cepacia

BDI - Beck Depression Inventory

BMI - Body-Mass Index

CF - Cystic Fibrosis

CFTR - Cystic Fibrosis Transmembrane Regulator

CFRD - Cystic Fibrosis Related Diabetes

CFQ-R - Cystic Fibrosis Questionnaire-Revised

CFQ-R 14+ - Cystic Fibrosis Questionnaire-Revised for adolescents and adults greater than 14 years of age

CFQoL - Cystic Fibrosis Quality of Life Questionnaire

CFQ - Cystic Fibrosis Questionnaire

CFQ-14+ - Cystic Fibrosis Questionnaire for adolescents and adults greater than 14 years of age

CRS - Chronic Rhinosinusitis

CT - Computed Tomography

DAG - Directed Acyclic Graph

ESCF - Epidemiologic Study of Cystic Fibrosis

$\mathrm{FEV}_{1} \%$ predicted - percent predicted forced expiratory volume in one second

GER - Gastro-Esophageal Reflux

GI - Gastrointestinal

GRADE - Grades of Recommendation, Assessment, Development and Evaluation

HADS - Hospital Anxiety and Depression Scale

HRQoL - Health-Related Quality of Life

LES - Liverpool Epidemic Strain of Pseudomonas aeruginosa

MAR - Missing at Random

MLR - Multivariable Linear Regression 
MOOSE - Meta-Analysis of Observational Studies in Epidemiology

MSAS - Memorial Symptom Assessment Scale

NHP -Nottingham Health Profile

RESP - Respiratory

RSOM-31 - Rhinosinusitis Outcome Measure-31

P. aeruginosa - Pseudomonas aeruginosa

PRISMA - Preferred Reporting Items for Systematic Reviews and Meta-analysis

PRO - Patient Reported Outcomes

PSYCH - Psychological

SF-36 - Short Form-36

STROBE - Strengthening the Reporting of Observational Studies in Epidemiology

TCPS - Tri-Council Policy Statement

US FDA - United States Food and Drug Administration

WHO - World Health Organization 


\section{ACKNOWLEDGEMENTS}

I offer my gratitude to the faculty, staff and my fellow students at the School of Population and Public Health, for encouraging my thesis research. I owe special thanks to Dr. Jane A. Buxton, for supporting my research interests, supervising my thesis and for challenging me to evolve as an investigator and communicator. I sincerely appreciate your kindness, patience and commitment throughout this process. I thank Dr. Amin R. Javer for his mentorship and constant support, for which this project could not have existed. I am inspired by your work ethic and the care you provide to your patients. I am grateful to Dr. Pearce G. Wilcox and the staff at the St. Paul's Cystic Fibrosis Clinic, for supporting this project and allowing me to approach the patients in their care. In particular to Dr. Bradley S. Quon, I appreciate your critical insight, patience and commitment to this project. Thank you for your mentorship throughout my graduate studies. I also thank Dr. Joel Singer, for guiding me through the statistical analysis. Thank you for sharing your expertise with me. To Eri, Stephanie and Joannne, thank you for assisting with enrollment and providing timely updates regarding the clinic schedule. Our recruitment could not have been successful without your efforts. To Saad, Erin, Jamil, Karina, Rachelle and Frances, thank you for managing our participants and ensuring they were seen in a timely manner. Your work ethic is admirable. Lastly, my sincere thanks to all the individuals participating in this study. I appreciate the time you spent filling out questionnaires, walking between clinic locations and sharing your experiences.

I thank Cystic Fibrosis Canada for providing financial support to allow me to share these findings at the 2014 Canadian Society of Epidemiology and Biostatistics Student Conference. 


\section{DEDICATION}

I dedicate this thesis to Rozina Habib 


\section{CHAPTER 1: INTRODUCTION}

\subsection{Background}

\subsubsection{Cystic Fibrosis}

Cystic Fibrosis (CF) is an autosomal recessive disease that is caused by genetic mutations in the cysticfibrosis transmembrane regulator (CFTR) gene located on chromosome- $7 .{ }^{1}$ The CFTR protein is responsible for chloride and bicarbonate transport in epithelial cells. ${ }^{1}$ Epithelial cells are commonly found in the lungs, sinuses, gastrointestinal tract and vas deferens. ${ }^{1}$ CFTR dysfunction leads to the impairment of chloride transport channels and as a result, mucus becomes thick, sticky and unable to be cleared. ${ }^{1}$ The accumulation of mucus in these areas increases the propensity for infection, as bacterial and viral pathogens may colonize in this environment. ${ }^{1}$ To date, more than 1900 different mutations have been identified in the CFTR gene. ${ }^{1}$ Mutations are dichotomized into Class I to III versus Class IV to $\mathrm{V}$ and determined from genetic test results indicating the mutation type, location and corresponding functionality of the CFTR. ${ }^{2}$ Individuals presenting with Class I to III mutations are known to have a more severe phenotype of CF that includes an absent or nonfunctional CFTR, increased likelihood of developing pancreatic insufficiency and a worse prognosis. ${ }^{1,3,4}$

CF is the most common lethal genetic disease affecting Canadian children and adults. ${ }^{5}$ In 2012, it was estimated that nearly 4,000 Canadians were living with $\mathrm{CF}^{5}{ }^{5}$ This condition predominantly affects Caucasians (proportion of current cases: 92.5\%) but is also found in non-Caucasian individuals (i.e. Black: 0.8\%, Asian: 0.6\%, First Nations: 1.0\%, South Asian: 0.1\%). In 2012, 105 new diagnoses were made in Canada and the mean age at diagnosis was 4 years. ${ }^{5}$ Newborn screening programs have enabled early detection of $\mathrm{CF}$ and are suggested to have contributed to an increase in survival. . $^{1,34}$ Impressively, over the past four decades the median age of survival has nearly doubled in this patient population. Recent estimates from the Canadian CF Foundation Patient Database indicate that the 
median age of survival has increased from 28.4 years to 49.7 years from 1987 to $2012 .{ }^{5}$ Previously, care providers for these individuals were concerned predominantly with preventing premature death due to respiratory failure, as life expectancy was restricted to the late teens to early twenties. ${ }^{4}$ In 1987 , the median age of death for these individuals was 17 years and the proportion of adults living with severe lung function, defined as percent predicted forced expiratory volume in one second $\left(\mathrm{FEV}_{1} \%\right.$ predicted) $<40 \%$, was $30 \% .{ }^{5}$ However, the most recent estimates indicate the median age of death has increased to 31 years and the proportion of adults with severe $\mathrm{FEV}_{1} \%$ has dropped to $16 \%{ }^{5}$ This has also been paralleled with an upward trend in adequate nutrition, as measured by body-mass index (BMI, measured in $\left.\mathrm{kg} / \mathrm{m}^{2}\right)^{5}$

Various factors have attributed to the increase in life expectancy of this patient population. These include care delivery through CF-specific tertiary care centres, multi-disciplinary heath care teams and availability of antibacterial and pancreatic enzyme replacement therapies. ${ }^{3,4}$ Lung transplantation has improved the survival of individuals with end-stage CF and advancements in genetic testing have also contributed to improving life expectancy. ${ }^{2}$ Individuals with less severe phenotypes of $\mathrm{CF}$ are being diagnosed later in life and contribute to an increase in the overall age of survival. ${ }^{2}$ On the other hand, individuals diagnosed early in life due to severe phenotypes may die sooner if lung transplantation or necessary treatment is not received. ${ }^{2}$ Regardless of these factors the age demographic of the $\mathrm{CF}$ population has shifted, where to date over half of individuals living with CF are adults ( $\geq 18$ years of age) ${ }^{3-6}$ This has translated to individuals living further into adulthood than ever before and as result, a new assortment of challenges has emerged. The changing demographic of CF has enabled individuals to achieve higher levels of education, employment, the prospect of marriage and the opportunity to bear children. ${ }^{3,4}$ However, this has come at a cost of allocating more time to treatment and the emergence of chronic disease. ${ }^{3,4}$ The prevalence of chronic diseases such as CF-related diabetes (CFRD), bone 
disease (fracture, osteopenia, osteoporosis), anxiety and depression, joint problems (arthritis, arthropathy) and chronic rhinosinusitis has increased with older age. ${ }^{6}$

\subsubsection{Chronic Rhinosinusitis}

Chronic rhinosinusiits (CRS) is an inflammatory and infectious disease of the nose and paranasal sinuses, where symptoms present for greater than 12 weeks. ${ }^{7}$ The paranasal sinuses are comprised of four distinct sinus cavities (maxillary, ethmoid, frontal, sphenoid) that are occur bilaterally. CRS is characterized by five major symptoms: 1) nasal congestion, 2) facial pain or pressure, 3) nasal obstruction, 4) anterior or posterior nasal discharge and 5) loss of smell. ${ }^{7,8}$ Objectively, CRS is characterized by the presence of nasal polyps (fleshy, grape-like structures) or discoloured mucus, pus or inflammation in the middle meatus. ${ }^{9}$ The middle meatus can be considered as the anterior intersection of the maxillary, ethmoid and frontal sinuses. CRS is considered as an inflammatory and infectious disease. ${ }^{7}$ Inflammatory responses to allergic reactions initiated by cytokines and allergic mediators or increased activation of eosinophils and neutrophils, can cause swelling of sinus mucosa and obstruct sinus ostia (i.e. openings to the sinus cavities). ${ }^{7}$ As a result, secondary bacterial infections may occur contributing to a cascade of responsive inflammation and subsequent bacterial infections. ${ }^{7}$

The diagnosis of CRS is comprised of subjective and objective components. Subjectively, sufficient diagnosis requires the presence of symptoms, more specifically, at least 2 of the 5 major symptoms discussed above. ${ }^{9}$ Objective evidence is assessed by two methods: nasal endoscopy or sinus computed tomography (CT) scans. Nasal endoscopy is a procedure where a thin endoscope that is attached to a camera is inserted into the nose to allow visualization of the middle meatus and other intra-nasal anatomy and pathology. Sinus-CT scans allow otorhinolaryngologists to visualize mucosal walls and sinus ostia in extreme detail, thereby allowing for the determination of the presence or absence of CRS. 
For cases in which nasal endoscopy is negative, sinus-CT scans offer additional diagnostic value to observe anatomy that is not accessible by endoscopy. ${ }^{7}$ It is important to note that objective evidence alone is not sufficient to confirm diagnosis of CRS, as it has been shown that asymptomatic non-CRS individuals can present with objective findings. ${ }^{7}$ Several expert groups and task forces have been constructed to establish standardized guidelines for the diagnosis of CRS. These guidelines include the 2012 European Position Paper on Rhinosinusitis and Nasal Polyps (2012-EPOS) and the Canadian Clinical Practice Guidelines for Acute and Chronic Rhinosinusitis. ${ }^{8,9}$ Both guidelines agree on symptomatology, the necessity of subjective and objective findings and the utility of radiographic imaging as an adjunct to nasal endsocopy.

In the non-CF population, the prevalence of CRS has been estimated to range from 14 to $16 \%$ in the United States and 5\% in Canada. ${ }^{10-12}$ These estimates were based on national, population-based health surveys using self-reported responses from participants. CRS was more frequently associated with females, older age, obesity, cigarette smoking, asthma and allergies (food and non-food related). ${ }^{11,12}$ In the $\mathrm{CF}$ population, the prevalence of $\mathrm{CRS}$ has been reported to be much higher than in the non-CF population. In a cross-sectional study of 104 adults with $\mathrm{CF}$, Berkhout et al. (2013) found the prevalence of CRS was $63 \%$ based on the 2012-EPOS guidelines. ${ }^{13}$ In regards to radiographic imaging, this study supported previous findings that the majority of sinus-CT scans among individuals with CF are positive for CRS. ${ }^{13,14}$ Despite the increased prevalence of CRS in this patient population, there are few studies systematically investigating the effect of this chronic disease on the health-related quality of life of individuals with CF. 


\subsubsection{Health-Related Quality of Life}

Quality of life is a broad, multi-dimensional concept that includes the perception of physical, psychological and social states. ${ }^{15}$ The World Health Organization (WHO) defines quality of life as 'an individual's perception of their position in life in the context of the culture and value systems in which they live and in relation to their goals, expectations, standards and concerns ${ }^{\prime} .{ }^{15}$ This can be considered as an all-inclusive concept of quality of life that considers factors related to an individual's health. ${ }^{15}$ The WHO defines health as 'a state of complete physical, mental and social well-being not merely in the absence of disease... ${ }^{16}$ In other words, health is a broad assessment of well-being and not only the existence or severity of disease. Health-related quality of life (HRQoL) is important to consider because changes in health may not be adequately represented by physiological measurements and perceptions may vary across individuals. ${ }^{17}$ This has resulted in HRQoL becoming increasingly studied in health-related research to determine the burden of disease, measure the effect of treatment and costeffective analysis. ${ }^{17}$

In the non-CF population, several studies have investigated the impact of CRS on HRQoL. Two notable studies used the Short Form-36 (SF-36), a generic HRQoL instrument scored on 8 domains, to compare responses between participants with CRS versus a national sample of non-CRS respondents. ${ }^{18,19}$ Participants with CRS reported significantly worse scores on nearly all SF-36 domains. ${ }^{18,19}$ When compared to other chronic diseases, individuals with CRS reported significantly more bodily pain and limitations in social functioning than individuals with congestive heart failure, chronic obstructive pulmonary disease, angina and chronic back pain. ${ }^{17}$ More recently, Macdonald et al. (2009) found that respondents with CRS were twice as likely stay in bed because of their illness and more likely to consult a physician than non-CRS counterparts. ${ }^{20} \mathrm{CRS}$ was found to also be associated with depressive symptoms, visiting a mental-health professional and greater use of antidepressants and sleeping pills. ${ }^{20}$ 
In the CF population, the relationship between CRS and HRQoL is less understood. To date, the current gold standard to measure HRQoL is the Cystic Fibrosis Questionnaire-Revised for adolescents and adults over 14 years of age (CFQ-R 14+). ${ }^{21}$ This disease-specific instrument has been validated with the SF-36 and has been replicated in several countries. ${ }^{22-30}$ It is comprised of twelve domains that are scored independently (Physical functioning, Energy, Emotion, Social functioning, Role functioning, Eating disturbances, Body image, Treatment burden, Health perception, Respiratory symptoms, Digestion, Weight). ${ }^{25}$ Although the CFQ-R 14+ has existed since 2003, comparison of HRQoL between CRS and non-CRS individuals using this instrument is yet to be completed. However, sinus symptoms have been compared using CRS-specific instruments, like the Rhinosinusitis Outcome Measure-31 (RSOM-31). Berkhout et al. 2013 showed that individuals with Class I to III mutations had a greater prevalence of CRS, worse nasal symptoms and CRS-related HRQoL than individuals with Class IV to V mutations. ${ }^{13}$ Although this study provides a better understanding of CRS in adults with $\mathrm{CF}$, there are several limitations. Firstly, the authors did not provide a direct comparison between CRS and non-CRS individuals, only between severe and mild phenotypes of CF. Secondly, the use of a nonCF-specific HRQoL instrument limits applicability to the CF population. It has been previously shown that individuals with $\mathrm{CF}$ face unique challenges from living with a life-long genetic disease that can affect responses to generic HRQoL questionnaires, when compared to healthy non-CF individuals. ${ }^{31-33}$ As a result, $\mathrm{HRQoL}$ instruments established for individuals without CF may not provide an adequate assessment of impact of this chronic disease.

\subsection{Rationale}

CRS is a prevalent chronic disease that is associated with poor HRQoL among adults without CF. However, CRS has been shown to occur much more frequently in the CF population. To date, the effects of this chronic disease on HRQoL have not been studied for these individuals. Research using 
non-CF participants cannot be generalized to the CF population, as responses on generic HRQoL instruments are not equivalent. As these individuals encounter different challenges from living with a life-long genetic disease, evaluation using a CF-specific HRQoL instrument is warranted. The purpose of this thesis will be to evaluate the effect of CRS on HRQoL, using a CF-specific questionnaire (i.e. CFQ-R 14+).

Participants will be sampled from the St. Paul's CF Clinic. This is a tertiary adult-specific CF clinic located in the St. Paul's Hospital in Vancouver, Canada. This centre is optimal for this research because it provides care for the majority of adults with CF in British Columbia. Also, this centre is in close proximity to the St. Paul's Sinus Centre, a tertiary sinus-clinic in the St. Paul's Hospital. This centre is the largest tertiary sinus clinic in British Columbia and frequently provides sinus-related care for adults with $\mathrm{CF}$.

By conducting this study, we aim to improve the understanding of CRS in the lives of adults with CF. Identifying the impact on HRQoL can contribute to individuals receiving timely specialist care, reduce the risk of CRS-related co-morbidities and limit the deterioration of daily functioning.

\subsection{Study Objectives}

1. To determine the prevalence of CRS among individuals actively enrolled at the St. Paul's CF Clinic.

2. To compare socio-demographic and clinical factors between individuals with or without CRS.

3. To compare HRQoL using a CF-specific instrument (i.e. CFQ-R 14+), between individuals with or without CRS. 


\subsection{Research Hypotheses}

1. We hypothesize that individuals with CRS will differ from individuals without CRS, in regards to socio-demographic and clinical factors.

2. We hypothesize that individuals with CRS will report significantly worse HRQoL on all domains of the CFQ-R 14+, compared to those without CRS. 


\section{CHAPTER 2: SYSTEMATIC REVIEW}

\subsection{Introduction}

In the past four decades, the mean age of survival has nearly doubled for individuals living with cystic fibrosis (CF). ${ }^{5}$ This has resulted in a tremendous growth in the proportion of individuals living into adulthood. ${ }^{1}$ As survival age increases, living with CF has become increasingly complex as chronic CFrelated conditions such as diabetes, kidney disease, bone and joint disease, depression and sinus disease rise in prevalence. ${ }^{4}$ With ongoing improvements in pulmonary and nutritional outcomes, the impact of treatment burden and extra-pulmonary conditions such as diabetes on health-related quality of life (HRQoL) are likely to grow in importance.

Patient-reported outcomes (PROs) have been widely studied in the CF population. ${ }^{21}$ PROs evaluate the biopsychosocial dimensions of patient lives, as they consider an individual's ability to function in daily life. ${ }^{21}$ PRO instruments can be used to measure $\mathrm{HRQoL}^{21}$, a multifaceted concept that includes physical health, psychological state, level of independence, social relationships and interpersonal relationships with the environment. ${ }^{16}$ Currently two CF-specific HRQoL instruments have been psychometrically evaluated, the Cystic Fibrosis Questionnaire-Revised (CFQ-R) and Cystic Fibrosis Quality of Life questionnaire (CFQoL). Both questionnaires are considered valid HRQoL instruments, measure multiple dimensions (e.g. Physical, Social and Emotional functioning) and have demonstrated adequate reliability, internal validity and clinical sensitivity. ${ }^{34-36}$ However, the CFQ-R is the most widely used HRQoL instrument in CF-related research and its Respiratory domain has been approved by the United States Food and Drug Administration (US FDA) for use as an endpoint in clinical trials. ${ }^{21}$

As individuals with CF now live longer, it is important to identify socio-demographic and clinical factors associated with HRQoL in this aging cohort. Equipped with this knowledge, CF clinicians can focus their efforts on optimizing the management of factors that impact most on HRQoL. The objective 
of this study was to systematically review the literature to identify socio-demographic and clinical factors associated with HRQoL in adolescents and adults, as measured by the CFQ-R 14+.

\subsection{Materials and Methods}

\section{$\underline{2,2.1 \text { Study Population }}$}

The patient population of interest was defined as adolescents and adults ( $\geq 14$ years old) who were diagnosed with CF based on a positive sweat chloride test and/or positive CF genotyping.

Observational studies investigating the association between socio-demographic and clinical factors with HRQoL measured by the CFQ-R $14+$ were included in this study. ${ }^{35}$ Studies utilizing the predecessor of the CFQ-R 14+, the Cystic Fibrosis Questionnaire for adolescents and adults (CFQ 14+) were also included. A list of all a priori chosen candidate factors has been outlined in Table 2.1. These factors were chosen following discussion with CF clinical experts with the purpose of establishing a comprehensive list of variables that were both clinically meaningful and could influence HRQoL (e.g. socio-demographic, clinical, co-morbidities). As the CFQ-R 14+ evaluates HRQoL on 12 independent domains, it was decided a priori to include studies reporting at least 1 domain score. Articles that did not follow guidelines for calculating CFQ-R 14+ domain scores, as discussed by Quittner et al, were excluded. ${ }^{35}$ Narrative reviews, systematic reviews, opinion commentaries, conference abstracts and studies with less than 10 subjects were excluded. Studies focused exclusively on interventions (i.e. medical, surgical or behavioral) were also excluded, unless associations between baseline candidate factors and CFQ-R 14+ domain scores were reported. 
Table 2.1- Description of a priori chosen socio-demographic and clinical factors potentially associated with health-related quality of life in adults with cystic fibrosis.

\begin{tabular}{|c|c|}
\hline Category & Factors \\
\hline Socio-Demographic & $\begin{array}{l}\text { Age, Gender, Race } \\
\text { Household or personal income, Education, Employment, Marital status }\end{array}$ \\
\hline $\begin{array}{l}\text { Clinical (including co- } \\
\text { morbidities) }\end{array}$ & $\begin{array}{l}\text { Age of CF diagnosis, Genotype, Transplant-status } \\
\text { Forced Expiratory Volume in } 1 \text { second }\left(\mathrm{FEV}_{1}\right) \text {, Forced Vital Capacity (FVC) } \\
\text { Body-mass index (BMI), Weight, Nutritional status } \\
\text { Schwachmann score } \\
\text { Use and frequency of nebulized, oral or inhaled medications } \\
\text { Exacerbation status, frequency of exacerbation, use of intravenous antibiotics, } \\
\text { hospitalization at time of questionnaire completion } \\
\text { Positive sputum culture for Pseudomonas aeruginosa, Burkholderia cepacia or Aspergillus } \\
\text { fumigatus } \\
\text { Pneumothorax, hemoptysis, supplemental oxygen use, use of home ventilation } \\
\text { CF-related diabetes (impaired glucose intolerance, dysglycemia, diabetes requiring insulin } \\
\text { treatment, diabetes with microvascular complications) } \\
\text { Liver disease with or without portal hypertension } \\
\text { Chronic rhinosinusitis, nasal polyposis, allergic fungal sinusitis } \\
\text { Gastro-esophageal reflux disorder } \\
\text { Pancreatic insufficiency with or without enzyme treatment } \\
\text { Distal intestinal obstruction syndrome } \\
\text { Depression, use of anti-depressants, anxiety disorder, mood disorder, stress, self-esteem, } \\
\text { body satisfaction, acceptance, symptom burden, illness perception } \\
\text { Osteopenia, osteoporosis } \\
\text { Renal stones, chronic renal failure, chronic kidney disease } \\
\text { CF-related arthopathy } \\
\text { Insomnia, sleep apnea, daytime sleepiness, sleep quality } \\
\text { Phronic Pain }\end{array}$ \\
\hline
\end{tabular}




\subsubsection{Search Strategy}

Our search strategy followed the Preferred Reporting Items for Systematic Reviews and Meta-analysis (PRIMSA) guidelines. ${ }^{37}$ A search was conducted of articles published in the English language between January $1^{\text {st }}, 1989$ and April $1^{\text {st }}, 2014$ using MEDLINE, EMBASE, CENTRAL, CINAHL and psychINFO. A detailed description of the search strategy for each literature database is provided in Appendix A: Table A.1. All exact duplicates were removed prior to reviewing abstracts. Abstracts were screened by two independent reviewers (A.R.H and J.M) and disagreements were resolved by a third, independent investigator (B.S.Q). Studies were selected for full-text review if they had: 1) investigated the effect of any candidate factor discussed a priori; 2) used the CFQ or CFQ-R 14+; and 3) met the eligibility criteria discussed above. Reference lists of included articles were reviewed to ensure all relevant articles were included in the final collection.

\subsubsection{Data Collection Process}

Once the abstract review process was completed and eligible articles for full-text review were identified, a standardized data collection form was established according to PRISMA, Meta-Analysis of Observational Studies in Epidemiology (MOOSE), the Strengthening the Reporting of Observational Studies in Epidemiology (STROBE) guidelines and the Grades of Recommendation, Assessment,

Development and Evaluation (GRADE) Working Group. ${ }^{37-40}$ This included an evaluation of study and patient characteristics, a description of the patient population from which the study sample was recruited, socio-demographic factors and clinical characteristics of the subjects included, description of statistical methods, magnitude of observed effects and an assessment of study quality and potential risk of bias (Appendix A: Table A.2).

\subsubsection{Synthesis of Results}

In order to synthesize the results extracted from studies, candidate factors that were examined in at least two studies were analyzed. To accommodate the heterogeneity in reporting of results, the 
standardized data collection form included details pertaining to the appropriate statistical tests required to quantify the association between candidate factors with CFQ-R 14+ domain scores. Firstly, candidate factors were identified by type (e.g. binary, categorical, continuous) and definition (e.g. depression defined by use of anti-depressants or by symptoms). In situations where candidate factors were identified by an additional questionnaire (e.g. depression defined by the Hospital Anxiety and Depression Scale), the questionnaire name and numeric values used to categorize subjects were recorded. Secondly, the statistical tests used to examine the associations were recorded (e.g. Student's t-test, Chi-squared test, Analysis of Variance, Pearson's or Spearman's correlation test) and whether the analysis was bivariable or multivariable. Covariates included or adjusted for in multivariable models were also recorded. Thirdly, the effect estimates were recorded for the association between each candidate factor and CFQ-R 14+ domain. These included mean differences, F-statistics, correlation coefficients, regression coefficients and effect sizes. Levels of statistical significance as measured by p-values, were recorded and grouped into four categories: $<0.001,0.001$ to $<0.01,0.01$ to $<0.05, \geq 0.05$ (i.e. non-significant). To consolidate our findings, we calculated the proportion of studies reporting significant findings $($ i.e. $\mathrm{p}$-value $<0.05)$ for each candidate factor on each of the $12 \mathrm{CFQ}-\mathrm{R}$ 14+ domains.

\subsection{Results}

\subsubsection{Study Selection}

Our search strategy identified a total of 2,677 potentially relevant abstracts and articles. After removing duplicates $(n=756)$, a total of 1,921 abstracts were reviewed for eligibility. A total of 199 articles were eligible for full-text review. Following full-text review, 28 articles met the inclusion and exclusion criteria as illustrated in Figure 2.1 22,23,25,26,29,30,35,41-61 . No additional articles were found from screening the reference lists of these 28 articles. 
Figure 2.1- PRISMA (Preferred Reporting Items for Systematic Reviews and Meta-Analyses) flow diagram depicting search results and eligible articles. $(\mathrm{CF}=$ cystic fibrosis).

Total number of abstracts identified after searching databases

(Medline, Embase, Central, CINAHL, PsychINFO, Web of Science):

$$
(n=2,677)
$$
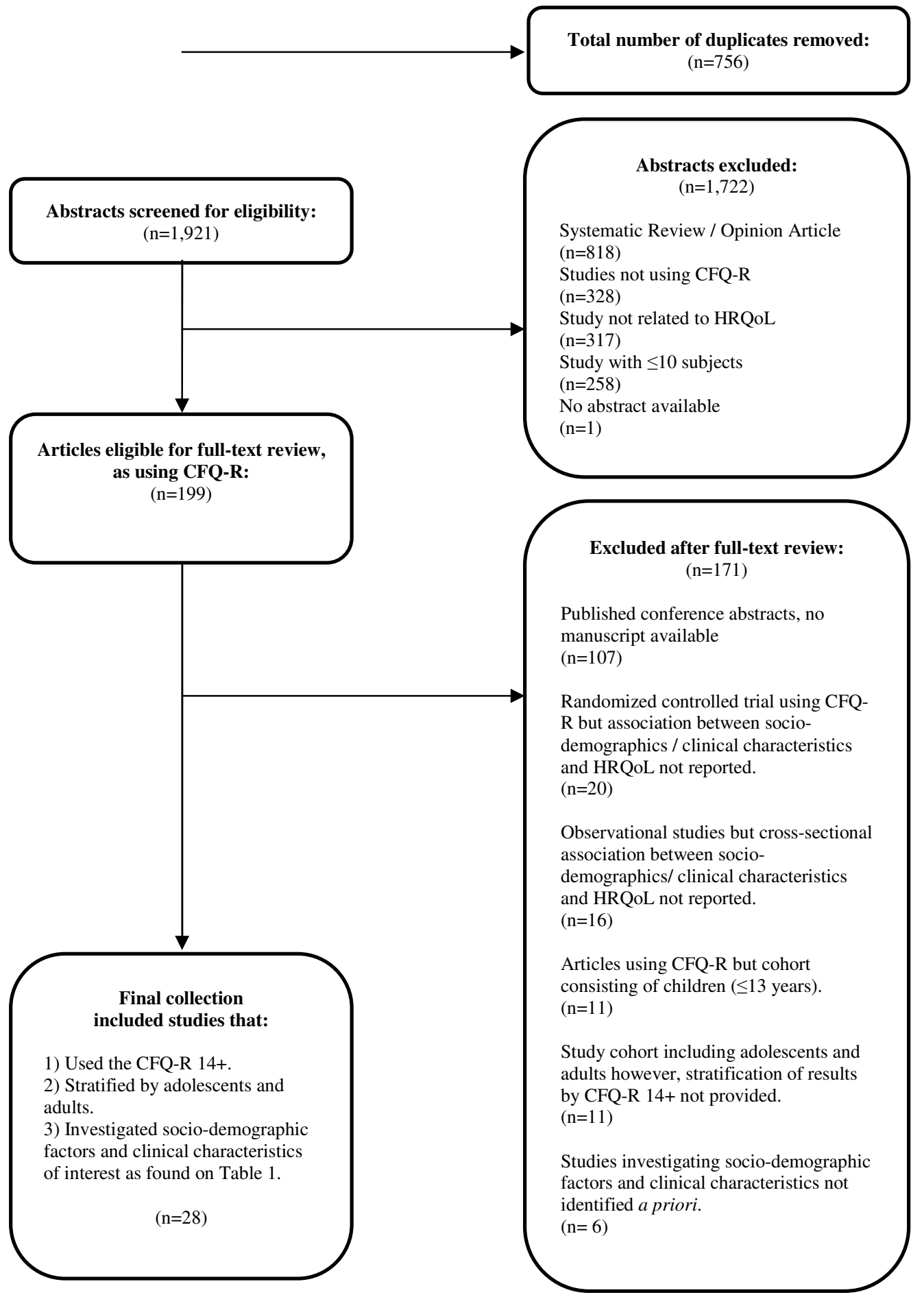


\subsubsection{Summary of Risk of Bias, Study Design and Subject Characteristics}

According to the GRADE system of Quality of Evidence, 23\% of studies were moderate quality, $71 \%$ were low quality and $7 \%$ were very low quality. The characteristics of included studies are described in Table 2.2 and the composition of study participants are detailed in Appendix A: Table A.3. The mean age of subjects in the included articles was 26 (median: 26) years and the mean $\mathrm{FEV}_{1} \%$ predicted of participants was 64\% (median: 63\%).

Table 2.2 Characteristics of the 28 articles meeting the inclusion/exclusion criteria.

\begin{tabular}{|c|c|c|c|c|c|c|}
\hline $\begin{array}{l}\text { Primary } \\
\text { Author }\end{array}$ & Year & $\begin{array}{c}\text { Single or } \\
\text { Multicent } \\
\text { re } \\
(\mathrm{S}, \mathbf{M}) \\
\end{array}$ & Countries & $\begin{array}{c}\text { No. Subjects } \\
\geq 14 \text { years of } \\
\text { age } \\
\left(n, \%^{1}\right)\end{array}$ & $\begin{array}{c}\text { Socio-demographic / Clinical } \\
\text { factor studied }\end{array}$ & $\begin{array}{c}\text { GRADE } \\
\text { Study } \\
\text { Quality }\end{array}$ \\
\hline Quittner ${ }^{23}$ & 2000 & $\mathrm{M}$ & USA & $10(33)$ & Gender, $\mathrm{FEV}_{1} \%$ & Low \\
\hline Henry $^{22}$ & 2003 & $\mathrm{~S}$ & France & $124(59)$ & Schwachmann score, FVC & Low \\
\hline Wenninger $^{29}(1)$ & 2003 & $\mathrm{M}$ & Germany & $103(100)$ & BMI, $\mathrm{FEV}_{1} \%$ & Low \\
\hline Wenninger $^{41}(2)$ & 2003 & $S$ & Germany & $72(100)$ & BMI, $\mathrm{FEV}_{1} \%$ & Low \\
\hline Klijn 30 & 2004 & S & Netherlands & $84(100)$ & Age, Gender, BMI, $\mathrm{FEV}_{1} \%$ & Low \\
\hline Dobbin $^{42}$ & 2005 & S & Australia & $22(100)$ & Exacerbation status & Low \\
\hline Quittner $^{34}$ & 2005 & M & USA & $206(100)$ & Age, BMI, $\mathrm{FEV}_{1} \%$ & Low \\
\hline Riekert $^{43}$ & 2007 & $\mathrm{~S}$ & USA & $76(100)$ & Depression, $\mathrm{FEV}_{1} \%$ & Moderate \\
\hline Bregnballe $^{26}$ & 2008 & M & Denmark & $180(100)$ & $\mathrm{BMI}, \mathrm{FEV}_{1} \%$ & Very low \\
\hline Havermans $^{44}$ & 2008 & $\mathrm{~S}$ & Belgium & $57(100)$ & Depression, $\mathrm{FEV}_{1} \%$ & Low \\
\hline Sawicki $^{45}$ & 2008 & M & USA & $303(100)$ & $\begin{array}{l}\text { Symptom burden } \\
\text { (CF-specific psychological, } \\
\text { gastrointestinal, respiratory) }\end{array}$ & Low \\
\hline Dunnick $^{46}$ & 2009 & S & Netherlands & $27(100)$ & Gender & Low \\
\hline Havermans $^{47}$ & 2009 & $S$ & Belgium & $57(100)$ & $\begin{array}{l}\mathrm{BMI}, \mathrm{FEV}_{1} \% \text {, Employment, } \\
\text { Pseudomonas aeurginosa infection }\end{array}$ & Low \\
\hline Sawicki $^{48}$ & 2009 & M & USA & $204(100)$ & Age, Gender, $\mathrm{FEV}_{1} \%$ & Low \\
\hline Quittner $^{49}$ & 2010 & M & USA & $3,030(46)$ & Socioeconomic status & Moderate \\
\hline Casier $^{50}$ & 2011 & M & Belgium & $40(100)$ & Gender, $\mathrm{FEV}_{1} \%$ & Moderate \\
\hline Cohen $^{51}$ & 2011 & $S$ & Brazil & $24(32)$ & $\mathrm{FEV}_{1} \%$ & Low \\
\hline Hayes $^{52}$ & 2011 & S & USA & $83(100)$ & $\begin{array}{l}\text { Overall pain, Chest pain, Back pain, } \\
\text { Abdominal pain }\end{array}$ & Low \\
\hline Sawicki $^{53}$ & 2011 & M & USA & $199(100)$ & $\begin{array}{l}\text { Age, Gender, } \mathrm{BMI}, \mathrm{FEV}_{1} \% \text {, } \\
\text { Exacerbation status, } \\
\text { Symptom burden } \\
\text { (CF-specific psychological, } \\
\text { gastrointestinal, respiratory) }\end{array}$ & Moderate \\
\hline Ashish $^{54}$ & 2012 & S & UK & $157(100)$ & Pseudomonas aeurginosa infection & Moderate \\
\hline Bouka $^{62}$ & 2012 & $S$ & Germany & $55(100)$ & Daytime sleepiness, Sleep quality & Moderate \\
\hline Quittner $^{35}$ & 2012 & M & USA & $4,679(64)$ & $\begin{array}{l}\text { Gender, BMI, } \mathrm{FEV}_{1} \% \text {, Exacerbation } \\
\text { status }\end{array}$ & Low \\
\hline Bradley $^{56}$ & 2013 & M & $\begin{array}{l}\text { UK } \\
\text { Ireland }\end{array}$ & $94(100)$ & Exacerbation status & Very low \\
\hline Dill $^{57}$ & 2013 & M & USA & $303(100)$ & $\begin{array}{l}\text { Age, Gender, } \mathrm{FEV}_{1} \% \text {, Exacerbation } \\
\text { status }\end{array}$ & Moderate \\
\hline Platten $^{58}$ & 2013 & $\mathrm{M}^{2}$ & UK & $74(100)$ & Age, Gender, $\mathrm{FEV}_{1} \%$ & Low \\
\hline
\end{tabular}




\begin{tabular}{|c|c|c|c|c|c|c|}
\hline $\begin{array}{l}\text { Primary } \\
\text { Author }\end{array}$ & Year & $\begin{array}{c}\text { Single or } \\
\text { Multicent } \\
\text { re } \\
(\mathrm{S}, \mathrm{M})\end{array}$ & Countries & $\begin{array}{l}\text { No. Subjects } \\
\geq 14 \text { years of } \\
\text { age } \\
\left(n, \%^{1}\right)\end{array}$ & $\begin{array}{c}\text { Socio-demographic / Clinical } \\
\text { factor studied }\end{array}$ & $\begin{array}{c}\text { GRADE } \\
\text { Study } \\
\text { Quality }\end{array}$ \\
\hline Sawicki $^{59}$ & 2013 & $\mathrm{M}$ & $\begin{array}{c}\text { USA } \\
\text { Canada }\end{array}$ & $4,228(58)$ & Treatment complexity & Low \\
\hline Targett ${ }^{60}$ & 2014 & M & UK & $254(100)$ & Employment & Low \\
\hline Wojewodka $^{61}$ & 2014 & $\mathrm{~S}$ & Canada & $52(100)$ & Exacerbation status & Low \\
\hline
\end{tabular}

('S'=single, ' $\mathrm{M}$ ' =multi-centre, $\mathrm{BMI}=$ body mass index, $\mathrm{FEV}_{1} \%=$ forced expiratory volume in 1 second $\%$ predicted, $\mathrm{FVC}=$ forced vital capacity).

1. Proportion of subjects among the entire study sample that are $\geq 14$ years of age.

2. Subjects recruited from online discussion boards and social media websites. We have categorized this as 'multi-centre' because it is unclear if these subjects received care from a single centre.

Nine of $28(32.1 \%)$ studies examined the effect of a single factor on CFQ-R 14+ domain scores and the remainder examined multiple factors (Table 2). $\mathrm{FEV}_{1} \%$ predicted was the most frequently studied factor, being evaluated in 16 of 28 of articles. Gender (32.1\%), body-mass index (28.6\%) and age (17.9\%) were the next most frequently studied factors. Twenty-one of 28 articles investigated all 12 domains of the CFQ-R 14+. For data analysis, a total of 23 studies were included as the candidate factors were investigated in at least two studies. ${ }^{23,25,26,30,35,41-48,50,51,53,54,56-58,60,61}$

\subsubsection{Association Between Socio-Demographic and Clinical Factors With the CFQ-R 14+}

Socio-demographic Factors

1. Age

In bivariable analysis, older age was significantly associated with worse scores on the domains of Physical functioning (correlation coefficients: -0.10 to -0.36$)^{25,30,58}$, Emotion (correlation coefficient: 0.23 to -0.28$)^{25,58}$, Respiratory symptoms (correlation coefficient: -0.19$)^{25}$ and Health perception (correlation coefficient: -0.22$)^{25}$, in all studies investigating these domains (Appendix A: Table A.4).

Of the statistically significant bivariable associations, only Physical functioning remained associated with age after adjustment in multivariable analysis (Appendix A: Table A.5). Two additional studies 
examined the relationship between age and CFQ-R 14+ domains using multivariable methods. ${ }^{53,57}$ Sawicki et al found that age was associated with Treatment burden following adjustment for gender, $\mathrm{BMI}$, maximum $\mathrm{FEV}_{1} \%$ predicted, frequency of pulmonary exacerbations, and sputum culture positive for B. cepacia and/or P. aeruginosa. ${ }^{53}$ Dill et al found that age was associated with Physical functioning, Social functioning and Treatment Burden following adjustment for gender, weight, education, $\mathrm{FEV}_{1} \%$ predicted, pancreatic insufficiency, frequency of exacerbations, and the probability of participants being sampled from the eligible population. ${ }^{16}$ In both studies using multivariable methods, Treatment burden was consistently associated with age but the association of age with Physical functioning and Social functioning was inconsistent.

\section{Gender}

In bivariable analysis, females reported significantly higher scores on the Body Image domain than males in 3 of 4 studies $^{23,30,35}$. However, females scored significantly lower on the domains of Emotion in 4 of 6 studies $^{30,35,50,58}$, Social functioning in 3 of 6 studies $^{35,50,58}$, Respiratory symptoms in 2 of 4 studies $^{35,46}$ and Physical functioning in 1 of 6 studies. $^{50}$

Two studies examined the relationship between gender and CFQ-R 14+ domains using multivariable analysis. ${ }^{53,57}$ Gender was significantly associated with Body Image and Physical functioning in both studies (Appendix A: Table A.4). Sawicki et al found that females scored significantly higher on the Body Image domain and lower on Physical functioning than males, after adjustment for age, maximum $\mathrm{FEV}_{1} \%$ predicted, body-mass index, frequency of pulmonary exacerbations, and positive sputum culture of B. cepacia and/or P. aeruginosa. ${ }^{53}$ Dill et al also found that females scored significantly higher on the Body Image domain and lower on Physical functioning than male counterparts, following adjustment for age, weight, education, $\mathrm{FEV}_{1} \%$ predicted, pancreatic insufficiency, frequency of exacerbations and sampling method. ${ }^{16}$ 


\section{Employment}

Employment, defined as current participation in part- or full-time employment or school, was associated with higher scores on all CFQ-R 14+ domains in bivariable analysis. ${ }^{60}$ When studied using multivariable methods, Havermans et al found that employment remained associated with Physical functioning, Social functioning and Role functioning, following adjustment for BMI, $\mathrm{FEV}_{1} \%$ predicted, use of caloric supplements, CF-related diabetes and presence or absence of a central venous implantable device. ${ }^{63}$

\section{Clinical Factors:}

\section{Lung Function}

In bivariable analysis, $\mathrm{FEV}_{1} \%$ predicted was significantly associated with 11 of 12 domains of the CFQ-R 14+. $\mathrm{FEV}_{1} \%$ predicted was consistently associated with Physical functioning (13 of 13 studies, (correlation coefficients: 0.27 to 0.76$)^{23,25,26,29,30,35,41,43,44,50,51,58,63}$, Health perception (9 of 11 studies, correlation coefficients: 0.24 to 0.66$)^{25,26,29,30,35,41,43,44,63}$, Respiratory symptoms (7 of 11 studies, correlation coefficients: 0.36 to 0.47$)^{25,26,29,30,35,43,51}$ and Treatment burden ( 5 of 12 studies, correlation coefficient: 0.11 to 0.39$)^{26,29,30,35,43}$ (Appendix A: Table A.4). $\mathrm{FEV}_{1} \%$ predicted was not associated with Digestion in any of the 11 studies having evaluated this domain..$^{23,25,26,29,30,35,41,43,44,51,63}$

Of the significant bivariable associations, 9 of 11 domains were still significant in at least one of the two studies using multivariable methods. ${ }^{53,57}$ However, Emotion and Social functioning were no longer associated with $\mathrm{FEV}_{1} \%$ predicted after adjustment. Both studies using multivariable analysis found that $\mathrm{FEV}_{1} \%$ predicted was associated with Physical functioning and Treatment burden (Appendix A: Table A.5). Sawicki et al adjusted for age, gender, body-mass index, frequency of pulmonary exacerbations, and sputum culture positive for B. cepacia and/or P. aeruginosa. ${ }^{53}$ Dill et al adjusted for age, gender, 
weight, education, pancreatic insufficiency, frequency of exacerbations and the probability of participants being sampled from the eligible population. ${ }^{16}$

\section{Body-Mass Index}

In bivariable analysis, BMI was consistently associated with the Body Image (correlation coefficients: 0.28 to 0.54 ) and Weight (correlation coefficients: 0.43 to 0.47 ) domains in 6 of 7 studies. ${ }^{25,26,29,30,35,63}$ BMI was also associated with Eating disturbances ( 5 of 7 studies, correlation coefficients: 0.16 to

$0.44)^{25,26,29,30,63}$, Health perception ( 4 of 7 studies, correlation coefficients: 0.14 to 0.30$)^{25,26,29,41}$ and Energy (1 of 7 studies, correlation coefficient: -0.24$).^{41}$

Compared to bivariable findings, only the domains of Body Image, Weight and Energy remained significantly associated with BMI following adjustment for age, gender, $\mathrm{FEV}_{1} \%$ predicted, frequency of pulmonary exacerbations and sputum culture positive for B. cepacia and/or P. aeruginosa. ${ }^{16}$

\section{Pulmonary Exacerbations}

In bivariable analysis, Quittner et al found that pulmonary exacerbations were associated with significantly lower scores on all CFQ-R 14+ domains (effect sizes: -0.09 to -0.83 ). ${ }^{35}$ Wojewodka et al also compared the presence or absence of pulmonary exacerbation on CFQ-R scores and found significant differences in Physical functioning, Emotion, Role functioning, Body image, Health perception and Weight but effect estimates were not reported. ${ }^{61}$

Compared to bivariable findings, Dobbin et al found that scores for individuals experiencing a pulmonary exacerbation were significantly lower on 5 of 12 domains (Respiratory Symptoms, Physical functioning, Energy, Role functioning, and Health perception), following adjustment for age and gender. ${ }^{42}$. 


\section{Frequency of Pulmonary Exacerbations}

In bivariable analysis, Quittner et al found that the frequency of pulmonary exacerbations was associated with lower scores on the domains of Physical functioning (correlation coefficient $=-0.35)$, Energy (correlation coefficient $=-0.25)$, Role functioning (correlation coefficient $=-0.32$ ), Health perception (correlation coefficient $=-0.30)$ and Respiratory symptoms (correlation coefficient $=-0.27){ }^{8}$ All other domains were not significantly correlated with frequency of pulmonary exacerbations. ${ }^{8}$

All domains significantly associated with frequency of pulmonary exacerbations in bivariable analysis were also supported in studies using multivariable methods. Sawicki et al found that frequency of pulmonary exacerbations was associated with Role functioning, Eating disturbances, Body image, Respiratory symptoms and Weight, following adjustment for age, gender, body-mass index, $\mathrm{FEV}_{1} \%$ predicted and sputum culture positive for B. cepacia and/or P. aeruginosa. ${ }^{15}$ Dill et al also found that frequency of pulmonary exacerbations was associated will all CFQ-R 14+ domains except for Digestion, after adjustment for age, gender, weight, education, $\mathrm{FEV}_{1} \%$, pancreatic insufficiency and sampling method. ${ }^{16}$ Consistent associations in multivariable analysis were found in regards to Respiratory Symptoms, Role functioning, Body Image, Eating disturbance, and Weight.

\section{Pseudomonas Aeruginosa Infection}

In bivariable analysis, Ashish et al found that individuals harboring the Liverpool Epidemic Strain (LES) of $P$. aeruginosa reported significantly lower scores for Physical functioning, Emotion, Role functioning, Body image, Weight and higher scores for Respiratory symptoms and Treatment burden compared to individuals without any $P$. aeruginosa infection. However, individuals infected with strains other than LES reported significantly lower scores only on the Body Image domain, compared to individuals without any $P$. aeruginosa infection. ${ }^{54}$ Among individuals infected with $P$. aeruginosa, those with LES reported significantly worse scores on all domains except Body Image and Weight. A secondary analysis using propensity scores found that individuals with LES $P$. aeruginosa reported 
significantly lower scores in Physical functioning, Treatment burden, Health perception and Respiratory symptom domains, when compared those infected with non-LES P. aeruginosa. ${ }^{54}$

In multivariable analysis, Sawicki et al compared CFQ-R 14+ domain scores between individuals with or without $P$. aeruginosa infection, regardless of strain. No significant associations were found for any domains of the CFQ-R $14+$ and P. aeruginosa strain. $^{53}$

\section{Depression}

Depression was assessed using the Beck Depression Inventory (BDI). Scores were considered continuous and correlation was investigated with each CFQ-R 14+ domain. Riekert et al found that greater depressive symptoms were associated with worse scores on all domains of the CFQ-R 14+ (correlation coefficients: -0.21 to -0.74$).{ }^{43}$ All associations remained significant despite stratification by lung function, except the Weight domain (correlation coefficients: -0.44 to -0.85$){ }^{43}$

In a second study, Havermans et al used the Hospital Anxiety and Depression Scale (HADS) to quantify depression. ${ }^{44}$ Individuals scoring greater than 8 were considered depressed. The authors found that depression was significantly associated with Emotion, Eating disturbances and Body Image, despite adjustment for lung function. ${ }^{27}$

\section{Symptom Burden}

Symptom burden was measured using the Memorial Symptom Assessment Scale (MSAS), to assess the severity, frequency and distress caused by psychological, gastrointestinal and respiratory symptoms. ${ }^{14,28}$ Symptom burden was categorized into three CF-specific groups: psychological (MSASCF-PSYCH), gastrointestinal symptoms (MSAS-CF-GI) and respiratory symptoms (MSAS-CF-RESP). In bivariable analysis, Sawicki et al found that all symptom burden groups were associated with Emotion, Respiratory symptoms, Digestion and Weight (correlation coefficients $=-0.11$ to -0.69$).{ }^{28}$ 
In multivariable analysis, Sawicki et al found that MSAS-PSYCH was associated with Energy, Emotion, Social functioning, Role functioning, Eating disturbances, Body Image and Weight following adjustment for several socio-demographic and clinical factors. ${ }^{14}$ MSAS-CF-GI was associated with Role functioning, Eating disturbances, Body Image and Weight. ${ }^{14}$ MSAS-CF-RESP was associated with all CFQ-R 14+ domains, except Eating disturbances and Body Image. ${ }^{14}$

\subsection{Discussion}

As the life expectancy of individuals with CF increases, the prevalence of extra-pulmonary comorbidities is also rising. This has shifted the concern of CF care providers to achieving a balance between maintaining lung function and nutritional status, and preventing/managing age-related chronic disease- related complications such as diabetes. As a result, treatment regimens are becoming more complex and are placing an increasing burden on the time of patients. With many potentially competing diagnoses and treatments, the emphasis on optimizing HRQoL has become increasingly important. The primary purpose of this systematic review was to identify socio-demographic and clinical factors associated with the CFQ-R 14+ in adolescents and adults with CF so that clinicians can prioritize issues that have the most significant impact on HRQoL.

All articles included in this review were observational, the majority of which were of low quality (70\%). Few studies $(22 \%)$ used multivariable methods to adjust for potentially confounding variables. In total, ten socio-demographic/clinical factors were found to be associated with domains of the CFQ-R 14+ and were examined in at least 2 studies. $\mathrm{FEV}_{1} \%$ predicted has been the most widely studied factor to date and consistently associated with multiple domains of the CFQ-R except Digestion, Social Functioning, and Emotion. As expected, lower BMI was associated with worse Body Image and less Energy. Pulmonary exacerbations were consistently associated with Respiratory Symptoms, Physical functioning, Energy, Body Image, Eating Disturbance, Weight, and Role Functioning, the latter most likely attributed to the adverse impact these events and their treatments have on work or school 
absenteeism and productivity. Compared to male counterparts, females reported lower scores on the domain of Physical functioning, but reported higher scores with respect to Body Image. While this latter finding was contrary to expectations, a prior study has also demonstrated that CF males desire to be much heavier and are thus less content with their body image, whereas females are often content with their body shape. ${ }^{64}$ Older age was consistently associated with greater Treatment burden scores independent of lung function, chronic $P$. aeruginosa and $B$. cepacia infection status, and pulmonary exacerbations, suggesting that therapies related to other age-related extra-pulmonary co-morbidities increase treatment burden. As expected, individuals who were currently employed or attending school had higher scores for the Physical, Social and Role functioning domains compared to those unemployed or not attending school, highlighting the relationship between participation in school and work and higher level of functioning.

This systematic review had several potential limitations. First, the data synthesis criteria (i.e., candidate factors examined in at least 2 studies) might have introduced selection bias with overlooking of factors associated with CFQ-R based on single studies. However, this criterion was incorporated to minimize conclusions based on single studies with potentially spurious findings. Second, we focused on the cross-sectional associations between the factors of interest and CFQ-R domains scores. CFQ-R domain scores can change over time in response to treatment and changes in health status. However, with the exception of studies focused on the impact of exacerbations on CFQ-R, most studies examined the association between factors and the CFQ-R when study subjects were clinically stable, which would have ensured that the self-reported CFQ-R scores were generally representative of their usual health status. Lastly, cross-sectional associations cannot be used to imply cause-and-effect and therefore longitudinal studies are required to evaluate the impact of the candidate factors on HRQoL.

While this systematic review has found several socio-demographic and clinical factors associated with CFQ-R domains among adolescents and adults, the HRQoL impact of other chronic disease-related 
complications such as CFRD and chronic rhinosinusitis (CRS) have not been examined to date. With nearly $50 \%$ of the adult population developing CFRD, it is important to understand the relative impact this condition has on HRQoL, as it often necessitates frequent blood glucose monitoring and insulin therapy. CRS has been shown to significantly reduce HRQoL among individuals without $\mathrm{CF}^{18-20}$. While CRS occurs with greater frequency in the CF population, its relative impact on HRQLL has yet to be explored. ${ }^{13}$ Traditionally, CRS has been overshadowed by lung disease in CF but the landscape might change with better management of lung disease.

In conclusion, HRQoL is an important outcome measure in $\mathrm{CF}$ and we have identified a number of socio-demographic and clinical factors relating to multiple domains of the CFQ-R 14+. FEV1\% predicted and pulmonary exacerbations have the broadest impact on HRQoL and should remain the focus of attention for CF clinicians. Future studies examining HRQoL in CF adults should also focus on the impact of chronic CF-related conditions such as CFRD, CRS, and osteopenia/osteoporosis that rise in prevalence with age and could adversely impact on HRQoL. 


\section{CHAPTER 3: METHODS}

This chapter will describe the overall study design, method of recruitment, define the explanatory and outcome variables and provide a detailed description of the statistical analyses used to investigate the effect of CRS on the HRQoL among adults with CF. Data used for this thesis were collected directly from individuals providing informed consent to participate in this cross-sectional research study.

\subsection{Conceptual Overview}

\subsubsection{Ethics}

Ethics approval was provided by the Clinical Research Ethics Board at the University of British Columbia-Providence Health Care Research Institute prior to the initiation of enrollment on August 22, 2013 (approval number: H13-01848).

\subsubsection{Study Design and Rationale}

A cross-sectional study design was selected for this research study. A cross-sectional or prevalence study is comprised of individuals sampled from a known population irrespective of exposure to the primary explanatory variable or outcome of interest. ${ }^{65}$ The exposure and outcome status in crosssectional studies are selected simultaneously without regard to which parameter occurred first in time. ${ }^{66}$ The advantages of this type of epidemiologic study design are that they can be inexpensive to conduct, allow investigation of multiple outcomes, consist of a single evaluation without subsequent reassessment and provide prevalence estimates that may be useful in identifying associations that may warrant future research. Prevalence for the purposes of this thesis can be defined as the proportion affected by the condition of interest divided the total number of participants recruited. ${ }^{67}$ Depending on the research question, subject selection may not be restricted by exposure or outcome-status. ${ }^{66}$ Similarly, both the exposure and outcome are identified at the time of investigation. ${ }^{66}$ 
This type of epidemiological study design was well suited for our research question, as it provided an opportunity to investigate the prevalence of CRS among the adult CF population at the St. Paul's CF Clinic and compare HRQoL between those with or without CRS. Participants were selected without regard to pre-existing CRS-status or current HRQoL. Both explanatory (CRS) and outcome parameters (HRQoL) were measured at the time of enrollment, in addition to socio-demographic and relevant clinical factors.

\subsubsection{Target Population}

The target population for this cross-sectional study consisted of adults ( $\geq 19$ years of age) with a confirmed diagnosis of CF who are currently enrolled at the St. Paul's CF Clinic. Confirmatory diagnosis of $\mathrm{CF}$ consists of positive genetic testing for CF-related alleles presenting on chromosome-7 or positive sweat chloride test results greater than $60 \mathrm{meq} / \mathrm{L} .{ }^{1}$ Results from these tests were retrospectively reviewed from subject medical charts to confirm the diagnosis and eligibility for the study. A total of 207 adults with confirmed diagnosis of CF were enrolled at the St. Paul's CF Clinic prior to the start of recruitment.

\section{$\underline{3.1 .4 \text { Recruitment }}$}

Currently two adult-specific CF clinics exist in British Columbia (BC), located at St. Paul's Hospital (Vancouver, BC) and Royal Jubilee Hospital (Victoria, BC). Based on the most recent estimates from 2012, there are approximately 246 adults living with CF in British Columbia.

Participants were from a single, adult-specific CF Clinic located on the $8^{\text {th }}$ floor of the St. Paul's Hospital in Vancouver, BC. A non-statistical, non-probabilistic, convenience sampling method was used to recruit participants for this cross-sectional study. ${ }^{68}$ All individuals in the target population received study packages that included an invitation letter and consent forms prior to their appointment at the CF Clinic. Two days prior to their scheduled visit, a single investigator (A.R.H) contacted individuals to ensure the study package was received and to evaluate eligibility. A maximum of two 
attempts were conducted by phone and voice messages were left. On the day of their appointment, a single investigator (A.R.H) approached interested individuals to acquire informed consent to participate in this cross-sectional research study. Individuals who could not be contacted by phone were not approached. The investigator had previously received certification from the Tri-Council Policy Statement (TCPS): Ethical Conduct for Research Involving Humans ${ }^{69}$ to consent individuals in healthrelated research studies. The consent process was performed in accordance with the guidelines provided by the TCPS, which included ensuring participants were aware that enrollment was voluntary, able to withdraw at any time and understood the study purpose, risks and potential benefits. ${ }^{69}$ Individuals refusing to participate were not included in the final study cohort and demographic data were not recorded.

\section{$\underline{\text { 3.1.5 Sample Size }}$}

As discussed in Chapter 2, a comprehensive review of relevant literature found a variety of sociodemographic and clinical factors associated with HRQoL. As one of the objectives of this research study was to estimate the effect of CRS on HRQoL, our aim was to establish multivariable linear regression models that would account for potential confounders. From the findings of our systematic review, we anticipated to include up to six independent predictor variables (including CRS) in our final regression model. As described by Vittinghoff et al (2005), approximately 10-15 observations per

predictor variable are required to ensure multivariable linear regression models are fit appropriately. ${ }^{70}$ Therefore, our aim was to include over 100 participants in our final study sample. Once the target of 100 was reached, enrollment was terminated at the end of the calendar month. This was to ensure that any individuals interested in participating could be enrolled by April 30, 2014.

\subsubsection{Conduct of Study}

Figure 3.1 is a schematic describing the number of individuals eligible for enrollment, approached during the recruitment period, providing informed consent and the frequency of participants who 
completed study questionnaires and procedures. Individuals providing consent were given paper copies of research-related questionnaires to complete during their routine visit. Participants electing to receive nasal endoscopy were directed to the St. Paul's Sinus Centre, located within the Department of Otolaryngology on the $2^{\text {nd }}$ floor of St. Paul's Hospital. A senior otorhinolaryngologist performed a standard nasal assessment that included an interview of sinus-related symptoms, history of treatment and nasal endoscopy. Findings were recorded by the research staff and forwarded to the St. Paul's CF Clinic for inclusion into participants' medical charts. Consent forms, questionnaire responses and interview results were stored in separate binders in a locked cabinet at the St. Paul's Sinus Centre. All participants received unique participant codes that prevented identification of participant names and provincial health numbers. Participant codes were stored separately from the study questionnaires on a password-protected Microsoft Excel spreadsheet. This research study was comprised of a single evaluation (questionnaires, interviews and nasal endoscopy) and participants were not contacted for secondary assessments.

Of the total population $(n=207), 160(77.3 \%)$ were eligible to participate. Of these, a total of 121 were approached to provide informed consent. The remaining 39 individuals could not be successfully contacted by phone. Also due to time constraints, the investigators were unable to meet with these individuals during their appointments and discuss participation.

Of the 121 individuals approached, 113 (93.4\% response rate) individuals provided informed consent and $8(6.6 \%)$ refused to participate. Among those enrolled $(n=113), 94.7 \%$ completed the study HRQoL questionnaire and $5.3 \%$ did not to return these documents. As a result, HRQoL data was missing for these individuals. 
Figure 3.1- Schematic describing the frequency and proportion of individuals eligible, approached, participating, refusing and completing study questionnaires and nasal endoscopy.

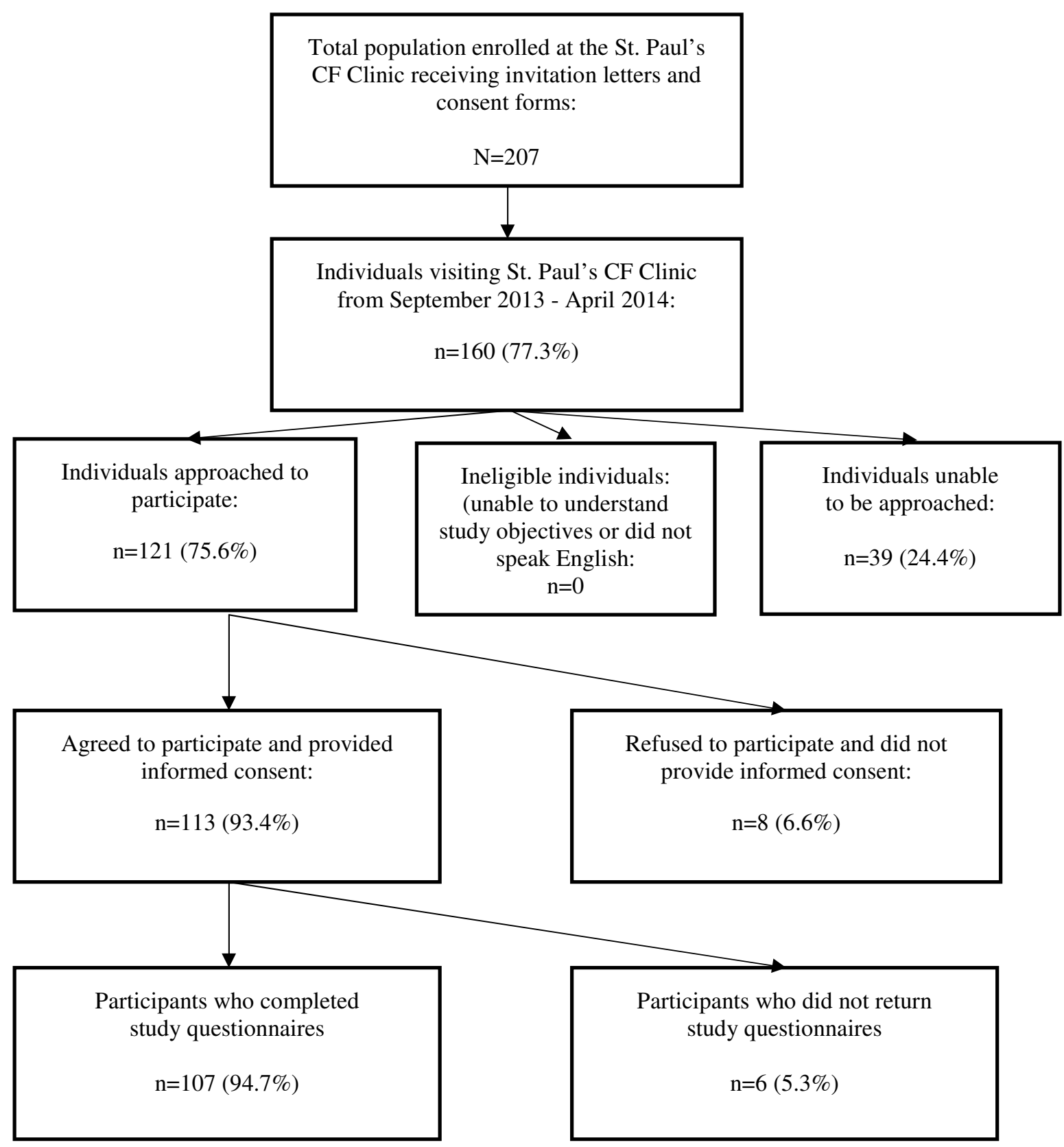




\subsection{Definition of Explanatory Variable}

\subsubsection{Chronic Rhinosinusitis}

An a priori definition of CRS was established from a review of existing literature and consultation with clinical experts. To prevent potential misclassification bias, we decided to utilize existing guidelines to diagnosis CRS.

The Canadian Clinical Practice Guidelines for Acute and Chronic Rhinosinusitis were established to provide health professionals a comprehensive document to guide diagnosis and management of CRS. ${ }^{9}$ The authors reviewed and graded the quality of existing literature and used the Delphi voting process to formulate recommendations. The Delphi process is a qualitative consensus method of establishing recommendations based on the agreement of experts. ${ }^{71}$ The first round consists of opinions categorized under common headings and questionnaires are then distributed to participating members. Respondents are asked to score agreement or disagreement and this process repeats until satisfactory consensus is achieved. Statements accepted by over half the participating expert group were retained in the final document.

Table 3.1 describes the methods used to diagnosis CRS. The Canadian Clinical Practice Guidelines for Acute and Chronic Rhinosinusitis recommends the presence of at least 2 major symptoms and at least 1 objective clinical finding. ${ }^{9}$ Major symptoms include nasal congestion, facial pain or pressure, nasal obstruction, anterior or posterior nasal discharge and loss of smell, presenting for at least 12 weeks. Major symptoms are rated as 'none', 'mild', 'moderate' or 'severe'. Individuals reporting at least 2 major symptoms (defined as 'mild', 'moderate' or 'severe') were recorded as fulfilling the subjective component for the diagnosis of CRS. 
Objective findings are evaluated from nasal endoscopy and include presence of nasal polyps or, discolored mucus, pus or inflammation of the middle meatus. A senior otorhinolaryngologist (A.R.J) performed nasal endoscopy by inserting a 3.0mm endoscope (Karl Storz GmbH \& Co. KG, Tuttlingen, Germany) into the right and left nostrils. The middle meatus was visualized and findings were recorded on individualized data collection forms. Alternatively, the Canadian Clinical Practice Guidelines for Acute and Chronic Rhinosinusitis indicate that objective findings can also be identified from sinus-CT scans. From consultation with CF-experts and otorhinolaryngologists, it was considered invasive and costly to request sinus-CT scans for participants in this research study. However for individuals with previously requested sinus-CT scans (i.e. prior to the conduct of this research study), scans were reviewed and used for diagnostic purposes.

As shown in Table 3.1, diagnosis of CRS required: 1) subjective symptoms plus 2) objective findings. An alternative parameter, history of sinus surgery, was also included as indication of CRS. On occasion when sinus-CT scans were available from previous non-research related requests, findings were included to support the objective component of the CRS diagnosis. Individuals reporting a history of sinus surgery or nasal polypectomy at any point during their lives were also identified as CRS-positive, regardless of symptoms. This was decided from consultation with clinical experts, as clinical experience to date suggests that individuals with $\mathrm{CF}$ and with a history of sinus surgery often require constant sinus-related treatment post-surgery. We defined sinus surgery as sinus-specific procedures to remove nasal polyposis or open obstructed sinus ostia under local or general anesthesia. 
Table 3.1- Summary of methods used to diagnosis CRS.

\begin{tabular}{|l|l|}
\hline Components & \multicolumn{1}{|c|}{ Description } \\
(Presence of $\geq 2$ major symptoms) & $\begin{array}{l}\text { Nasal congestion, facial pain or pressure, nasal obstruction, anterior or } \\
\text { posterior nasal discharge, loss of smell }\end{array}$ \\
\multicolumn{1}{c|}{ Plus } & \\
2. Objective findings & Presence of nasal polyps or, \\
From nasal endoscopy & Discolored mucus, pus or inflammation of the middle meatus \\
From sinus-CT scans & Evidence of CRS from radiographic imaging \\
3. History of sinus surgery & Self-reported history of sinus surgery or nasal polypectomy requiring local or \\
& \\
\hline
\end{tabular}

\subsection{Health-Related Quality of Life Outcomes}

\section{$\underline{\text { 3.3.1 Cystic Fibrosis Questionnaire-Revised }}$}

The Cystic Fibrosis Questionnaire-Revised for Adolescents and Adults $\geq 14$ years (CFQ-R 14+) was used to measure the HRQoL among study participants. ${ }^{25}$ The CFQ-R $14+$ is a disease-specific instrument that measures HRQoL for English speaking adolescents and adults with $\mathrm{CF}^{28,72}$ This questionnaire can be found at: http://www.psy.miami.edu/cfq_QLab/. From our systematic review in Chapter 2, we found that the CFQ-R (for all ages) has been the most commonly used instrument to measure HRQoL in the CF patient population. Of the 527 abstracts assessed for eligibility, approximately 199 (37.8\%) had used the CFQ-R. Validation studies using national CF patient registries and comparison with popular generic, non-CF HRQoL questionnaires (e.g. Short Form-36 (SF-36) and 
Nottingham Health Profile (NHP)) have resulted in the CFQ-R being the leading instrument to quantify HRQoL. $^{21}$

The CFQ-R was initially the Cystic Fibrosis Questionnaire (CFQ). This questionnaire was created to address the need for a CF-specific HRQoL instrument. ${ }^{73}$ Although the SF-36 and NHP were available and previously used to assess the impact of lung transplantation or pulmonary exacerbation on HRQoL, these instruments were not designed for individuals with $\mathrm{CF}^{22}$ Generic HRQoL questionnaires are considered to lack sensitivity of the challenges posed by individuals with $\mathrm{CF}^{23}$ As a result, generic instruments cannot quantify the effect of new interventions or disease progression. $^{23}$

To fill the need for a CF-specific HRQoL measure, the CFQ was developed from a cohort of children, adolescents and adults in multiple centres in France. Three distinct versions of the CFQ were established, specific for children between 6 and 13 years of age (CFQ Child), adolescents and adults over 14 years of age (CFQ 14+) and parents of children with CF (CFQ Parent). Items for the CFQ were generated from extensive review of the literature, discussion with experts, $\mathrm{CF}$ associations and qualitative interviews with patients and parents. $^{23,73}$ Thirteen domains were established for the CFQ 14+, these included; Physical functioning, Energy, Emotion, Social limitations, Role limitations, Embarrassment, Eating disturbances, Body image, Treatment burden, Health perception, Respiratory symptoms, Digestion and Weight. A total of 534 questionnaires were completed at 24 hospital sites in France and the final instrument had high internal consistency (i.e. Cronbach's alpha for each domain was between 0.61 and 0.92$).{ }^{23,73}$ Moderate convergent validity was also found between CFQ 14+ domains and the NHP (i.e. correlation coefficients ranging between 0.43 to 0.75). Similarly, the CFQ 14+ sufficiently discriminated individuals by disease severity and test-retest reliability (inter-class correlation coefficients ranging from 0.66 to 0.97 ). Disease severity was assessed using Shwachman 
scores and forced vital capacity. The results of this study suggested that the CFQ 14+ could be a reliable and valid instrument to measure HRQoL among CF individuals, yet required further validation.

Quittner et al. attempted to validate an English version of the CFQ 14+ in two samples of CF patients (Part 1 and Part 2). The CFQ was translated to English from French by two independent forward translations and subsequent backward translation, in order to resolve any conceptual or semantic discrepancies. ${ }^{23}$ Consensus was established and the new English-translated questionnaire was provided to the two cohorts. Part 1 consisted of 10 adolescents and adults recruited from two tertiary CF centres in the United States. The mean age of this cohort was 23.3 years with an equal distribution of males and females. Interviews were conducted with each participant after completion of the questionnaire to evaluate the clarity of questions, factors that affected response and record suggestions for topics not covered by the initial version of the CFQ 14+. A detailed description of this process can be found elsewhere. ${ }^{23}$ Modifications were made to the CFQ 14+ in response to findings from Part 1. In Part 2, an additional 10 subjects were recruited (mean age 22.9 years, $40 \%$ females), with the objective to identify remaining semantic and conceptual discrepancies, compare responses with the cohort in Part 1 and to correlate scores with $\mathrm{FEV}_{1} \%$ predicted. The majority of adolescents and adults found the updated CFQ 14+ easy to understand and $\mathrm{FEV}_{1} \%$ predicted was significantly associated with Physical functioning (correlation coefficient $=0.62, \mathrm{p}<0.01)$, Body image $($ correlation coefficient $=0.56, \mathrm{p}<0.05)$ and Emotion (correlation coefficient $=0.54, \mathrm{p}<0.05$ ). This study successfully translated the CFQ $14+$ from French to English, corrected semantic and conceptual discrepancies and found significant associations between $\mathrm{FEV}_{1} \%$ predicted and domain scores.

Following linguistic validation from French to English, two studies validated the CFQ 14+ in German and Dutch populations, respectively. ${ }^{29,30}$ Wenninger et al. translated the CFQ $14+$ to German and distributed the updated questionnaire to 197 adolescents and adults (mean age: 23.2 years) followed 
with a retest in a cohort of 103 patients (mean age: 25.5 years). ${ }^{18}$ The authors reported that the updated questionnaire resulted in comparable internal consistency and construct validity, as found in the original French version. ${ }^{18}$ Similarly, this instrument successfully differentiated subjects by disease severity, as measured by a weighted score calculated from $\mathrm{FEV}_{1} \%$ predicted and BMI. ${ }^{18}$ Klijn et al . translated the CFQ 14+ into Dutch and investigated its validity in a cohort of 84 adolescents and adults (mean age: 21.4 years).${ }^{19}$ The authors reported acceptable internal consistency, high test-retest reliability and significant differentiation by disease severity, nourished versus malnourished and $\mathrm{FEV}_{1} \%$ predicted. ${ }^{19}$ However, the most notable validation study of the CFQ $14+$ was conducted by Quittner et al. in cohort of 212 adolescents and adults. ${ }^{34}$ Similar to previous findings, the authors reported high internal consistency, test-retest reliability and validity at differentiating individuals of varying age, $\mathrm{FEV}_{1} \%$ predicted and BMI. To improve internal consistency, the author suggested revising the CFQ 14+ by adding additional questions and rewording existing items in the Treatment burden, Digestion, Role and Social functioning domains. ${ }^{34,35}$ The purpose of these revisions was to improve internal consistency and minimize ceiling effects. ${ }^{35}$ As a result of these changes, the modified CFQ 14+ was re-labeled as the CFQ-R 14+.

As stated earlier, the CFQ-R 14+ has been translated into 34 languages and is widely used in clinical trials. Similar to its predecessor, the CFQ-R 14+ consists of distinct domains that cover generic HRQoL functioning (Physical functioning, Energy, Emotion, Social and Role functioning), CF-specific aspects (Eating disturbances, Body Image, Treatment burden), an overall health assessment (Health perception) and symptom evaluations (Respiratory symptoms, Digestion and Weight). This questionnaire consists of 50 items and responses are made using a 4-point Likert scale. This is comprised of frequency ('always', 'often', 'sometimes', 'never'), intensity ('a great deal', 'somewhat', 'a little', 'not at all') and true-false ('very true', 'somewhat true', 'somewhat false', 'very false'). Scores are standardized by dividing responses by the total achievable score on each domain and range 
from 0 to 100. Higher scores indicate better HRQoL. The CFQ-R 14+ consists of additional questions related to date of birth, gender, martial status, race, highest level of education completed and current employment or school status.

Recently, the psychometric properties of the CFQ-R 14+ were evaluated using the Epidemiologic Study of CF (ESCF) database. The ESCF is a multicentre, longitudinal cohort study originating in 1994 with the purpose of investigating quality of care, treatment methods and HRQoL outcomes. The CFQR 14+ was the primary instrument to assess HRQoL and responses from 4,679 adolescents and adults were assessed. The authors found that ceiling effects were most common in the Eating disturbances and Weight domains. Moderate to high internal consistency was found with Cronbach's alpha values ranging from 0.51 to 0.94 . When comparing individuals by presence or absence of pulmonary exacerbation, CFQ-R 14+ scores were significantly lower on all domains except on the Digestion domain. The findings from this study provide additional evidence that the CFQ-R 14+ is a valid and reliable instrument to assess HRQoL.

The CFQ-R 14+ has become the primary instrument to quantify HRQoL among adolescents and adults with CF. The USFDA has recommended the use of the Respiratory symptoms domain as an endpoint in CF-related clinical trials. ${ }^{74}$ It is for this reason that we have utilized this questionnaire as our primary outcome measure. From our literature review, we have yet to identify a clinical or population-based study that has utilized the CFQ-R 14+ to quantify the impact of CRS on HRQoL.

\subsection{Data Collection}

Data was collected from participant interviews on the day of study enrollment and from medical charts located at the St. Paul's CF Clinic. All participants signed consent forms and completed paper copies of the CFQ-R 14+, which were stored in separate binders locked in a cabinet at the St. Paul's Sinus 
Centre. Responses to CFQ-R 14+, endoscopic findings and additional data extracted from medical charts were manually entered into a password-protected Microsoft Excel sheet. This was stored on a password-protected computer in the St. Paul's Sinus Centre. Participant identification codes were also stored in a separate password-protected Microsoft Excel spreadsheet. Endoscopic findings were recorded in an electronic medical records program and copies were faxed to the St. Paul's CF Clinic to be stored in each subject's medical charts. This was performed to allow clinicians to refer to these findings for future patient assessments. The data collection form is provided in Appendix B.

\subsection{Coding of Outcome and Explanatory Variables}

This section describes the methods used to define and categorize the outcome variable, explanatory variable and covariates. The parameters used to define each variable were directed from utilizing the understanding of existing literature gained from Chapter 2 and consultation with clinical experts. The following sections provide a detailed description of each variable and justification for inclusion.

\subsubsection{CFQ-R 14+ Domain Scores}

CFQ-R 14+ domain scores were considered as continuous, non-discrete numeric variables, ranging from 0 to 100. Twelve independent scores were calculated for each CFQ-R 14+ domain. Table 3.2 details the items and scoring method of each domain. 
Table 3.2- Number of items and items numbers used in the scoring of each CFQ-R 14+ domain.

\begin{tabular}{|l|c|c|}
\hline CFQ-R 14+ Domains & $\begin{array}{c}\text { Number of Items } \\
\text { Included in Scoring }\end{array}$ & $\begin{array}{c}\text { Item } \\
\text { Numbers }\end{array}$ \\
\hline Physical functioning & 8 & $1,2,3,4,5,13,19,20$ \\
Energy & 4 & $6,9,10,11$ \\
Emotion & 5 & $7,8,12,31,33$ \\
Social functioning & 4 & $22,23,27,28,29,30$ \\
Role functioning & 3 & $35,36,37,38$ \\
Eating disturbances & 3 & $14,21,50$ \\
Body image & 3 & $24,25,26$ \\
Treatment burden & 3 & $15,16,17$ \\
Health perception & 6 & $18,32,34$ \\
Respiratory symptoms & 3 & $40,41,42,43^{1}, 44,45,46$ \\
Digestion & 1 & $47,48,49$ \\
Weight & 6 & 39 \\
\hline
\end{tabular}

1. Based on the CFQ-R 14+ scoring guidelines, item number 43 is not included in the calculation of the Respiratory domain score. ${ }^{35}$ This is reflected in the column 'Number of Items Included in Scoring'.

\subsubsection{CRS Status}

CRS status was based on both 1) subjective symptoms plus 2) objective findings or alternatively, 3) history of sinus surgery.

\section{Subjective Symptoms}

Respondents were then categorized into positive or negative symptom groups. Individuals experiencing at least 2 subjective symptoms, defined as 'mild' and above, were allocated to the positive-symptom group. Individuals who did not indicate 'mild' or above in at least 2 symptom categories were allocated 
to the negative-symptom group. Participants who did not return study questionnaires were considered as missing subjective symptom data.

\section{Objective Findings}

Objective findings consisted of nasal endoscopy results or if available, sinus-CT scan results. A senior otorhinolaryngologist performed nasal endsocopy. Individuals presenting with at least 1 finding were considered positive for objective evidence of CRS. For individuals refusing nasal endoscopy, sinus-CT scans were used to assess objective evidence of CRS if available. A senior otorhinolaryngologist reviewed each scan independently and categorized individuals as positive- or negative- for radiographic evidence. Individuals refusing nasal endoscopy and in whom sinus-CT scans were not available, were defined as missing objective evidence for CRS.

\section{History of Sinus Surgery}

History of sinus surgery or nasal polypectomy was added as an alternative parameter to identify CRS and non-CRS individuals. This variable was considered as a categorical, binary variable (positive, negative). Participants positive for a history of sinus surgery were subsequently asked the year in which their surgery occurred, in order to determine the time elapsed since the procedure was performed. This was considered as a continuous, discrete numerical variable and recorded in years. Individuals not responding to questions regarding history of sinus surgery were considered as missing.

\section{Classifying CRS Status}

CRS status was considered as a categorical, binary variable (positive, negative). Positive CRS individuals were defined as presenting with at least 2 subjective symptoms and at least 1 objective finding of endoscopic or radiographic evidence. Alternatively, individuals were considered CRSpositive if they reported a history of sinus surgery. Individuals who were symptomatic (i.e. at least 2 
symptoms) but were negative for endoscopic or radiographic evidence and history of sinus surgery were considered as CRS-negative. Individuals for which symptom, objective or a history of sinus surgery data were absent, were considered having missing data.

\subsection{Coding of Covariates}

Covariates were selected to account for potential confounding of the relationship between CRS and CFQ-R 14+ domain score. Confounders may contribute to all or part of the association observed and may be identified by three characteristics: 1) must be a risk factor for the outcome, 2) must be associated with the explanatory variable and 3) must not be a intermediary factor between the explanatory and outcome variables. ${ }^{65,67}$ The systematic review of the literature described in Chapter 2 allowed us to identify socio-demographic and clinical factors associated with CFQ-R 14+ domain scores. Similarly, a review of CRS-related literature and discussion with clinical experts identified factors previously associated with CRS. Combining the information accumulated from both of these processes allowed us to document potentially confounding variables. Confounding variables were controlled for in multivariable analysis. The following section include a description of each potential confounder. Additional auxiliary variables were recorded from patient charts, although not considered as potential confounders are also described. Table 3.3 summarizes the outcome variable, explanatory variable and covariates.

\subsubsection{Socio-Demographic Factors}

\section{Age}

Age was considered as a continuous variable and measured in years. The date of birth for each subject was recorded and subtracted from the day on which the data was collected to determine each participant age. In multivariable analyses, results from Chapter 2 suggest that Age was associated with 
the CFQ-R 14+ domains Treatment burden and Physical functioning. In regards to the relationship between Age and CRS, a population-based study in non-CF individuals found that the prevalence of CRS increased with Age. These findings suggest that Age may potentially confound the relationship between CRS and CFQ-R 14+ domain scores.

\section{Gender}

Gender was considered as a categorical, binary variable and grouped into Male or Female. Based on multivariable findings in Chapter 2, gender was significantly associated with CFQ-R 14+ domains: Body image, Physical functioning, Energy, Emotion, Social functioning, Treatment burden and Weight. In regards to CRS, the prevalence of CRS has been shown to differ between males and females. ${ }^{1}$ These findings suggest that Gender may potentially confound the relationship between CRS and CFQ-R 14+ domain scores.

\section{Current Employment or School Status}

Current employment or school status was defined as a categorical, dichotomous variable. This was extracted from the CFQ-R 14+ question G. Respondents were asked to indicate if they were currently: A) Attending school outside of the home, B) Taking educational courses at home, C) Seeking work, D) Working full or part time either outside of the home or at home-based businesses, E) Full time homemaker, F) Not attending school or work due to my health or G) Not working for other reasons.

Utilizing the method described by Havermans et al., participants were dichotomized into 'currently employed or attending school' or 'unemployed or not attending school' ${ }^{47}$ Membership into each group was considered mutually exclusive. From the CFQ-R 14+, participants indicating options A, B, D or E were allocated to the 'currently employed or attending school' group. For the purposes of this study, this group also included individuals self-identifying as homemakers (i.e. option D), as this was not 
clearly described by Havermans et al. ${ }^{23}$ Participants indicating options C, F or G were allocated to the 'unemployed or not attending school' group.

From multivariable findings in Chapter 2, current employment or school status was associated with higher scores on the domains Physical functioning, Social functioning and Role functioning. ${ }^{23}$ To the best of our knowledge, no association has been reported between current employment or school status and CRS. However, it has been shown that individuals unemployed or not attending school have significantly higher rates of chronic P.aeruginosa infection than counterparts employed or going to school. CRS has been found to occur more frequently among individuals with chronic P.aeruginosa infection. Based on these, we inferred that current employment or school status is indirectly associated with CRS through chronic P.aeruginosa infection. ${ }^{75}$ For this reason, we felt it was necessary to record this variable.

Body-Mass Index

Body-mass index (BMI) was considered as a continuous variable and measured in kilograms per metresquared $\left(\mathrm{kg} / \mathrm{m}^{2}\right)$. Multivariable results from Chapter 2 suggest that BMI was associated with the domains of Energy, Body Image and Weight. In regards to CRS, it has been shown that obesity $\left(\mathrm{BMI}>30 \mathrm{~kg} / \mathrm{m}^{2}\right.$ ) was significantly associated to $\mathrm{CRS} .{ }^{12}$ Given the associations found between BMI and CFQ-R+ and CRS respectively, this variable was considered as a potential confounder.

\section{$\underline{\text { 3.6.2 Clinical Characteristics }}$}

Age of CF Diagnosis

The variable Age of CF Diagnosis was considered as a continuous variable and measured in years. This variable was collected as an indication of disease severity, as it is suggested early diagnosis of CF is 
associated with genotype mutation and CF phenotype. ${ }^{4,13}$ Based on these associations, this variable was also used to categorize mutation class.

Time Since CF Diagnosis

The variable 'Time since CF diagnosis' was considered as a continuous variable and measured in years. This was ascertained from subtracting participant age and from the year in which CF was diagnosed. To the best of our understanding, a significant association between time since CF diagnosis and CRS has not been established. However after discussion with clinical experts, we felt it was necessary to capture this variable as a possible indication of CF disease severity.

\section{Pancreatic Insufficiency}

Pancreatic insufficiency was considered as a categorical, binary variable (Yes, No). Subject medical charts were reviewed for indications of pancreatic insufficiency. Individuals currently using pancreatic enzyme treatment or identified as pancreatic insufficient by attending clinical experts at the time of enrollment, were allocated to the 'pancreatic insufficient' group. Individuals who did not meet these criteria were allocated to the 'pancreatic insufficient' group. We felt it was necessary to capture this variable after discussion with clinical experts, as an additional indication of CF disease severity.

\section{Mutation Class}

CF genotype mutation was considered as a categorical, binary variable and extracted from medical charts. Based on research conducted by Berkhout et al. participants were grouped into two categories, individuals with Class I to III or Class IV to V mutations. ${ }^{13}$ Based on this, mutation details were extracted from medical charts and participants were grouped accordingly. Membership into each group was mutually exclusive. For individuals for whom mutation details were unknown or missing, categorization methods described previously were used. Participants who were pancreatic insufficient 
and were diagnosed with $\mathrm{CF}$ at an age $<10$ years were considered to have been carrying the Class I to III genotype. ${ }^{26}$ Participants who were pancreatic sufficient and were diagnosed with $\mathrm{CF}$ at an age $\geq 10$ years were considered to have been carrying the Class IV to V genotype. ${ }^{13}$ Individuals who did not meet these criteria were considered missing.

Mutation class was considered as a potential confounder because of its indirect association with CFQ-R 14+ domains mediated by age. ${ }^{13}$ It has been shown previously that CRS occurs more frequently among individuals with Class I to III than Class IV to V mutations. ${ }^{26}$ Given the associations found in Chapter between mutation class and CFQ-R 14+ domain, we felt it was important to capture this variable.

\section{Lung Function}

Lung function was considered as a continuous variable and measured by $\mathrm{FEV}_{1} \%$ predicted. From Chapter $2, \mathrm{FEV}_{1} \%$ predicted was found to be significantly associated with 9 of 12 CFQ-R 14+ domains. To the best of our understanding, an association between $\mathrm{FEV}_{1} \%$ predicted and CRS has not been established. However, after consulting with clinical experts we felt it was important to capture this variable as another indication of disease severity and because of its previous associations with CFQ-R 14+ domains.

\section{History of Lung Transplant}

Transplant status was considered as a categorical, binary variable (Yes, No). We decided to record this variable after consultation with clinical experts, as individuals receiving lung transplant require different treatment regimens and follow-up visits than counterparts having not received a transplant. Transplant was considered as an auxiliary variable and not as a potential confounder. 


\section{Depression}

Depression was considered as a categorical, binary variable, defined as the use of medical treatment. Individuals currently prescribed anti-depressants were considered positive for depression. Individuals not using anti-depressants were considered negative for depression. These details were extracted from medical charts and subsequent clinician and pharmacist notes.

In multivariable findings as discussed in Chapter 2, depression was significantly associated with domains Emotion, Eating disturbances, Body Image. Havermans et al. used the Hospital Anxiety and Depression Scale (HADS) to categorize individuals as depressed or not depressed. ${ }^{44}$ As administering the HADS questionnaire was not feasible for the purposes this cross-sectional study, an alternative definition based on current medication was used to categorize depression status.

In regards to CRS, epidemiological research conducted by Macdonald et al. found that individuals with CRS were associated with depressive symptoms and more frequent use of anti-depressants. Discussion with clinical experts suggests that depression may occur as a result of CRS, although to the best of our understanding no literature to date has evaluated this temporal relationship. Depression was recorded as an auxiliary variable due to previous associations with CFQ-R 14+ and CRS but not considered as a potential confounder.

\section{Chronic Pseudomonas Aeruginosa Infection}

Chronic P.aeruginosa infection was considered as a categorical, binary variable (Yes, No) and ascertained from the St. Paul's Hospital electronic medical records and CF Clinic medical charts. Chronic P.aeruginosa infections were defined as presenting with at least 3 positive sputum cultures in the 6 months prior to enrollment. ${ }^{54}$ In bivariable results, the authors found that individuals with chronic P.aeruginosa infection reported significantly worse scores on all domains of the CFQ-R 14+, except 
Energy and Health perception. ${ }^{26}$ In regards to the relationship between chronic lung infection of P.aeruginosa and CRS, it has been shown that cultures from the sinuses and bronchoalveolar lavages are associated among individuals with $\mathrm{CF}$ requiring sinus surgery. Based on these findings, we felt it was necessary to account for this potentially confounding variable. 
Table 3.3- Summary of outcome variable, explanatory variable and covariates captured in crosssectional evaluation of the impact of CRS on the HRQoL of adults with CF.

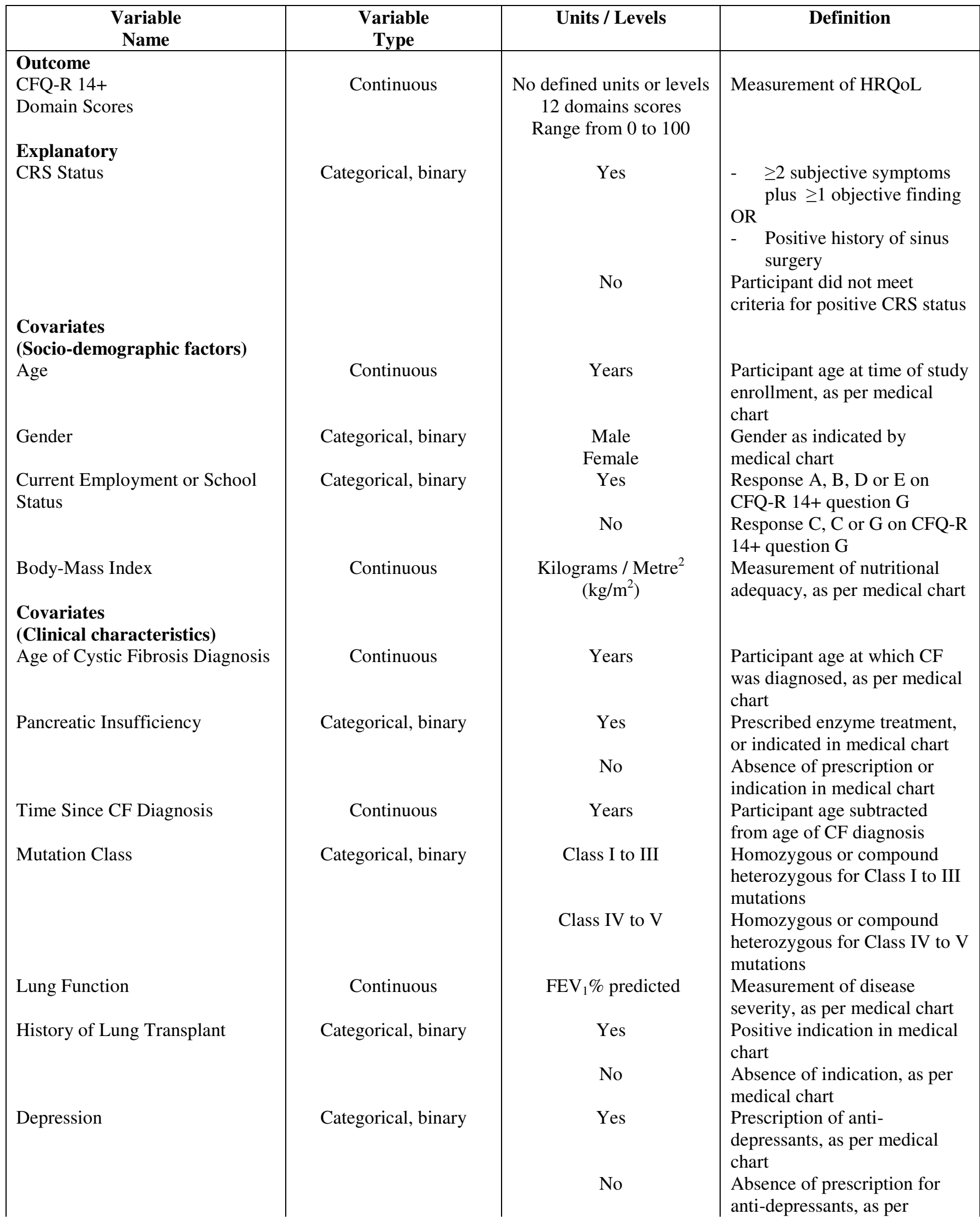




\begin{tabular}{|c|c|c|l|}
\hline $\begin{array}{c}\text { Variable } \\
\text { Name }\end{array}$ & $\begin{array}{c}\text { Variable } \\
\text { Type }\end{array}$ & Units / Levels & \multicolumn{1}{c|}{ Definition } \\
\hline Chronic P.aeruginosa Infection & Categorical, binary & Yes & $\begin{array}{l}\text { medical chart } \\
\geq 3 \text { positive sputum cultures in } \\
6 \text { months prior to enrollment } \\
<3 \text { positive sputum cultures in } \\
6 \text { months prior to enrollment }\end{array}$ \\
\hline
\end{tabular}

\subsection{Statistical Analysis}

\section{$\underline{\text { 3.7.1 Missing Data }}$}

Multiple imputations were used to address indices of missing data. This method predicts multiple values for every missing cell in a dataset, based on patters observed in available data. ${ }^{76}$ Multiple complete datasets are created for statistical testing in order to prevent introducing additional bias from subjectively choosing values for missing cells. ${ }^{76}$ These include assigning the overall mean to missing cells or analyzing only complete case data. ${ }^{76}$ The observed values may not be equal across the newly established datasets due to the uncertainty presented by missing cells. This method allows researchers the ability to treat multiply imputed data sets as though no data were missing. It is important to note that multiple imputations are most commonly utilized when data is missing at random (MAR). ${ }^{76}$ MAR can be defined as missing data that is dependent on observed subject characteristics (e.g. outcome variable). ${ }^{76}$ SAS version 9.4 (SAS Institute, Cary, NC) was used to perform multiple imputations on the study dataset and was repeated 50 times. Regression coefficients and standard errors were calculated for each multiple imputed dataset $(\mathrm{m}=50)$ and averaged to yield overall estimates.

In our study sample, missing data was found to be MAR after comparing respondents with complete data to respondents with missing data. In regards to the primary outcome, the response rate to the CFQR 14+ was 94.7\%. Six participants did not return their CFQ-R 14+ questionnaires and as a result, domain scores could not be calculated for these participants. CRS was evaluated in $93.8 \%$ of participants, as these individuals answered subjective nasal symptom and history of sinus surgery 
questions. CRS diagnosis was missing for 7 individuals. Table 3.4 details missing data for each variable recorded.

Table 3.4- Frequency of missing data for outcome variable, explanatory variable and covariates.

\begin{tabular}{|c|c|c|}
\hline Variable Name & $\begin{array}{c}\text { Frequency } \\
\text { (n) }\end{array}$ & $\begin{array}{c}\text { Proportion } \\
(\%)\end{array}$ \\
\hline CFQ-R 14+ Domain Scores & 6 & 5.3 \\
\hline CRS & & \\
\hline Subjective Symptoms & & \\
\hline Nasal congestion & 7 & 6.2 \\
\hline Facial pain or pressure & 7 & 6.2 \\
\hline Nasal obstruction & 7 & 6.2 \\
\hline Anterior or posterior discharge & 7 & 6.2 \\
\hline Loss of smell & 7 & 6.2 \\
\hline History of Sinus Surgery & 7 & 6.2 \\
\hline Objective Characteristics & & \\
\hline Sinus-CT scan & 59 & 52.2 \\
\hline Endoscopic Findings ${ }^{1}$ & & \\
\hline Nasal polyps & 0 & 0 \\
\hline Discoloured mucus & 0 & 0 \\
\hline Middle meatal edema & 0 & 0 \\
\hline Middle meatal pus & 0 & 0 \\
\hline Age & 0 & 0 \\
\hline Gender & 0 & 0 \\
\hline Current Employment or School Status & 5 & 4.4 \\
\hline Body-Mass Index & 1 & 0.9 \\
\hline CF Genotype Class & 8 & 7.1 \\
\hline Time Since CF Diagnosis & 3 & 2.7 \\
\hline Lung Function $\left(\mathrm{FEV}_{1} \%\right)$ & 3 & 2.7 \\
\hline History of Lung Transplant & 0 & 0 \\
\hline Depression & 0 & 0 \\
\hline Pancreatic Insufficiency & 0 & 0 \\
\hline Chronic PA Infection & 9 & 8.0 \\
\hline
\end{tabular}

1. This section refers to the group of individuals ( 69 of $113,61.1 \%$ ) who had elected to receive nasal endoscopy. 


\subsubsection{Methods to Assess Representativeness of Study Sample}

To determine sample representativeness, the study sample recruited was compared to the eligible clinic population. Summary statistics based on the population enrolled at the St. Paul's CF Clinic were compared with those of the study sample included in this cross-sectional study. To assess representativeness, mean values for continuous variables and absolute proportions for categorical variables were compared between the study sample and eligible clinic population. No statistical tests were conducted.

\subsubsection{Methods to Analyze Socio-Demographic Factors and Clinical Characteristics by CRS status}

Socio-demographic and clinical factors were examined to detect noticeable differences between CRS positive and negative individuals. The purpose of this bivariate analysis was to test the null hypothesis that no significant differences existed between CRS positive and negative individuals in the study sample recruited. Continuous variables were summarized using descriptive statistics such as mean, median, standard deviation and interquartile range. Differences in means were examined using the parametric Student's t-test, if the following assumptions were met: 1) sample was representative of eligible population, 2) observations were obtained independently and were not paired, 3) observations followed a normal distribution and 4) the standard deviations of CRS-positive and negative groups

were similar. ${ }^{77}$ If these assumptions were not met, the non-parametric Wilcoxon Rank-Sum test was used to test for statistical significance. Categorical variables were summarized using frequencies, absolute proportions and assessed for statistical significance using the Chi-square test for independence. If expected cell counts were $<5$, the Fisher's Exact test was used to test for statistical significance. Odds ratios with corresponding 95\% confidence intervals were reported to illustrate the magnitude of association. Type I error $<0.05$ was considered statistically significant. 


\subsubsection{Methods to Analyze CRS Status and CFQ-R 14+ Domain Scores}

Multivariable linear regression (MLR) was used to determine if CRS status was linearly associated with CFQ-R 14+ domain scores, after controlling for several potentially confounding variables. The objective of MLR is to fit a linear model to the data, in order to best account for variability in the outcome variable. ${ }^{77}$ Models that achieve this are known as the 'best-fit model' ${ }^{77}$ Adjusted linear regression models measure the relationship between an independent (e.g. CRS status) and a dependent variable (e.g. CFQ-R 14+ domain scores) while simultaneously adjusting for other factors known to influence the dependent variable. Although stratification could have been employed to isolate the effect of CRS status on CFQ-R 14+ domain scores, regression-based techniques were more suitable as

multiple covariates could be adjusted for simultaneously. ${ }^{77}$ In order to create adjusted MLR models, simple, bivariate relationships between covariates and CFQR-14+ domains were assessed. Based on these results, finding in Chapter 2 and discussion with clinical experts, MLR models were then established.

\subsubsection{Bivariate Analysis}

Bivariate analysis of continuous and categorical variables was undertaken to test their significance on CFQ-R 14+ domain scores. These methods tested the significance of relationships between covariates and provided justification for inclusion in MLR models. The Perason's and Spearman's correlation tests were used to test continuous variables, while the Student's t-test and Wilcoxon Rank-sum tests were used to assess categorical variables. The null hypothesis for each of the above tests was that no relationship existed between each covariates and CFQ-R 14+ domain scores. 


\subsubsection{Multivariable Analysis}

Multivariable analyses were used to address issues of confounding and bias identified in this study.

This allows statistical adjustments in order to control for possible confounders while estimating the association between explanatory and outcome variables. ${ }^{77}$

MLR was used to model the relationship between CRS status (explanatory, independent variable) and CFQ-R 14+ domain (outcome, dependent variable). A linear equation was constructed hat modeled the strength of association between CRS status and CFQ-R 14+ domain scores, simultaneously adjusting for relevant covariates. MLR tests whether an independent variable $\left(\mathrm{X}_{\mathrm{n}}\right)$ is linearly related to a dependent variable $\left(Y_{n}\right)$, while adjusting for other covariates. ${ }^{77}$ The dependent variables for the purposes of this thesis, were CFQ-R 14+ domain scores $\left(\mathrm{Y}_{\mathrm{n}}\right)$ and the main independent variable of interest was CRS status $\left(\mathrm{X}_{\mathrm{n}}\right)$. Confounders forced into the final MLR model but restricted if associated with other covariates (i.e. collinearity). The null hypothesis states that each individual variable included in the model provides no additional information to the model. All tests were 2-tailed and p-values $<0.05$ were considered significant. The null hypothesis was rejected when $\mathrm{p}<0.05$ and not rejected when $\mathrm{p} \geq 0.05$.

The general form of the equation used to estimate the strength of the linear relationship between CRS status and CFQ-R 14+ domain score is:

Equation: $Y=\beta_{0}+\beta_{1} X_{1}+\beta_{n} X_{n}$

Where:

- Y: indicates a dependent variable (outcome) and represents CFQ-R 14+ domain scores (1-12). 
- $\beta_{0}$ : represents the intercept when all $\mathrm{X}$ values are equal to 0 .

- $\beta_{1}$ : represents the regression coefficient for CRS status. This is equivalent to the slope of the linear relationship and represents the difference in CFQ-R 14+ domain score between CRS positive and negative individuals. Regression coefficients equal to 0 suggest that no association exists between the dependent and independent variables.

- $\mathrm{X}_{1}$ : represents the primary explanatory, independent variable (i.e. CRS status: positive or negative).

- $\beta_{\mathrm{n}}$ : represents the regression coefficient for each covariate entered into the MLR model. This is equivalent to the slope of the linear relationship and represents: 1) the difference in CFQ-R 14+ score between levels of categorical covariates or 2) the increase in CFQR-14+ score for every single unit increase in continuous covariates. A regression coefficient is assigned for each unique covariate in the model.

- $\mathrm{X}_{\mathrm{n}}$ : represents the covariates included in the MLR model. Each covariate is assigned an individual $\mathrm{X}$-variable and this parameter can be either continuous or categorical.

Adjusted $\mathrm{R}^{2}$ values were also reported. Unadjusted $\mathrm{R}^{2}$ values represent the proportion of variation in the dependent variable that is explained by the variables included in the regression model. ${ }^{77}$ As more predictors are added to model, the proportion of variance explained by the MLR model increases and may be a result of chance occurrence. ${ }^{77}$ This means that as the number of covariates increases in the MLR model, the unadjusted $\mathrm{R}^{2}$ value will also increase. ${ }^{77}$ In order to provide a more accurate assessment of the proportion of variation explained by the MLR model, the adjusted $\mathrm{R}^{2}$ is reported. $^{77}$ This parameter accounts for the number of variables included in the MLR model and the equation is described below.

Equation for adjusted $\mathrm{R}^{2}$ : 
Where $\mathrm{N}$ is the sample size, $\mathrm{k}$ is the number of predictors included in the model and $\mathrm{R}^{2}$ is the unadjusted $\mathrm{R}^{2}$ value.

\subsubsection{Collinearity}

Collinearty was assessed between covariates because multiple covariates were eligible to be entered into the MLR models. Collinearity occurs because highly correlated covariates are included together in MLR models. ${ }^{70,77}$ As a result, regression estimates can be distorted. Strongly correlated covariates can produce false impressions of a null association between dependent and independent variables, when a true association may exist. ${ }^{77}$

To assess collinearity, correlation coefficients were examined between continuous variables, odds ratios were examined between categorical variables and means differences were compared between continuous and categorical variables. Directed Acyclic Graphs (DAGs) were constructed to visualize the relationship between CRS and CFQ-R 14+ taking into account the role of each covariate. These were used to decide which covariates to include in the final MLR models. Significance tests (i.e. Pearson's or Spearman's correlation tests, Chi-squared or Fisher's exact tests, Student-t or Wilcoxon rank-sum tests) were used as an adjunct to DAGs, to minimize chance findings from determining covariate selection in the final MLR models.

DAGs are schematics that allow investigators to identify alternative pathways involving covariates that may bias the main relationship being investigated. ${ }^{78}$ From this, potential confounders can be recognized and adjusted for in the MLR models. Connections between variables represent associations, 
unconnected variables represent no association and unidirectional arrows indicate the direction of association.

Twelve DAGs were constructed for each of the CFQ-R 14+ domains. Connections between variables were based on the findings from Chapter 2 and results from bivariable analysis. If covariates were strongly associated with one another, the final MLR models contained the covariate most precisely measured, lowest frequency of missing data and most strongly associated with the dependent variable from bivariable findings. Comparisons were provided for regression coefficients, standard errors, $\mathrm{R}^{2}$ and mean squared error (MSE) between unadjusted and adjusted models.

Statistical analysis was completed using SAS Version 9.4 (SAS Institute, Cary, NC). 


\section{CHAPTER 4: PREVALENCE OF CHRONIC RHINOSINUSITIS}

\subsection{Descriptive Analysis of Study Sample}

One hundred twenty-one of 160 eligible individuals were approached to participate in this crosssectional study. A total of 113 provided informed consent, which represented a response rate of $93.4 \%$. Among the eight individuals refusing to participate, all had indicated that they were not interested in the study objectives and methods. The final study sample of 113 participants represented $54.9 \%$ of the total clinic population $(n=207)$ and $70.6 \%$ of the eligible population $(n=160)$. The 47 patients who did not attend the St. Paul's CF Clinic for routine assessment within the enrollment period could not be approached to participate and were considered ineligible.

\subsubsection{Socio-Demographic Factors}

A summary of socio-demographic characteristics is shown in Table 4.1. The final study sample was comprised primarily of males (66.4\%) with a mean age of 36.1 years. Sixty-seven (62.0\%) individuals self-identified themselves as currently part- or full-time employed or attending school. This consisted of $44.4 \%$ currently employed outside of their home or at home-based businesses, $14.8 \%$ attending school outside and $2.8 \%$ self-identified as full-time homemakers.

Table 4.1- Descriptive summary of socio-demographic factors for final study sample.

\begin{tabular}{|l|rrrr|}
\hline & \multicolumn{4}{|c|}{$\begin{array}{c}\text { Overall Study Sample } \\
\text { (n=113) }\end{array}$} \\
\hline Continuous & Mean & Standard & Median & $\begin{array}{r}\text { Interquartile } \\
\text { Range }\end{array}$ \\
Socio-demographic Factors & & Deviation & 34.0 & 19.0 \\
$\quad$ Age (years) & 36.1 & 12.9 & 22.7 & 4.6 \\
$\quad$ Body-mass index $\left(\mathrm{kg} / \mathrm{m}^{2}\right)$ & 23.4 & 3.5 & & \\
Categorical & & & Absolute & \\
Socio-demographic Factors & $\mathrm{n}$ & Frequency & \\
$\quad$ Males & & $(\%)$ & \\
$\quad$ Current Employment or & 75 & 66.4 & \\
$\quad$ School Status & 67 & 62.0 & \\
& & & & \\
\end{tabular}




\subsubsection{Clinical Characteristics}

A summary of clinical characteristics based on all available data is shown in Table 4.2. From participant medical records, the mean age at $\mathrm{CF}$ diagnosis was 9.7 years and the mean time since $\mathrm{CF}$ diagnosis was 26.2 years. The study sample consisted predominantly of individuals with more severe genotype mutations (i.e. class I to III mutations, 75.2\%) and those who were pancreatic insufficient

(74.3\%). Lung function, as measured by $\mathrm{FEV}_{1} \%$ predicted, was on average $73.4 \%$. Chronic P.aeruginosa infection, defined by at least three positive sputum cultures within six months prior to enrollment, was prevalent in $43.3 \%$ of all participants. Medical records indicated that 20 individuals were currently using anti-depressants at the time of enrollment. 
Table 4.2- Descriptive summary of clinical characteristics for final study sample.

\begin{tabular}{|c|c|c|c|c|}
\hline & \multicolumn{4}{|c|}{$\begin{array}{l}\text { Final Study Sample } \\
(n=113)\end{array}$} \\
\hline Continuous & Mean & Standard & Median & Interquartile \\
\hline Clinical Characteristics & & Deviation & & Range \\
\hline $\begin{array}{l}\text { Age at CF Diagnosis } \\
\text { (years) }\end{array}$ & 9.7 & 13.8 & 2.8 & 11.6 \\
\hline $\begin{array}{l}\text { Time since CF Diagnosis } \\
\text { (years) }\end{array}$ & 26.2 & 12.4 & 25.0 & 14.3 \\
\hline $\begin{array}{l}\text { Lung Function } \\
\text { (FEV } \% \text { predicted) }\end{array}$ & 73.4 & 25.8 & 75.0 & 40.0 \\
\hline Categorical & $\mathrm{n}$ & Absolute & & \\
\hline Clinical Characteristics & & $\begin{array}{r}\text { Frequency } \\
(\%)\end{array}$ & & \\
\hline $\begin{array}{l}\text { Class I to III Genotype } \\
\text { Mutations }\end{array}$ & 79 & 75.2 & & \\
\hline Pancreatic Insufficiency & 84 & 74.3 & & \\
\hline $\begin{array}{l}\text { Chronic P.aeruginosa } \\
\text { Infection }\end{array}$ & 43 & 43.3 & & \\
\hline Depression & 20 & 17.7 & & \\
\hline History of Lung Transplant & 16 & 14.2 & & \\
\hline
\end{tabular}

\subsubsection{Comparison With Clinic Population}

Socio-demographic factors and clinical characteristics were compared to determine if the study sample represented the clinical population from which participants were recruited. Findings from the most recent evaluation of the St. Paul's CF Clinic population in 2012 were used for comparison purposes. A summary of socio-demographic factors and clinical characteristics for the total clinic population and study sample is shown in Table 4.3. Covariates such as current employment or school status, class I-III CF genotype and time since CF diagnosis were unavailable in the 2012 report and as such, comparisons of these factors could not be made. As shown in Table 4.3, continuous and categorical covariates are similarly distributed between the study sample and total clinic population. However, the study sample consisted of a greater proportion of males than the total clinic population (66.4\% versus $57.5 \%)$. 
Table 4.3- Descriptive summary of socio-demographic factors and clinical characteristics to compare total clinic population and study sample recruited.

\begin{tabular}{|c|c|c|}
\hline & $\begin{array}{l}\text { Total Clinic Population } \\
(\mathrm{N}=\mathbf{2 0 7})\end{array}$ & $\begin{array}{c}\text { Study Sample } \\
(\mathbf{n}=113)\end{array}$ \\
\hline $\begin{array}{l}\text { Continuous } \\
\text { Socio-demographic Factors }\end{array}$ & Mean & Mean \\
\hline $\begin{array}{l}\text { Age } \\
\text { (years) }\end{array}$ & 34.0 & 36.1 \\
\hline $\begin{array}{l}\text { Body-mass index } \\
\left(\mathrm{kg} / \mathrm{m}^{2}\right)\end{array}$ & 22.6 & 23.4 \\
\hline $\begin{array}{l}\text { Categorical } \\
\text { Socio-demographic Factors } \\
\quad \text { Males }\end{array}$ & $\begin{array}{r}\text { Absolute Frequency } \\
(\%) \\
57.5\end{array}$ & $\begin{array}{r}\text { Absolute Frequency } \\
(\%) \\
66.4\end{array}$ \\
\hline $\begin{array}{l}\text { Continuous } \\
\text { Clinical Characteristics }\end{array}$ & Mean & Mean \\
\hline $\begin{array}{l}\text { Lung Function } \\
\left(\mathrm{FEV}_{1} \% \text { predicted) }\right. \\
\text { Age of CF diagnosis } \\
\text { (years) }\end{array}$ & $\begin{array}{r}69.2 \\
9.0\end{array}$ & 73.4 \\
\hline $\begin{array}{l}\text { Categorical } \\
\text { Clinical Characteristics } \\
\text { Pancreatic Insufficiency } \\
\text { Chronic P.aeruginosa } \\
\text { infection } \\
\text { Depression }\end{array}$ & $\begin{array}{r}\text { Absolute Frequency } \\
(\%) \\
79.2 \\
47.8 \\
\\
14.5\end{array}$ & $\begin{array}{r}\text { Absolute Frequency } \\
(\%) \\
74.3 \\
43.3\end{array}$ \\
\hline
\end{tabular}

\subsection{Summary of Sinus Symptoms}

A descriptive summary of the frequency of sinus symptom is shown in Table 4.4. Participants reported the severity of their sinus symptoms using a four-point scale. Five major symptoms were evaluated (Appendix B): nasal congestion, facial pain or pressure, nasal obstruction, anterior or posterior nasal discharge and loss of smell. Individuals indicating symptoms were 'mild', 'moderate' or 'severe' were classified as positive for the symptom component of CRS diagnosis. Seventy-eight participants met the symptom component of CRS having indicated they experienced at least two sinus symptoms. Using relative proportions (i.e. frequency of symptoms among symptomatic individuals), this consisted of $23.6 \%$ experiencing all five major symptoms, $19.2 \%$ reporting four symptoms, $28.2 \%$ reporting three symptoms and $20.5 \%$ reporting two symptoms. Twenty-eight individuals did not fulfill the subjective component of CRS, as they reported experiencing at most one symptom. Only $7.6 \%$ of all respondents 
reported experiencing no sinus symptoms. In summary, 78 respondents were symptomatic and 28 were asymptomatic for CRS. Symptom data were missing for remaining 7 (6.2\%) participants.

\subsubsection{Nasal Congestion}

Nasal congestion was the most prevalent sinus symptom reported, as indicated by $72.6 \%$ of all respondents. This symptom was most frequently reported as 'mild' when compared to all other symptoms. 'Severe' nasal congestion was experienced by $6.5 \%$ of participants.

\subsubsection{Facial Pain or Pressure}

Facial pain or pressure was the least prevalent sinus symptom, as reported by $40.6 \%$ of respondents.

'Severe' facial pain or pressure was experienced by $5.7 \%$ of all participants.

\section{$\underline{4.2 .3 \text { Nasal Obstruction }}$}

Nasal obstruction was the second least prevalent sinus symptom, as reported by $51.0 \%$ of respondents. 'Severe' nasal obstruction was indicated by $7.6 \%$ of all participants.

\subsubsection{Anterior or Posterior Nasal Discharge}

Anterior or posterior nasal discharge was the second most prevalent sinus symptom, as indicated by $65.2 \%$ of respondents. This symptom was most frequently reported as 'moderate' $(27.4 \%)$. Similar to nasal obstruction, 'severe' anterior or posterior nasal discharge was indicated by $7.6 \%$ of participants.

\subsubsection{Loss of Smell}

A reduction or loss of smell was reported by $56.6 \%$ of all respondents. This symptom was most frequently reported as 'severe', as indicated by $25.5 \%$ of all participants. Responses of 'mild' and 'moderate' loss of smell were similarly reported (16.0\% and $15.1 \%$, respectively). 
Table 4.4- Descriptive summary of sinus symptoms for overall study sample.

\begin{tabular}{|l|rrrr|}
\hline Subjective Sinus Symptoms & $\begin{array}{r}\text { None } \\
\text { Absolute } \\
\text { Frequency } \\
(\%)\end{array}$ & $\begin{array}{r}\text { Mild } \\
\text { Absolute } \\
\text { Frequency } \\
(\%)\end{array}$ & $\begin{array}{r}\text { Moderate } \\
\text { Absolute } \\
\text { Frequency } \\
(\%)\end{array}$ & $\begin{array}{r}\text { Severe } \\
\text { Absolute } \\
\text { Frequency } \\
(\%)\end{array}$ \\
\hline Nasal Congestion & 27.4 & 40.6 & 25.5 & 6.5 \\
Facial Pain or Pressure & 59.4 & 18.9 & 16.0 & 5.7 \\
Nasal Obstruction & 49.1 & 27.4 & 16.0 & 7.6 \\
Anterior or Posterior & 34.9 & 30.2 & 27.4 & 7.6 \\
Nasal Discharge & 43.4 & 16.0 & 15.1 & 25.5 \\
Loss of Smell & & & & \\
\hline
\end{tabular}




\subsection{Objective Findings}

A summary of the distribution of participants with objective findings is shown in Figure 4.1.

Figure 4.1- Venn diagram showing distribution of objective findings (endoscopic and radiographic evidence and history of sinus surgery).

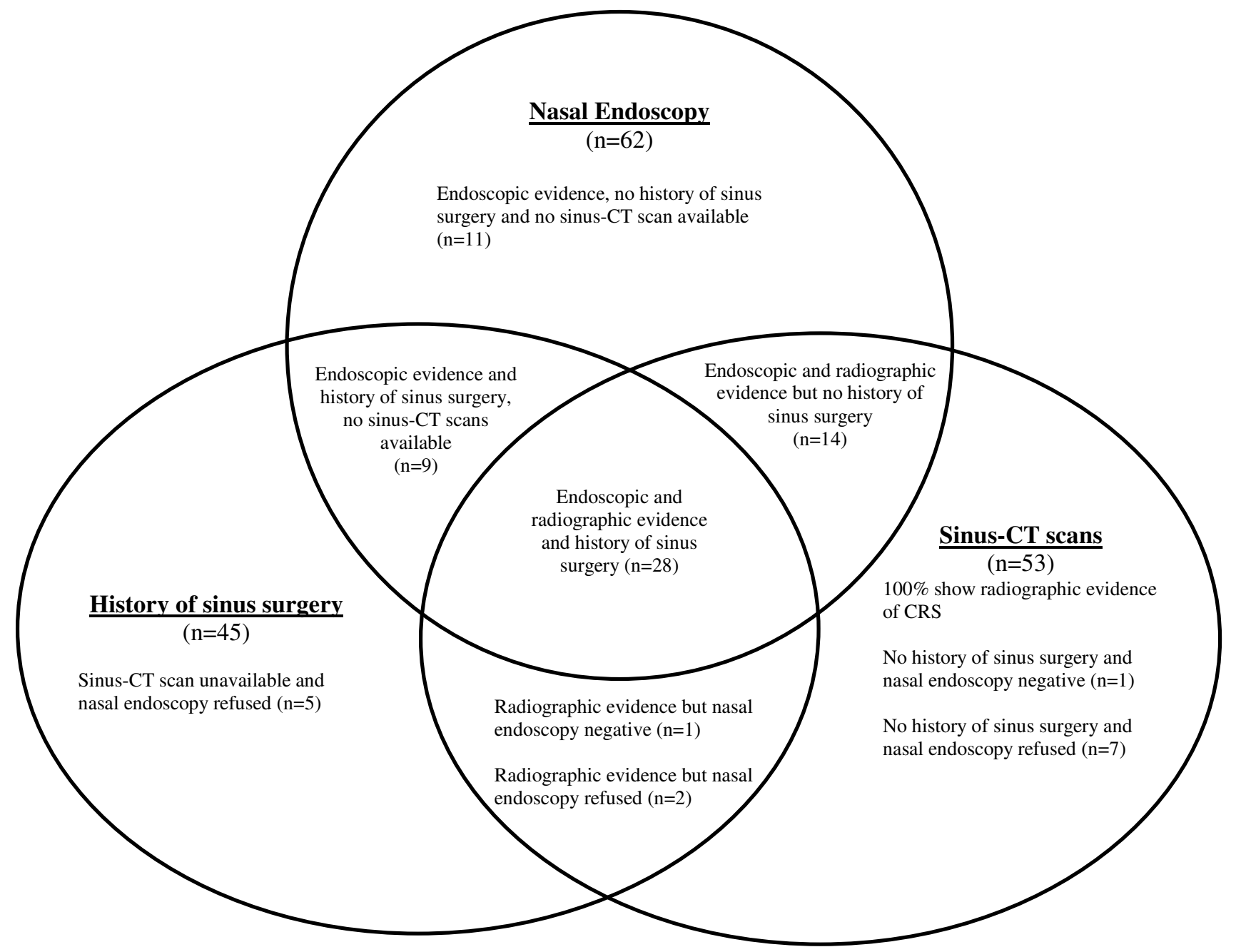

\subsubsection{Nasal Endoscopy}

A summary of nasal endoscopic findings is shown in Table 4.5. A total of $69(61.1 \%)$ participants of the overall study sample elected to receive nasal endoscopy. At least one endoscopic finding of CRS was visualized in 62 of $69(89.6 \%)$ individuals. Inflammation of the middle meatus was the most prevalent endoscopic finding, as visualized in $78.3 \%$ of individuals receiving nasal endoscopy. The 
next most common endoscopic findings were discoloured mucus $(69.6 \%)$ and middle meatal pus (62.3\%). Nasal polyposis was visualized in $21.7 \%$ of participants receiving endoscopy.

Table 4.5- Summary of objective findings for CRS among individuals electing to receive nasal endoscopy.

\begin{tabular}{|c|cr|}
\hline & \multicolumn{3}{|c|}{$\begin{array}{c}\text { Study Sample Receiving Nasal Endoscopy } \\
\text { (n=69 of 113 participants, 61.1\%) } \\
\text { Objective Findings }\end{array}$} & n & $\begin{array}{r}\text { Absolute Frequency } \\
\text { (\%) }\end{array}$ \\
\hline Evidence of $\geq 1$ endoscopic finding & 62 & 89.6 \\
Nasal polyposis & 15 & 21.7 \\
Discoloured mucus & 48 & 69.6 \\
Middle meatal inflammation & 54 & 78.3 \\
Middle meatal pus & 43 & 62.3 \\
& & \\
\hline
\end{tabular}

\subsubsection{Radiographic Findings}

Sinus-CT scans were available for 53 of 113 (46.9\%) participants. The remaining 60 participants, sinus-CT scans were not found on the St. Paul's Hospital electronic records system and as a result, were considered as having not been previously requested. Among individuals for which sinus CT scans were available $(n=53)$, all showed radiographic evidence of CRS.

\subsubsection{Summary of Objective Findings}

Among individuals electing to receive nasal endoscopy $(n=69), 43$ had previously received a sinus CT scan and all showed radiographic evidence of CRS. These 43 individuals had both endoscopic and radiographic evidence of CRS. The remaining 26 individuals electing to receive nasal endoscopy, did not have a sinus CT scan previously requested. As a result, nasal endoscopy was the only available measure to determine the objective component of CRS diagnosis. Among these participants, 20 were found to have at least one endoscopic finding for CRS.

In the sample cohort refusing nasal endoscopy (44 of 113), 10 had previously received a sinus CT scan and all showed radiographic evidence for CRS. 
In summary, 73 of $113(64.6 \%)$ individuals were found to have objective evidence of CRS (43 participants with both endoscopic and radiographic findings, 20 participants with only endoscopic findings, 10 participants with only radiographic findings).

\subsection{History of Sinus Surgery}

As described in Chapter 3, history of sinus surgery was included an alternative indication for the presence of CRS. A total of 45 of 106 respondents reported having previously received sinus surgery and was missing for 7 participants. The mean number of sinus surgeries received by these participants was 2.3 (standard deviation: 3.0, median: 1.0, interquartile range: 1.5). The last known sinus surgery was reported to have occurred on average 6.1 years prior to study enrollment (standard deviation: 6.0, median: 5.0, interquartile range: 5.0).

\section{$\underline{\text { 4.4.1 Sinus Symptoms }}$}

Among subjects with prior sinus surgery, the most prevalent sinus symptoms reported among these participants were loss of smell (80.0\%), nasal congestion $(77.8 \%)$ and anterior or posterior nasal discharge (75.6\%). A total of 39 of 45 individuals were symptomatic for CRS (i.e. presenting with at least 2 symptoms). Among these participants, 46.2\% presented with 5 symptoms, $20.5 \%$ presented with 4 symptoms, $17.9 \%$ presented with 3 symptoms and $15.4 \%$ presented with 2 symptoms.

\subsubsection{Objective Findings}

In total, objective evidence was found in 40 of 45 participants reporting a history of sinus surgery. This consisted of 28 individuals positive for both endoscopic and radiographic evidence, 9 individuals only positive for endoscopic evidence as sinus CT scans were unavailable, 2 individuals positive for radiographic evidence as nasal endoscopy was refused and 1 individual positive for radiographic evidence when nasal endoscopy was negative. 


\subsection{Diagnosis of CRS}

\subsubsection{Frequency of CRS in Overall Study Sample}

As discussed in Chapter 3, diagnosis of CRS was comprised of a subjective and objective component. Alternatively, participants reporting a history of sinus surgery were also considered positive for CRS. Based on these criteria, a total of 68 of 106 (64.2\%) participants were identified as CRS positive. The CRS positive group $(n=68)$ consisted of 59 symptomatic individuals presenting with objective findings, 6 asymptomatic individuals with history of sinus surgery (4 with and 2 without objective findings) and 3 symptomatic individuals with history of sinus surgery.

Among the 38 individuals considered as CRS negative (i.e. no history of sinus surgery), 16 were symptomatic, 21 were asymptomatic and 1 was missing symptom data. Among symptomatic individuals, 4 of 16 were negative for objective evidence of CRS. Among asymptomatic individuals, 8 of 21 presented with objective findings. This consisted of 2 individuals presenting with nasal polyposis.

CRS status could not be determined for 7 (6.2\%) participants as these individuals were missing symptom and history of sinus surgery data. A comparison of participants with or without missing data regarding CRS status is shown in Appendix C: Table C.1. Participants missing CRS status had an older age of CF diagnosis (mean age: 15.5 vs. 9.3 years), fewer chronic P.aeruginosa infections (14.3\% vs. 43.0\%) and lower prevalence of depression (0\% vs. 18.9\%), than counterparts not missing CRS status (Appendix C: Table C.1).

\subsubsection{Comparison of Covariates by CRS Status}

Using all available data for participants who were not missing CRS status ( $\mathrm{n}=106)$, socio-demographic factors and clinical characteristics were compared between CRS positive and negative individuals. As shown in Table 4.6, no significant differences in covariates were found between CRS positive and negative participants. Although CRS positive participants had an earlier diagnosis of CF than CRS 
negative counterparts (mean age: 7.0 vs. 13.5 years, respectively), this finding was not significant $(\mathrm{p}=0.13)$. Also, the frequency of depression and history of lung transplant were greater in CRS positive than CRS negative individuals (20.6\% vs. $15.8 \%$, respectively). However, these findings were not statistically significant $(\mathrm{p}=0.61$ and 0.37 , respectively). 
Table 4.6- Comparison of socio-demographic factors and clinical characteristics between CRS positive and negative individuals.

\begin{tabular}{|c|c|c|c|c|c|}
\hline & $\underset{(n=)}{\text { CRS I }}$ & $\begin{array}{l}\text { ositive } \\
68 \text { ) }\end{array}$ & $\begin{array}{r}\text { CRS I } \\
(\mathbf{n}\end{array}$ & $\begin{array}{l}\text { egative } \\
\text { =38) }\end{array}$ & \\
\hline Continuous & Mean & Standard & Mean & Standard & P-value \\
\hline Socio-demographic Factors & & Deviation & & Deviation & \\
\hline $\begin{array}{l}\text { Age }^{1} \\
\text { (years) }\end{array}$ & 34.6 & 11.7 & 38.4 & 14.9 & 0.29 \\
\hline $\begin{array}{l}\text { Body-mass index } \\
\left(\mathrm{kg} / \mathrm{m}^{2}\right)\end{array}$ & 23.4 & 3.5 & 23.2 & 3.7 & 0.69 \\
\hline Categorical & $\mathrm{n}$ & Absolute & $\mathrm{n}$ & Absolute & P-value \\
\hline Socio-demographic Factors & & $\begin{array}{r}\text { Frequency } \\
(\%)\end{array}$ & & $\begin{array}{r}\text { Frequency } \\
(\%)\end{array}$ & \\
\hline Males & 43 & 63.2 & 27 & 71.1 & 0.42 \\
\hline $\begin{array}{l}\text { Current employment or } \\
\text { school status }\end{array}$ & 39 & 58.2 & 25 & 67.6 & 0.35 \\
\hline Continuous & Mean & Standard & Mean & Standard & P-value \\
\hline Clinical Characteristics & & Deviation & & Deviation & \\
\hline $\begin{array}{l}\text { Lung Function } \\
\text { (FEV }{ }_{1} \% \text { predicted) }\end{array}$ & 74.2 & 23.7 & 71.1 & 29.4 & 0.57 \\
\hline $\begin{array}{l}\text { Age of CF diagnosis } \\
\text { (years) }\end{array}$ & 7.0 & 9.9 & 13.5 & 17.3 & 0.13 \\
\hline $\begin{array}{l}\text { Time since CF diagnosis } \\
\text { (years) }\end{array}$ & 27.4 & 11.5 & 24.9 & 13.6 & 0.32 \\
\hline Categorical & $\mathrm{n}$ & Absolute & $\mathrm{n}$ & Absolute & P-value \\
\hline Clinical Characteristics & & $\begin{array}{r}\text { Frequency } \\
(\%)\end{array}$ & & $\begin{array}{r}\text { Frequency } \\
(\%)\end{array}$ & \\
\hline $\begin{array}{l}\text { Class I to III Genotype } \\
\text { Mutations }\end{array}$ & 51 & 79.7 & 24 & 68.6 & 0.22 \\
\hline Pancreatic Insufficiency & 52 & 76.5 & 26 & 68.4 & 0.37 \\
\hline $\begin{array}{l}\text { Chronic P.aeruginosa } \\
\text { Infection }\end{array}$ & 30 & 46.9 & 13 & 36.1 & 0.30 \\
\hline Depression $^{2}$ & 14 & 20.6 & 6 & 15.8 & 0.61 \\
\hline History of Lung Transplant ${ }^{2}$ & 10 & 14.7 & 3 & 7.9 & 0.37 \\
\hline
\end{tabular}

1. Non-parametric Wilcoxon Rank Sum test used, as data does not follow a normal distribution.

2. Non-parametric Fisher's Exact test used, as expected and observed cell counts less than five.

\subsubsection{Participants Stratified by Receiving or Refusing Nasal Endoscopy}

Given that $61.1 \%$ of the entire study sample elected to receive nasal endoscopy, participants were stratified by this procedure to determine the existence of systematic differences in covariates. 
Among those receiving nasal endoscopy $(n=69)$, CRS was identified in $58(84.1 \%)$ participants. This consisted of 53 symptomatic individuals with objective evidence, 1 symptomatic individual without objective evidence but history of sinus surgery and 4 asymptomatic individuals with objective evidence and history of sinus surgery. Among participants refusing nasal endoscopy $(n=44)$, CRS was identified in $10(22.7 \%)$ participants. This consisted of 8 symptomatic individuals with radiographic findings or history of sinus surgery and 2 asymptomatic individuals without history of sinus surgery. Participants choosing nasal endsocopy were more likely to have reported a history of sinus surgery (OR: 6.71, 95\%CI: $2.48,18.17, \mathrm{p}<0.001)$ and be symptomatic (OR: 3.39, 95\%CI: 1.36, 8.42, p=0.007).

As shown in Table 4.7, participants receiving or refusing nasal endoscopy did not significantly differ in regards to any of the covariates recorded. Although not significant, participants receiving nasal endoscopy were less frequently employed, had an earlier age of CF diagnosis, greater prevalence of chronic P.aeruginosa infection and depression than counterparts refusing nasal endoscopy (Table 4.7). 
Table 4.7- Comparison of socio-demographic factors and clinical characteristics between participants receiving and refusing nasal endoscopy.

\begin{tabular}{|c|c|c|c|c|c|}
\hline \multirow[b]{2}{*}{$\begin{array}{l}\text { Continuous } \\
\text { Socio-demographic Factors }\end{array}$} & \multicolumn{2}{|c|}{$\begin{array}{c}\text { Elected Nasal } \\
\text { Endoscopy } \\
(\mathbf{n}=69)\end{array}$} & \multicolumn{2}{|c|}{$\begin{array}{c}\text { Refused Nasal } \\
\text { Endoscopy } \\
(n=44)\end{array}$} & \multirow[b]{2}{*}{ P-value } \\
\hline & Mean & $\begin{array}{r}\text { Standard } \\
\text { Deviation }\end{array}$ & Mean & $\begin{array}{r}\text { Standard } \\
\text { Deviation }\end{array}$ & \\
\hline $\begin{array}{l}\text { Age } 1 \\
\text { (years) }\end{array}$ & 36.2 & 13.1 & 35.4 & 12.6 & 0.63 \\
\hline $\begin{array}{l}\text { Body-mass index } \\
\left(\mathrm{kg} / \mathrm{m}^{2}\right)\end{array}$ & 23.5 & 3.5 & 23.2 & 3.5 & 0.66 \\
\hline Categorical & $\mathrm{n}$ & Absolute & $\mathrm{n}$ & Absolute & P-value \\
\hline Socio-demographic Factors & & $\begin{array}{r}\text { Frequency } \\
(\%)\end{array}$ & & $\begin{array}{r}\text { Frequency } \\
(\%)\end{array}$ & \\
\hline Males & 45 & 65.2 & 30 & 68.2 & 0.75 \\
\hline $\begin{array}{l}\text { Current employment or } \\
\text { school status }^{2}\end{array}$ & 38 & 55.9 & 29 & 72.5 & 0.10 \\
\hline Continuous & Mean & Standard & Mean & Standard & P-value \\
\hline Clinical Characteristics & & Deviation & & Deviation & \\
\hline $\begin{array}{l}\text { Lung Function } \\
\text { (FEV } \text { F }_{1} \% \text { predicted) }\end{array}$ & 73.0 & 26.1 & 74.0 & 25.7 & 0.83 \\
\hline $\begin{array}{l}\text { Age of CF diagnosis } \\
\text { (years) }\end{array}$ & 8.5 & 12.6 & 11.5 & 15.5 & 0.82 \\
\hline $\begin{array}{l}\text { Time since CF diagnosis } \\
\text { (years) }\end{array}$ & 27.9 & 11.9 & 23.5 & 12.8 & 0.06 \\
\hline Categorical & $\mathrm{n}$ & Absolute & $\mathrm{n}$ & Absolute & P-value \\
\hline Clinical Characteristics & & $\begin{array}{r}\text { Frequency } \\
(\%)\end{array}$ & & $\begin{array}{r}\text { Frequency } \\
(\%)\end{array}$ & \\
\hline $\begin{array}{l}\text { Class I to III Genotype } \\
\text { Mutations }\end{array}$ & 50 & 76.9 & 29 & 72.5 & 0.61 \\
\hline Pancreatic Insufficiency & 50 & 72.5 & 34 & 77.3 & 0.57 \\
\hline $\begin{array}{l}\text { Chronic P.aeruginosa } \\
\text { Infection }\end{array}$ & 31 & 46.9 & 13 & 34.2 & 0.20 \\
\hline Depression $^{2}$ & 14 & 20.3 & 6 & 13.6 & 0.45 \\
\hline History of Lung Transplant ${ }^{2}$ & 9 & 13.0 & 7 & 15.9 & 0.78 \\
\hline
\end{tabular}

1. Non-parametric Wilcoxon Rank Sum test used, as data does not follow a normal distribution.

2. Non-parametric Fisher's Exact test used, as expected and observed cell counts less than five. 


\section{CHAPTER 5: EFFECT OF CRS ON CFQ-R 14+ DOMAIN SCORES}

This chapter examines the relationship between CRS and CFQ-R 14+ domains. Bivariate comparisons of CFQ-R 14+ domain scores were completed for CRS status and each of the covariates recorded. Results from the bivariate analysis and findings from the systematic review conducted in Chapter 2 were used to construct unique multivariable linear regression models for each CFQ-R 14+ domain, in order to adjust for potential confounding. A sensitivity analysis was conducted using multiple imputations to account for missing data in the total study sample. Unadjusted and adjusted regression estimates were compared between complete case analysis (i.e. restricted to participants with only complete data and participants with missing data were excluded) and a sensitivity analysis using multiple imputations.

\subsection{Descriptive Summary of CFQ-R 14+}

A total of 107 participants completed the CFQ-R 14+ and domain scores are summarized in Table 5.1. Based on visual inspections of histograms plotted for each CFQ-R 14+ domain, Physical functioning, Role functioning, Eating disturbances, Body image, Digestion and Weight did not appear to follow a normal distribution. However, Energy, Emotion, Social functioning, Treatment burden, Health perception and Respiratory symptoms appeared to be normally distributed. 
Table 5.1- Descriptive summary of domain scores for study sample completing the CFQ-R 14+.

\begin{tabular}{|l|cccr|}
\hline & \multicolumn{4}{|c|}{$\begin{array}{c}\text { Study Sample Completing } \\
\text { CFQ-R 14+ Questionnaires } \\
\text { CF=107) }\end{array}$} \\
\hline Physical functioning & Mean & $\begin{array}{c}\text { Standard } \\
\text { deviation }\end{array}$ & Median & $\begin{array}{r}\text { Interquartile } \\
\text { Range }\end{array}$ \\
Energy & 64.8 & 29.3 & 70.8 & 54.2 \\
Emotion & 53.6 & 22.4 & 58.3 & 33.4 \\
Social functioning & 72.3 & 17.7 & 73.3 & 20.0 \\
Role functioning & 63.1 & 18.9 & 66.7 & 27.8 \\
Eating disturbances & 74.9 & 20.2 & 75.0 & 33.4 \\
Body image & 86.7 & 20.8 & 100.0 & 22.2 \\
Treatment burden & 71.9 & 26.5 & 77.8 & 44.4 \\
Health perception & 63.8 & 23.1 & 66.7 & 33.4 \\
Respiratory symptoms & 59.0 & 22.9 & 66.0 & 33.4 \\
Digestion & 65.3 & 21.1 & 66.7 & 33.3 \\
Weight & 79.3 & 20.0 & 88.9 & 33.3 \\
& 71.7 & 37.4 & 100.0 & 66.7 \\
\hline
\end{tabular}

CFQ-R 14+ domain scores were missing for 6 of 113 participants. A comparison of CRS status, sociodemographic factors and clinical characteristics between participants missing versus not missing CFQ$\mathrm{R}$ 14+ domains scores is shown in Appendix C: Table C.2. Of participants missing CFQ-R 14+ results $(\mathrm{n}=6), 50 \%$ were also missing CRS status, symptom responses and history of sinus surgery. Also, as current employment and school status was collected from the CFQ-R 14+ (question G, Appendix C), 5 of 6 individuals were also missing this characteristic. When compared to non-missing counterparts, participants with missing data were less frequently CRS positive, symptomatic and did not report a history of sinus surgery (Appendix C: Table C.2). In regards to the covariates, missing participants 
were older, had lower lung function, later age of CF diagnosis and fewer class I to III CF genotype mutations, than non-missing counterparts (Appendix C: Table C.2).

\subsection{Bivariate Analysis}

\section{$\underline{\text { 5.2.1 Summary of CFQ-R 14+ Domain Scores by CRS Status }}$}

Domain scores were compared between CRS positive and negative individuals using all available data

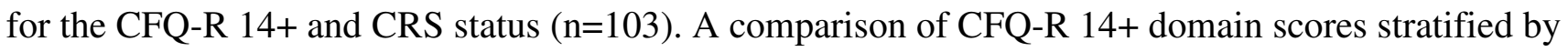
CRS status is shown in Table 5.2. CRS positive participants reported lower scores on all domains except Body image and Weight (Table 5.2). The CFQ-R 14+ domains Respiratory symptoms and Digestion were significantly lower for CRS positive versus negative individuals (Respiratory symptoms mean difference: $-10.5, p=0.02$ and Digestion mean difference: $-9.9 \mathrm{p}=0.04)$. All other CFQR 14+ domains were not associated with CRS status (Table 5.2). 
Table 5.2- Comparison of CFQ-R 14+ domains scores between participants positive versus negative for CRS.

\begin{tabular}{|c|c|c|c|c|c|c|c|c|c|c|}
\hline \multirow[b]{2}{*}{$\begin{array}{l}\text { CFQ-R 14+ } \\
\text { Domains }\end{array}$} & \multirow[b]{2}{*}{ Mean } & \multicolumn{3}{|c|}{$\begin{array}{c}\text { CRS Positive } \\
{ }_{(n=66)}\end{array}$} & \multicolumn{4}{|c|}{$\begin{array}{c}\text { CRS Negative } \\
\quad(n=37)\end{array}$} & \multirow[b]{2}{*}{$\begin{array}{r}\text { Mean } \\
\text { difference }\end{array}$} & \multirow[b]{2}{*}{$\mathrm{p}$-valuee } \\
\hline & & $\begin{array}{r}\text { Standard } \\
\text { deviation }\end{array}$ & Median & IQR & Mean & $\begin{array}{r}\text { Standard } \\
\text { deviation }\end{array}$ & Median & $\mathrm{IQR}$ & & \\
\hline $\begin{array}{l}\text { Physical } \\
\text { functioning }\end{array}$ & 62.9 & 29.3 & 70.8 & 54.2 & 66.6 & 30.4 & 75.0 & 59.3 & -3.7 & 0.44 \\
\hline Energy & 50.6 & 21.6 & 50.0 & 33.4 & 57.4 & 24.1 & 58.3 & 25.0 & -6.8 & 0.14 \\
\hline Emotion & 71.3 & 17.2 & 73.3 & 26.7 & 73.3 & 19.5 & 73.3 & 20.0 & -2.0 & 0.59 \\
\hline Social functioning $^{1}$ & 62.2 & 18.7 & 63.9 & 27.8 & 64.6 & 19.5 & 66.7 & 27.8 & -2.4 & 0.67 \\
\hline Role functioning $^{1}$ & 72.7 & 20.3 & 75.0 & 33.4 & 78.3 & 20.3 & 83.3 & 16.7 & -5.6 & 0.10 \\
\hline $\begin{array}{l}\text { Eating } \\
\text { disturbances }{ }^{1}\end{array}$ & 85.4 & 20.7 & 100.0 & 22.2 & 88.0 & 21.8 & 100.0 & 22.2 & -2.6 & 0.26 \\
\hline Body image $^{1}$ & 74.5 & 25.4 & 77.8 & 44.4 & 69.1 & 28.2 & 66.7 & 55.6 & 5.4 & 0.35 \\
\hline Treatment burden & 62.5 & 23.6 & 66.7 & 33.4 & 65.8 & 22.0 & 66.7 & 22.2 & -3.3 & 0.49 \\
\hline Health perception & 57.4 & 23.0 & 60.8 & 33.4 & 61.1 & 23.1 & 66.7 & 33.4 & -3.7 & 0.43 \\
\hline $\begin{array}{l}\text { Respiratory } \\
\text { symptoms }\end{array}$ & 61.6 & 21.8 & 61.1 & 33.4 & 72.1 & 18.7 & 77.8 & 27.8 & -10.5 & 0.02 \\
\hline Digestion $^{1}$ & 76.3 & 22.0 & 77.8 & 22.2 & 86.2 & 12.4 & 88.9 & 22.2 & -9.9 & 0.04 \\
\hline Weight & 73.2 & 36.6 & 100.0 & 33.3 & 70.3 & 38.3 & 100.0 & 66.7 & 2.9 & 0.79 \\
\hline
\end{tabular}

1. Non-parametric Wilcoxon Rank-sum test performed.

\subsubsection{Summary of CFQ-R 14+ Domain Scores by Covariates}

Bivariate associations were examined between the covariates and CFQ-R 14+ domains to identify factors other than CRS that were associated with the scores. All available participant data were used to examine statistical significance. Bivariate associations for each CFQ-R 14+ domain are shown in Appendix D: Tables D.1 to D.3. Physical functioning was associated with age $(\mathrm{p}<0.001)$, gender 
$(\mathrm{p}=0.02)$, current employment or school status $(\mathrm{p}<0.001)$, lung function $(\mathrm{p}<0.001)$, age of CF diagnosis and depression $(\mathrm{p}=0.001)$. Depressed participants reported significantly lower Energy scores than nondepressed participants (mean difference: $-16.09, \mathrm{p}=0.004$ ). Social functioning was associated age $(\mathrm{p}=0.002)$, current employment or school status $(\mathrm{p}=0.02)$, lung function $(\mathrm{p}=0.01)$, age of CF diagnosis $(\mathrm{p}<0.001)$, class I to III genotype mutations $(\mathrm{p}=0.01)$, pancreatic insufficiency $(\mathrm{p}=0.04)$ and depression $(\mathrm{p}=0.005)$. Health perception was associated with current employment and school status $(\mathrm{p}=0.01)$, lung function $(\mathrm{p}<0.001)$, age of CF diagnosis $(\mathrm{p}=0.01)$, depression $(\mathrm{p}=0.003)$ and history of lung transplant $(\mathrm{p}=0.013)$. Respiratory symptoms were associated with age of $\mathrm{CF}$ diagnosis $(\mathrm{p}=0.02)$, time since $\mathrm{CF}$ diagnosis $(\mathrm{p}=0.005)$, pancreatic insufficiency $(\mathrm{p}=0.04)$ and history of lung transplant $(\mathrm{p}=0.001)$. Digestion was negatively correlated with lung function $(r=-0.29, \mathrm{p}=0.002)$.

\subsubsection{Collinearity Between Covariates}

As shown in the previous section, several covariates were found to be associated with CFQ-R 14+ domains. Given these multiple associations, collinearity was assessed between the covariates. Lung function was found to be associated with class I to III genotype mutations (mean difference: -12.01 , p=0.04), chronic P.aeruginosa infection (mean difference: $-17.89, \mathrm{p}=0.0004$ ), current employment or school status (mean difference: 14.32, $\mathrm{p}=0.005$ ) and depression (mean difference: $-14.76, \mathrm{p}=0.02$ ). Among the continuous covariates, lung function was correlated with age $(r=-0.219, p=0.02)$, body-mass index $(r=0.258, p=0.007)$ and time since $\mathrm{CF}$ diagnosis $(\mathrm{r}=-0.353, \mathrm{p}=0.0002)$. Class I to III genotype mutations were also associated with chronic P.aeruginosa infection (OR: 6.70, p=0.0008), age (mean difference: $-8.68, \mathrm{p}=0.01$ ), body-mass index (mean difference: $-2.42, \mathrm{p}=0.002$ ), time since $\mathrm{CF}$ diagnosis (mean difference: 16.60, $\mathrm{p}<0.01$ ) and age of CF diagnosis (mean difference: $-25.29, \mathrm{p}<0.01$ ). Given that time since CF diagnosis was derived from participants' age and age of CF diagnosis, strong 
correlations were found with both of these factors $(\mathrm{r}=0.402, \mathrm{p}=<0.0001$ and $-0.523, \mathrm{p}<0.0001$, respectively) and between these factors $(\mathrm{r}=0.569, \mathrm{p}<0.0001)$.

Table 5.3 summarizes associations between the covariates and CFQ-R 14+ domains found in, 1) the total study sample and 2) the systematic review in Chapter 2. Schematics for each CFQ-R 14+ domain were established to visualize the multiple associations between the covariates. These were used to identify the factors to be adjusted for in multivariable linear regression models. An example of a schematic is illustrated in Figure 5.1. Schematics for all CFQ-R 14+ domains are provided in Appendix E Figures E.1 to E.12. 
Table 5.3- Summary of covariates significantly associated with CFQ-R 14+ domain scores from bivariate analysis of total study sample and from systematic review in Chapter 2.

\begin{tabular}{|c|c|c|c|c|c|c|c|c|c|c|c|}
\hline $\begin{array}{l}\text { CFQ-R 14+ } \\
\text { Domains }\end{array}$ & Age & Gender & BMI & $\begin{array}{c}\text { Current } \\
\text { Work } \\
\text { or } \\
\text { School } \\
\text { Status }\end{array}$ & $\begin{array}{c}\text { Lung } \\
\text { Function }\end{array}$ & $\begin{array}{c}\text { Age of } \\
\text { CF } \\
\text { Diagnosis }\end{array}$ & $\begin{array}{c}\text { Time } \\
\text { since CF } \\
\text { diagnosis }\end{array}$ & $\begin{array}{c}\text { CF } \\
\text { Genotype } \\
\text { Class }\end{array}$ & $\begin{array}{c}\text { Chronic } \\
\text { P.Aeruginosa } \\
\text { Infection }\end{array}$ & Depression & $\begin{array}{c}\text { History of } \\
\text { Lung } \\
\text { Transplant }\end{array}$ \\
\hline $\begin{array}{l}\text { Physical } \\
\text { functioning }\end{array}$ & A,B & A,B & & $\mathrm{A}, \mathrm{B}$ & A,B & A & & & & $\mathrm{A}$ & \\
\hline Energy & & B & B & & B & & & & & A & \\
\hline Emotion & & B & & A & A & & & & & $\mathrm{A}, \mathrm{B}$ & \\
\hline $\begin{array}{l}\text { Social } \\
\text { functioning }\end{array}$ & A,B & B & & $\mathrm{A}, \mathrm{B}$ & A & A & & A & & A & \\
\hline $\begin{array}{l}\text { Role } \\
\text { functioning }\end{array}$ & & & & A,B & A,B & & & & A & A & \\
\hline $\begin{array}{l}\text { Eating } \\
\text { disturbances }\end{array}$ & & & A & A & B & & & & & $\mathrm{A}, \mathrm{B}$ & \\
\hline Body image & & B & $\mathrm{A}, \mathrm{B}$ & A & A,B & & & & & B & \\
\hline $\begin{array}{l}\text { Treatment } \\
\text { burden }\end{array}$ & B & B & & & A,B & & & & A & A & A \\
\hline $\begin{array}{l}\text { Health } \\
\text { perception }\end{array}$ & A & & & & A,B & A & & & & A & A \\
\hline $\begin{array}{l}\text { Respiratory } \\
\text { symptoms }\end{array}$ & & & & & B & A & A & & & & A \\
\hline Digestion & & & & & A & & & & & & \\
\hline Weight & & A,B & $\mathrm{A}, \mathrm{B}$ & & B & & & & & & \\
\hline
\end{tabular}

$\mathrm{A}=$ significant bivariate associations in total study sample $(\mathrm{p}<0.05)$

$\mathrm{B}=$ significant multivariable associations found in Chapter 2 systematic review $(\mathrm{p}<0.05)$ 
Figure 5.1- Schematic illustrating primary relationship studied between CRS and CFQ-R 14+ and collinearity among covariates.

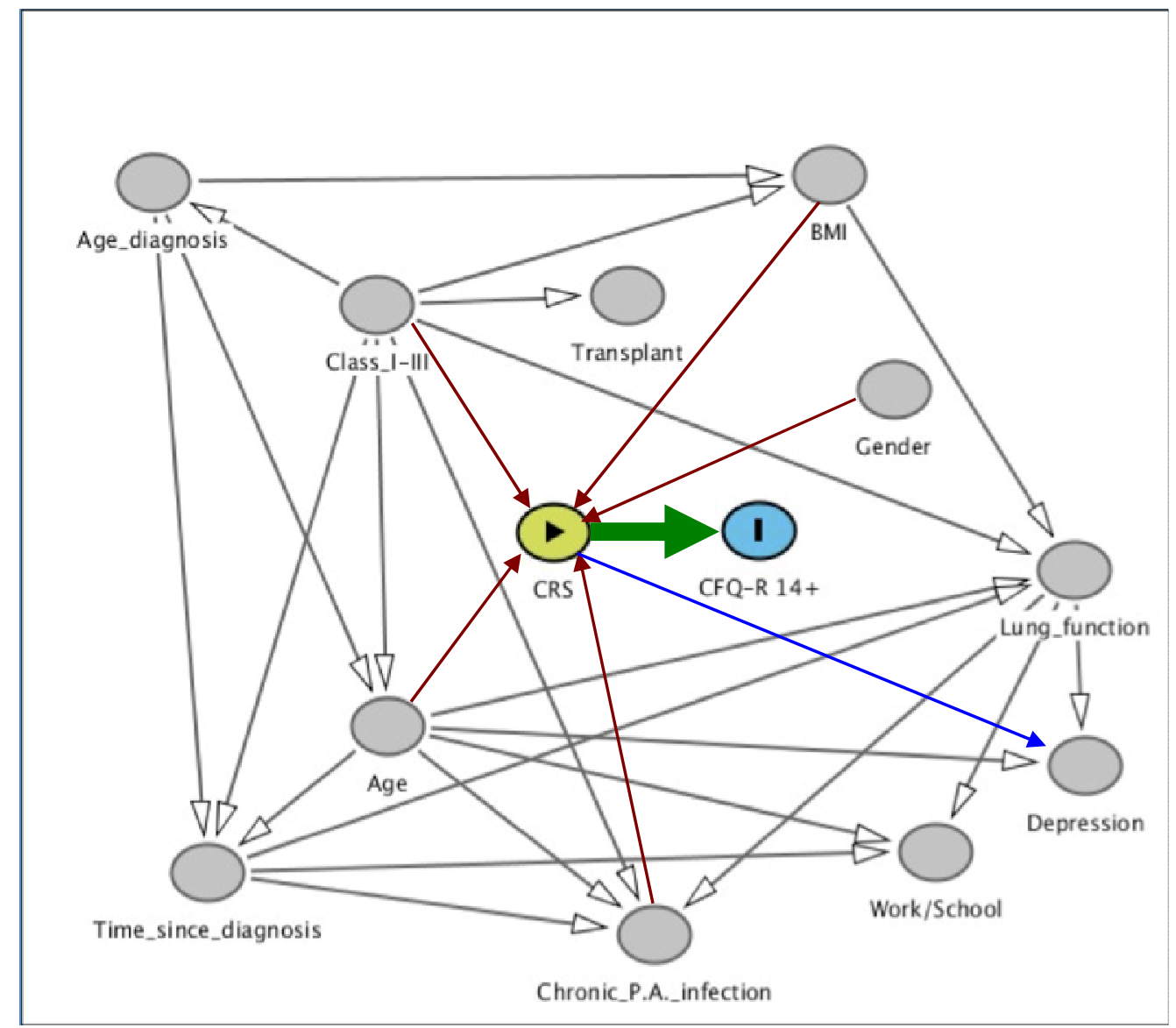

(primary explanatory variable $=$ yellow, primary outcome variable $=$ blue, covariates $=$ grey, primary relationship studied $=$ green arrow, significant covariate associations= black arrows, covariate associations with primary explanatory variable $=$ red arrows, potential causal association between explanatory variable and covariate $=$ blue arrow)

\subsection{Linear Regression}

\subsubsection{Complete Case Analysis}

Linear regression was used to examine the effect of CRS on CFQ-R 14+ domains, adjusted for potentially confounding covariates. Using all available participant data, unadjusted and adjusted linear regression models were constructed for each CFQ-R 14+ domain. Table 5.4 shows the unadjusted regression estimates for the differences in domain scores between CRS and non-CRS participants. In Models 1A: Unadjusted Linear Regression, CRS positive participants reported worse scores on all 
CFQ-R 14+ domains except the domains Body image and Weight, when compared to CRS negative counterparts (Table 5.4). Significant associations were found between CRS and the CFQ-R 14+ domains: Respiratory symptoms (F-value 5.75, $\mathrm{p}=0.02, \mathrm{n}=98, \mathrm{df}=96)$ and Digestion (F-value: 5.54, $\mathrm{p}=0.02, \mathrm{n}=100, \mathrm{df}=98)$. CRS positive individuals reported significantly worse Respiratory symptoms $((\beta=-9.84, \mathrm{SE}=4.10, \mathrm{p}=0.02)$ and Digestion-related quality of life $(\beta=-9.38, \mathrm{SE}=3.98, \mathrm{p}=0.02)$, than non-CRS individuals.

Table 5.4 shows the regression estimates for differences in CFQ-R 14+ domain scores between CRS positive and negative individuals, adjusted for various socio-demographic factors and clinical characteristics. In adjusted analysis, CRS positive participants were found to have worse scores on all CFQ-R 14+ domains except Body image, when compared to non-CRS participants. The differences in domain scores between CRS and non-CRS individuals, as represented by the regression estimates, increased for all domains except Body image and Digestion (unadjusted $\beta$ estimate: 4.15 versus adjusted $\beta$ estimate: 2.67 ; unadjusted $\beta$ estimate: -9.38 versus adjusted $\beta$ estimate: -8.71 respectively). The mean squared error for each regression estimate was lowered and the total variance explained by the regression model (i.e. overall adjusted $\mathrm{R}^{2}$ values for each regression model) was increased after adjustment in all domains (Table 5.4). Similar to the unadjusted results, significant associations were found between CRS and the CFQ-R 14+ domains: Respiratory symptoms (F-value: 6.58, p=0.0004, $\mathrm{n}=98, \mathrm{df}=94$ ) and Digestion (F-value: 7.38, $\mathrm{p}=0.001, \mathrm{n}=100, \mathrm{df}=97)$. After adjusting for lung function and age of CF diagnosis, CRS positive participants reported significantly worse Respiratory symptoms than non-CRS counterparts $(\beta=-13.33, \mathrm{SE}=4.03, \mathrm{p}=0.001)$. The adjusted linear regression model explained $14.7 \%$ of the variance for Respiratory symptom scores, compared to $5.7 \%$ in the unadjusted model. In regards to Digestion, CRS positive individuals reported significantly lower scores after adjusting for lung function, when compared to non-CRS individuals $(\beta=-8.71, S E=3.83, p=0.03)$. The 
adjusted linear regression model explained $11.4 \%$ of the variance in Digestion scores, compared to $5.4 \%$ in unadjusted models.

Table 5.4- Unadjusted and adjusted linear regression using complete case data.

\begin{tabular}{|c|c|c|c|c|c|c|c|c|c|c|c|}
\hline \multirow[b]{2}{*}{$\begin{array}{l}\text { CFQ-R 14+ } \\
\text { Domains }\end{array}$} & \multirow[b]{2}{*}{$\beta$} & \multicolumn{4}{|c|}{$\begin{array}{l}\text { Models 1A: Unadjusted } \\
\text { Linear Regression }\end{array}$} & \multicolumn{6}{|c|}{$\begin{array}{c}\text { Models 2A: Adjusted } \\
\text { Linear Regression } \\
\text { (based on bivariate associations found in study sample, } \\
\text { multivariable associations from Chapter 2: Systematic } \\
\text { Review and collinear covariates restricted) }\end{array}$} \\
\hline & & SE & $\mathrm{p}$ & $\mathrm{R}^{2}$ & MSE & $\beta$ & SE & $\mathrm{p}$ & $\mathrm{R}^{2}$ & MSE & $\begin{array}{c}\text { Covariates in } \\
\text { Model }\end{array}$ \\
\hline $\begin{array}{l}\text { Physical } \\
\text { functioning } \\
(\mathrm{n}=98)\end{array}$ & -2.31 & 6.12 & 0.71 & 0.002 & 853.24 & -7.20 & 5.33 & 0.18 & 0.296 & 595.54 & $\begin{array}{l}\text { Gender, } \\
\text { Lung function, } \\
\text { Age of CF } \\
\text { diagnosis }\end{array}$ \\
\hline $\begin{array}{l}\text { Energy } \\
(\mathrm{n}=101)\end{array}$ & -6.26 & 4.64 & 0.18 & 0.018 & 504.61 & -8.46 & 4.69 & 0.07 & 0.070 & 462.42 & $\begin{array}{l}\text { Gender, } \\
\text { Lung function, } \\
\text { Age of } \mathrm{CF} \\
\text { diagnosis }\end{array}$ \\
\hline $\begin{array}{l}\text { Emotion } \\
(\mathrm{n}=100)\end{array}$ & -2.49 & 3.78 & 0.51 & 0.004 & 329.63 & -2.77 & 3.72 & 0.46 & 0.034 & 316.40 & $\begin{array}{l}\text { Gender, } \\
\text { Lung function }\end{array}$ \\
\hline $\begin{array}{l}\text { Social } \\
\text { functioning } \\
(\mathrm{n}=98)\end{array}$ & -2.95 & 3.99 & 0.46 & 0.006 & 362.87 & -7.52 & 3.73 & 0.05 & 0.196 & 290.48 & $\begin{array}{l}\text { Gender, } \\
\text { Lung function, } \\
\text { Age of CF } \\
\text { diagnosis }\end{array}$ \\
\hline $\begin{array}{l}\text { Role } \\
\text { functioning } \\
(\mathrm{n}=100)\end{array}$ & -6.51 & 4.24 & 0.13 & 0.024 & 413.69 & -7.24 & 4.07 & 0.08 & 0.094 & 380.14 & Lung function \\
\hline $\begin{array}{l}\text { Eating } \\
\text { disturbances } \\
(\mathrm{n}=100)\end{array}$ & -2.58 & 4.45 & 0.56 & 0.003 & 455.77 & -3.47 & 4.38 & 0.43 & 0.045 & 435.99 & $\begin{array}{l}\text { Gender, } \\
\text { Body-mass } \\
\text { index }\end{array}$ \\
\hline $\begin{array}{l}\text { Body image } \\
(\mathrm{n}=93)\end{array}$ & 4.15 & 5.77 & 0.47 & 0.006 & 708.41 & 2.67 & 5.24 & 0.61 & 0.185 & 577.99 & $\begin{array}{l}\text { Gender } \\
\text { Lung function, } \\
\text { Body-mass } \\
\text { index }\end{array}$ \\
\hline $\begin{array}{l}\text { Treatment } \\
\text { burden } \\
(\mathrm{n}=100)\end{array}$ & -3.32 & 4.78 & 0.49 & 0.005 & 527.22 & -4.17 & 4.53 & 0.36 & 0.103 & 470.61 & $\begin{array}{l}\text { Gender, } \\
\text { Lung function }\end{array}$ \\
\hline $\begin{array}{l}\text { Health } \\
\text { perception } \\
(\mathrm{n}=98)\end{array}$ & -3.18 & 4.76 & 0.51 & 0.005 & 516.72 & -7.68 & 4.47 & 0.09 & 0.180 & 421.38 & $\begin{array}{l}\text { Lung function, } \\
\text { Age of CF } \\
\text { diagnosis }\end{array}$ \\
\hline $\begin{array}{l}\text { Respiratory } \\
\text { symptoms } \\
(\mathrm{n}=98)\end{array}$ & -9.84 & 4.10 & 0.02 & 0.057 & 383.42 & -13.33 & 4.03 & 0.001 & 0.147 & 343.00 & $\begin{array}{l}\text { Lung function, } \\
\text { Age of } \mathrm{CF} \\
\text { diagnosis }\end{array}$ \\
\hline $\begin{array}{l}\text { Digestion } \\
(\mathrm{n}=100)\end{array}$ & -9.38 & 3.98 & 0.02 & 0.054 & 365.48 & -8.71 & 3.83 & 0.03 & 0.114 & 338.57 & Lung function \\
\hline $\begin{array}{l}\text { Weight } \\
(\mathrm{n}=102)\end{array}$ & 2.56 & 7.69 & 0.74 & 0.001 & 1393.10 & -2.89 & 5.68 & 0.61 & 0.442 & 729.93 & $\begin{array}{l}\text { Gender, } \\
\text { Lung function, } \\
\text { Body-mass } \\
\text { index }\end{array}$ \\
\hline
\end{tabular}

( $\beta=$ regression coefficient, $\mathrm{SE}=$ standard error, $\mathrm{p}=$ probability value, $\mathrm{MSE}=$ mean squared error). 


\subsubsection{Sensitivity Analysis for Linear Regression}

Considering that the linear regression analysis described above excluded participants with missing data, a sensitivity analysis was conducted using a complete data set constructed from multiple imputations. Missing scores for each CFQ-R 14+ domain were predicted by using all covariates, CRS status and whether nasal endoscopy was performed. Fifty imputations were completed for each CFQ-R 14+ domain.

Table 5.5 shows the unadjusted and adjusted regression estimates calculated from using the complete study sample $(\mathrm{n}=113)$ constructed from multiple imputations. Similar to complete case analysis, unadjusted linear regression found that CRS positive participants reported worse scores on all CFQ-R 14+ domains except Body image and Weight, when compared to non-CRS participants. Significant associations were found between CRS and CFQ-R 14+ domains: Respiratory symptoms ( $\mathrm{p}=0.01)$ and Digestion $(p=0.04)$. CRS positive participants reported significantly worse Respiratory symptoms $(\beta=-$ 10.61, $\mathrm{SE}=4.21, \mathrm{p}=0.01)$ and Digestion-related quality of life $(\beta=-8.75, \mathrm{SE}=4.12, \mathrm{p}=0.04)$ than nonCRS counterparts. Similar to complete case analysis, these findings persisted despite adjustment (Table 5.5). When adjusted for lung function and age of diagnosis, Health perception was not significantly different between CRS and non-CRS individuals in the complete case analysis $(\beta=-7.68, \mathrm{SE}=4.47$, $\mathrm{p}=0.09$ ). However when using multiple imputations, CRS participants were significantly worse in the Health perception domain when compared to non-CRS counterparts $(\beta=-8.64, \mathrm{SE}=4.22, \mathrm{p}=0.04)$. 
Table 5.5- Sensitivity analysis of unadjusted and adjusted linear regression, using multiple imputations to construct a complete data set of the total study sample $(n=113)$.

\begin{tabular}{|c|c|c|c|c|c|c|c|}
\hline \multirow[b]{2}{*}{ CFQ-R 14+ Domains } & \multicolumn{3}{|c|}{$\begin{array}{l}\text { Models 1B: Unadjusted } \\
\text { Linear Regression }\end{array}$} & \multicolumn{4}{|c|}{$\begin{array}{l}\text { Models 2B: Adjusted } \\
\text { Linear Regression }\end{array}$} \\
\hline & $\beta$ & SE & $\mathrm{p}$ & $\beta$ & SE & $\mathrm{p}$ & Covariates in Model \\
\hline $\begin{array}{l}\text { Physical functioning } \\
(\mathrm{n}=113)\end{array}$ & -4.91 & 5.77 & 0.40 & -9.13 & 5.09 & 0.08 & $\begin{array}{l}\text { Gender, Lung function, Age of CF } \\
\text { Diagnosis }\end{array}$ \\
\hline $\begin{array}{l}\text { Energy } \\
(\mathrm{n}=113)\end{array}$ & -7.21 & 4.42 & 0.11 & -8.48 & 4.45 & 0.05 & $\begin{array}{l}\text { Gender, Lung function, Age of } \mathrm{CF} \\
\text { diagnosis }\end{array}$ \\
\hline $\begin{array}{l}\text { Emotion } \\
(\mathrm{n}=113)\end{array}$ & -2.48 & 3.54 & 0.49 & -2.56 & 3.50 & 0.47 & Gender, Lung function \\
\hline $\begin{array}{l}\text { Social functioning } \\
(\mathrm{n}=113)\end{array}$ & -2.72 & 3.83 & 0.48 & -6.81 & 3.50 & 0.05 & $\begin{array}{l}\text { Gender, Lung function, Age of } \mathrm{CF} \\
\text { Diagnosis }\end{array}$ \\
\hline $\begin{array}{l}\text { Role functioning } \\
(\mathrm{n}=113)\end{array}$ & -5.66 & 4.04 & 0.16 & -6.31 & 3.88 & 0.11 & Lung function \\
\hline $\begin{array}{l}\text { Eating disturbances } \\
(\mathrm{n}=113)\end{array}$ & -3.10 & 4.13 & 0.45 & -3.66 & 4.15 & 0.38 & Gender, Body-mass index \\
\hline $\begin{array}{l}\text { Body image } \\
(\mathrm{n}=113)\end{array}$ & 6.38 & 5.22 & 0.22 & 4.78 & 4.73 & 0.31 & $\begin{array}{l}\text { Gender, Lung function, } \\
\text { Body-mass index }\end{array}$ \\
\hline $\begin{array}{l}\text { Treatment burden } \\
(\mathrm{n}=113)\end{array}$ & -3.70 & 4.64 & 0.43 & -4.38 & 4.39 & 0.32 & Gender, Lung function \\
\hline $\begin{array}{l}\text { Health perception } \\
(\mathrm{n}=113)\end{array}$ & -4.56 & 4.58 & 0.32 & -8.64 & 4.22 & 0.04 & Lung function, Age of CF Diagnosis \\
\hline $\begin{array}{l}\text { Respiratory symptoms } \\
(\mathrm{n}=113)\end{array}$ & -10.61 & 4.21 & $\mathbf{0 . 0 1}$ & -14.09 & 4.06 & 0.001 & Lung function, Age of CF Diagnosis \\
\hline $\begin{array}{l}\text { Digestion } \\
(\mathrm{n}=113)\end{array}$ & -8.75 & 4.12 & 0.04 & -8.11 & 3.95 & 0.04 & Lung function \\
\hline $\begin{array}{l}\text { Weight } \\
(\mathrm{n}=113)\end{array}$ & 3.94 & 7.41 & 0.60 & -0.04 & 5.75 & 0.99 & Gender, Lung function, Body-mass index \\
\hline
\end{tabular}

( $\beta=$ regression coefficient, $S E=$ standard error, $p=$ probability value). 
Figures 5.2 and 5.3 compare the unadjusted and adjusted regression estimates between the complete case and sensitivity analyses. From multiple imputations, the unadjusted linear regression estimates were increased (i.e. away from a null difference) for all domains except Role functioning and Digestion, when compared to those from the complete case analysis (Figure 5.2).

Figure 5.2- Comparison of unadjusted linear regression estimates between complete case analysis and sensitivity analysis using multiple imputations.

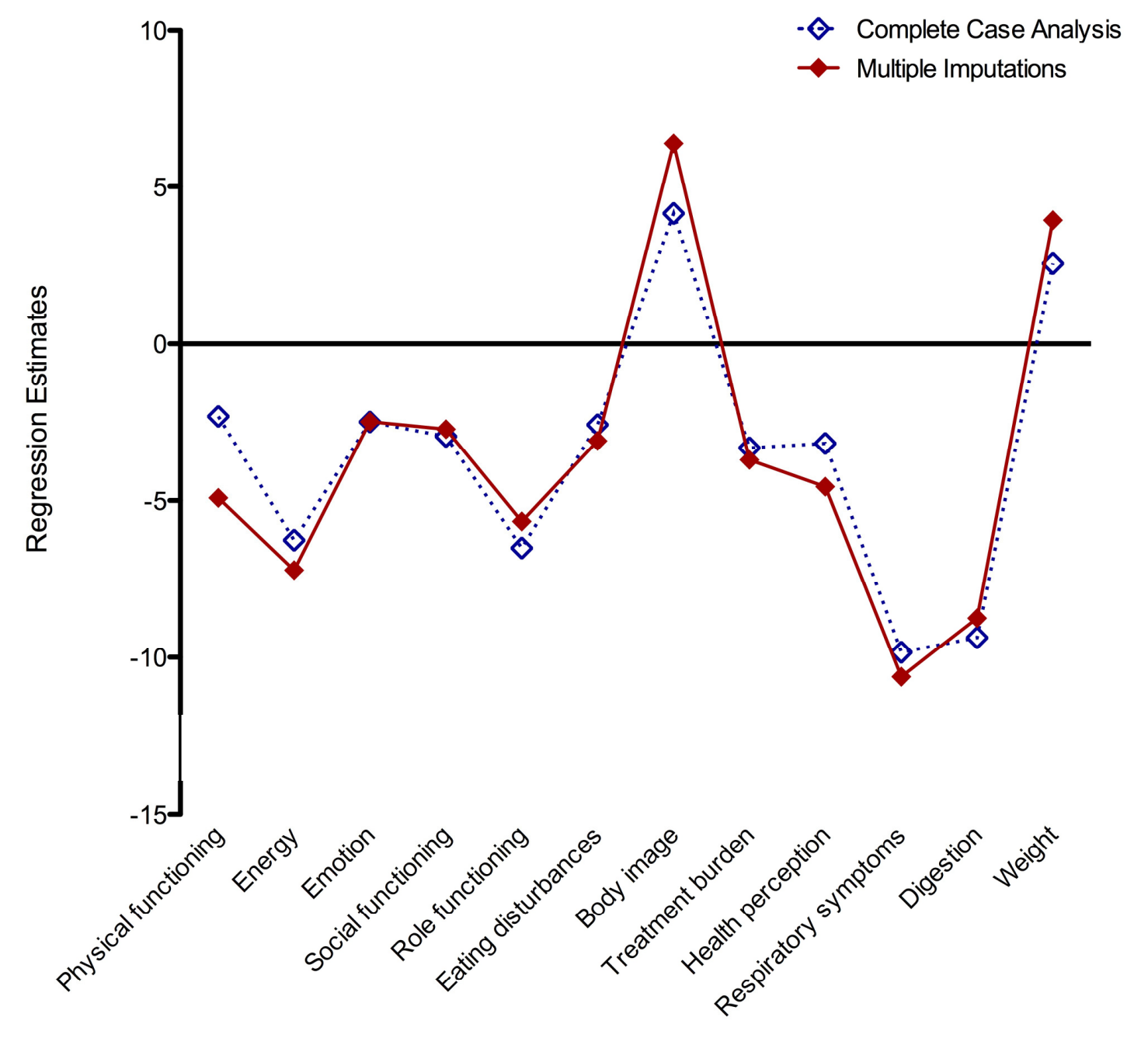

In the adjusted analysis, multiple imputations increased the regression estimates for all domains except Social functioning, Role functioning, Digestion and Weight, when compared the complete case 
analysis (Figure 5.3). The largest discrepancies in unadjusted and adjusted regression estimates between the analysis methods were found in the domains of Physical functioning, Body image and Weight (Figures 5.2 and 5.3).

Figure 5.3- Comparison of adjusted linear regression estimates between complete case analysis and sensitivity analysis using multiple imputations.

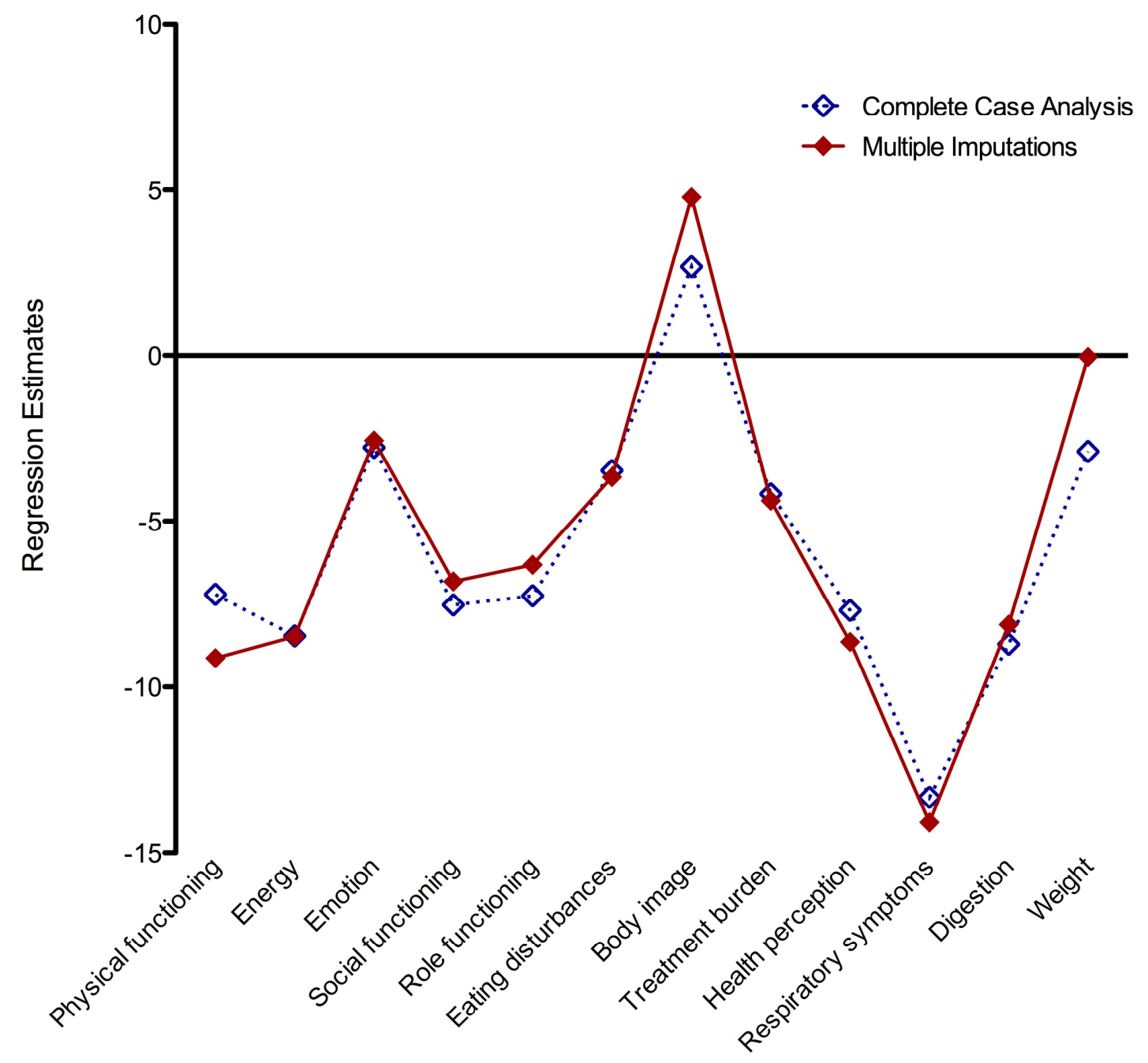




\section{CHAPTER 6: DISCUSSION}

The CF population has experienced a shift in age demographic in the past four decades, where adults are living farther into adulthood than previously known. ${ }^{6}$ As adults with $\mathrm{CF}$ maintain adequate lung function and nutritional status, the opportunity to reach higher rates of post-secondary education, employment and marriage are promising. ${ }^{3,4}$ Simultaneously, the increasing prevalence of age-related chronic diseases like CRS, has contributed to an increasing complexity in care and treatment burden. With the new opportunities and challenges in the lives of these individuals, the focus on HRQoL has become increasingly important. Several cross-sectional studies have shown that CRS is a highly prevalent chronic disease affecting individuals with $\mathrm{CF}^{13,79}$ The prevalence of $\mathrm{CRS}$ in the $\mathrm{CF}$ population is nearly four times higher than in the non-CF population. ${ }^{10,11,13,79} \mathrm{CRS}$ has been previously shown to be associated with a significantly reduced HRQoL in non-CF individuals. ${ }^{18-20}$ In those with $\mathrm{CF}$, sinus-specific questionnaires suggest a similar impairment in HRQoL ${ }^{80}$ However, these instruments were not constructed to account for the unique challenges individuals with CF encounter from living with a life-long genetic disease. The construction of CF-specific instruments like the CFQ$\mathrm{R}$, allow HRQoL to be measured in the context of the circumstances experienced by those with $\mathrm{CF}^{23,81}$ Given this, the purpose of the current study was to determine the impact of CRS on HRQoL of adults with $\mathrm{CF}$, using a CF-specific questionnaire (i.e. CFQ-R). Our primary objectives were to determine the prevalence of CRS, identify socio-demographic and clinical factors associated with CRS status and determine its effect on the domains of the CFQ-R 14+.

\subsection{Prevalence of CRS}

\subsubsection{Sinus Symptoms}

In the current study, the prevalence of CRS was found to be $64.2 \%$, which was consistent with previous estimates. ${ }^{13}$ The majority of participants with CRS were symptomatic (91\%) and the most common sinus symptoms were nasal congestion (81\%) and anterior or posterior nasal discharge (79\%). This was 
expected, as these symptoms are most commonly reported in non-CF counterparts with CRS. ${ }^{8}$ Interestingly, the majority of participants also reported a loss of smell (71\%). This is noteworthy because smell has been shown to be strongly associated with taste ${ }^{82}$ and subsequently, impaired taste may negatively affect eating habits. This is concerning because malnutrition, as a result of nutritional inadequacy, has been shown to be associated with significant reductions in lung function and survival in $\mathrm{CF}^{83,84}$ In non-CRS individuals, $42 \%$ fulfilled the symptom requirements but did not present with objective evidence or report a history of sinus surgery. Although these individuals were symptomatic, they could not be diagnosed with CRS because they did not meet the objective requirements. The most common sinus symptoms in these participants were also nasal congestion (58\%) and anterior or posterior nasal discharge (39\%). Loss of smell was reported by $32 \%$ of non-CRS individuals.

\subsubsection{Nasal Endoscopy}

Among individuals with CRS, 97\% had positive endoscopic evidence. The most common endoscopic finding for these participants was inflammation of the middle meatus, followed by discoloured mucus. Similar to previous studies in adults with CF, nasal polyposis was found in $22 \%$ of CRS participants. ${ }^{13,79}$ Among participants without CRS, 55\% were positive for endoscopic evidence. The most common endoscopic finding for these individuals was also inflammation of the middle meatus, followed by discoloured mucus. Although asymptomatic, nasal polyposis was visualized in $18 \%$ of these individuals. These findings are interesting because despite presenting with objective evidence, these individuals did not meet the symptom requirements for CRS as described in current guidelines.

\section{$\underline{6.1 .3}$ Sinus-CT Scans}

As expected, all available sinus-CT scans were positive for radiographic evidence of CRS. Previous findings have shown that nearly all individuals present with radiographic abnormalities consistent with CRS. ${ }^{14}$ However, in our final study sample only $87 \%$ were diagnosed with CRS because these 
individuals also reported symptoms. 'These findings support previous suggestions that in the $\mathrm{CF}$ population the evaluation of sinus-CT scans alone are not indicative of CRS status, as they also do not correlate with symptoms. ${ }^{85}$ Given that radiographic abnormalities are common, a detailed assessment of symptoms and nasal endoscopy is required to confirm CRS diagnosis. It is important to note that sinus-CT scans were not available for $53 \%$ of the final study sample. Based on previous research and findings among those with scans in the final study sample, it is likely that those without sinus-CT scans were also positive for radiographic evidence.

\subsubsection{History of Sinus Surgery}

History of sinus surgery was reported by $42 \%$ of participants, which was lower than previously estimated. ${ }^{13}$ Given that this factor was self-reported, this discrepancy may be due to recall basis, as participants may not have remembered if sinus surgery was performed especially if performed in childhood. Detailed retrospective review of all procedures performed in pediatric or adult centres would be required to ascertain more accurate estimates than self-reporting. However, this was not feasible for the current study. The underestimation in frequency of sinus surgery may also be due to centre-specific differences, in that the indications to perform sinus surgery may be inconsistent. Currently, there does not exist a standardized guideline for indications of sinus surgery in adults with CF.

\subsection{Socio-Demographic and Clinical Factors Associated with CRS Status}

Participants with or without CRS did not differ in any socio-demographic or clinical factors. Although these findings were not significant, several noteworthy results were found.

The prevalence of CRS was slightly higher in females than in males. This is consistent with previous epidemiologic literature studying this relationship in adults without $\mathrm{CF} .{ }^{11}$ Consistent with previous findings, it was expected that CRS was more frequent in participants with class I to III mutations than 
class IV to V mutations. ${ }^{13}$ From examining collinearity between covariates, mutation class was strongly associated with age of diagnosis, time since CF diagnosis and chronic P.aeruginosa infection. Individuals with CRS were also diagnosed with $\mathrm{CF}$ at an earlier age, had lived longer with $\mathrm{CF}$ and frequently presented with chronic P.aeruginosa infection than individuals without CRS. These findings suggest that CRS is associated with a more severe phenotype of CF. However, the difference in time since CF diagnosis between those with or without CRS, was not as large as the difference in age of CF diagnosis. It may be that time since CF diagnosis is not a sensitive parameter to quantify the severity of CF because participants may have similar values. For example, individuals diagnosed earlier may have lived with CF for the same amount of time as those diagnosed later but who are older. This is evident from the contrasting directions of correlation with age (positively correlated) and age of CF diagnosis (negatively correlated), respectively.

Consistent with previous findings, chronic P.aeruginosa infection was more frequent in CRS than nonCRS participants. ${ }^{75}$ It is appreciable that individuals with a severe CF phenotype would present with persistent bacterial infections and subsequently upper airway co-morbidities, like CRS. ${ }^{86}$ Similarly, CRS appeared to occur more frequently among participants with a history of lung transplant. Individuals reporting a history of lung transplant were more frequently diagnosed with $\mathrm{CF}$ at a younger age and presented with class I to III mutations. This also suggests that these participants had a more severe phenotype of CF. Given the higher prevalence of CRS among these individuals, it can be hypothesized that CRS existed prior to the lung transplant. Bacteria can remain colonized in the sinuses after transplant ${ }^{87}$ and sinus symptoms may been more noticeable afterwards, given that the emphasis of morbidity has shifted from deteriorating lung function to other co-existing airway conditions.

Although these findings suggest that individuals with a severe phenotype of CF are at greater risk for CRS, in the final study sample lung function did not differ between CRS and non-CRS individuals. This may have occurred for a several reasons. Firstly, CRS requires symptoms since objective findings 
alone cannot confirm diagnosis. It may be that the effects of lung function overshadow CRS symptomatology and that individuals living longer with CF are less inclined to report sinus symptoms. This may occur because these individuals cope with their sinus symptoms and do not interpret them as atypical. As a result, these participants may have been considered negative for CRS and subsequently, the difference in lung function may have been less apparent. Secondly, CRS may not have appreciable effects on lung function as originally hypothesized. Other lung-related issues (e.g. chronic P.aeruginosa infection) may overshadow the effects of CRS on lung function, despite sharing a common airway and epithelial cell composition. This is supported by previous studies suggesting that sinus surgery to open obstructed sinus ostia and remove bacteria does not result in significant improvements in lung function. ${ }^{88}$ Thirdly, CF clinicians are increasingly focused on maintaining adequate lung function and evaluate patients frequently. This may contributed to few outlying individuals with severely low $\mathrm{FEV}_{1} \%$ predicted. Given this, lung function may appear similar between CRS and non-CRS individuals despite the differences in phenotypic severity discussed earlier. Fourthly, individuals with CRS had a greater frequency of lung transplants. The difference in lung function may have been less apparent because participants with a history of lung transplant were found to have higher lung function.

Although not significant, depression occurred more frequently in participants with CRS. This is important because this association has been found previously in non-CF individuals ${ }^{20,89,90}$ but has yet to be observed in the CF population. This provides moderate evidence that the association between depression and CRS persists, even among individuals with genetic diseases like CF. 


\subsection{Health-Related Quality of Life}

\subsubsection{Relationship Between CRS and HRQoL}

From unadjusted linear regression models, individuals with CRS reported worse scores on 10 of 12 domains than non-CRS counterparts. Significant reductions in scores were found on the domains of Respiratory symptoms and Digestion. To evaluate whether potential confounders distorted the unadjusted regression estimates, unique multivariable linear regression models were constructed for each CFQ-R 14+ domains. This was based on findings from a systematic review of previous studies using the CFQ-R 14+ and bivariable associations between potential confounders and each domain.

In regards to the covariates, lung function as expected was positively correlated with 8 of 12 domains on the CFQ-R 14+. ${ }^{26,34,43}$ Higher lung function was associated with worse scores on the Digestion domain, which was unexpected given previous studies. ${ }^{26,34,43}$ As predicted, participant age was positively correlated with Physical and Social functioning. ${ }^{57}$ In regards to gender, males expectantly reported higher scores than female counterparts on Physical functioning and lower scores on Body Image, than female counterparts. ${ }^{57}$ The latter is consistent with previous findings suggesting that males are less satisfied with their body image than females, which can be attributed to desires to be heavier. ${ }^{64}$ BMI was positively correlated with Eating Disturbances, Body Image and Weight, consistent with previous studies. ${ }^{29,34,41,63}$ As expected, participants currently employed or attending school reported higher scores on Physical, Social and Role functioning. ${ }^{63}$

Given these findings, unique multivariable linear regression models were constructed for each domain. The use of DAGs allowed the relationship of CRS and CFQ-R 14+ to be visualized in the context of the associations between a priori confounders identified from discussion with clinical experts, a systematic review of relevant literature and from bivariable associations in the final study sample. It is important to note that although significance testing was used to determine the extent of association between the covariates and the CFQ-R 14+ domains, decisions to include them in the final model were 
not based only on their resulting probability values. Rather, these were used as an adjunct to the $a$ priori understanding of confounders. Based on this, probability values were not adjusted for the frequency of significance testing.

When compared to unadjusted regression parameters, the standard errors and the mean squared errors were reduced for nearly all adjusted regression models. Also, the proportion of variance in CFQ-R 14+ domain scores explained by the regression models, increased over two-fold between unadjusted and adjusted models. Although the final adjusted- $\mathrm{R}^{2}$ values were not as high as expected, this can be attributed to the use of methods to prevent cofounding rather than to predict CFQ-R 14+ domain scores. The predictive method encourages multiple variables related to the outcome to be entered into the final model, regardless of the extent of their effects. ${ }^{70}$ As our primary objective was to determine the effect of CRS on CFQ-R 14+ domain scores, variables were added to prevent confounding. However, it is also noteworthy that data collection may have not captured all variables that are known to affect CFQ-R 14+ domain scores, despite our best efforts. Residual confounding from unknown or unmeasured variables may also have prevented larger adjusted- $\mathrm{R}^{2}$ values.

As data were incomplete for CRS status, CFQ-R 14+ domain scores and several covariates, a sensitivity analysis was conducted using multiple imputations. This was performed because multivariable linear regression models require a complete set of data for each covariate included. Establishing a complete dataset resulted in the exclusion of up to $18 \%$ of participants for each CFQ-R 14+ domain, which could potentially bias the regression estimates. To address this, multiple imputations were used to generate several complete datasets where multivariable linear regressions models could be used with all participants in the final study sample. The final regression coefficients and standard errors represented an average of each imputed dataset. The regression estimates generated from the multiple imputed datasets were similar to those calculated from the complete case analysis. Although the regression estimates from the sensitivity analysis were increased in the majority of 
domains, they did not appear to significantly diverge from the complete case results. Significant differences in the domains of Respiratory symptoms and Digestion were consisted in both analyses. This suggests that the exclusion of participants with missing data in the complete case analysis did not result in significant biases.

\section{$\underline{\text { 6.3.2 Significant CFQ-R 14+ Domains }}$}

Respiratory Symptoms

Following adjustment for lung function and age of CF diagnosis, individuals with CRS reported significantly worse Respiratory symptom scores, than those without CRS. This was expected given the questions of this domain, which included items about congestion, daytime coughing, the colour of mucus resulting from coughing, wheezing, trouble breathing or waking up at night due to coughing. Included among these questions was nasal congestion, the most prevalent sinus symptom. Although this was highly reported by both CRS and non-CRS individuals, the CFQ-R 14+ scores responses according to severity. In contrast for the diagnosis of CRS, guidelines suggest that any responses from 'mild' to 'severe' are considered to fulfill this symptom component. It is likely that participants with CRS reporting worse Respiratory symptoms due to an increase in the severity of nasal congestion. In regards to the remaining questions, several are related to coughing and waking up at night. Although these are labeled as respiratory-related symptoms, it is possible that these may also have been interpreted as sinus-related symptoms. For example, anterior or posterior nasal discharge, which includes post-nasal drip, is a sensation of mucus dripping down the back of one's throat. As a result, this may contribute to coughing both during the day and at night in attempt to clear the mucus. Therefore, it is unclear if participants were responding to symptoms of coughing as a result of both accumulated mucus in the lungs and from the sinuses. It is also conceivable that mucus from the sinuses contributes to coughing related to the lungs, although from this cannot be confirmed from this study. Similarly, in participants with a history of lung transplant where lung function has improved, the 
subsequent effect of sinus symptoms may be more apparent. Also, responses to the question related to troubled breathing may include sinus symptoms, like nasal obstruction. We hypothesize that participants reporting nasal obstruction may be more likely to suffer from underlying septal deviations or nasal polyposis.

\section{Digestion}

Individuals with CRS reported significantly worse scores on the Digestion domain, than those without CRS following adjustment for lung function. This was unexpected and has not been previously found. The Digestion domain questions participants about gas, diarrhea and abdominal pain. Although CRS has not been shown to be directly responsible for these symptoms, investigations in non-CF individuals have found strong associations between CRS and gastro-esophageal reflux (GER). ${ }^{91,92}$ GER is a prevalent co-morbidity in the $\mathrm{CF}$ population and can characterized with symptoms like gas and abdominal pain. ${ }^{93}$ The current study cannot confirm the connection between CRS and GER. However, we hypothesize the association between CRS and worse Digestion-related HRQoL may involve GER.

\subsection{Limitations}

As the design of this study was cross-sectional, the primary explanatory and outcome variables were recorded simultaneously and the direction of association could not be concluded. Our findings suggest that CRS is associated with significantly worse Respiratory symptom- and Digestion-related HRQoL. However, given that the assessment of CRS and HRQoL occurred together, it unclear if HRQoL was reduced as a result of CRS or if HRQoL was already reduced prior the diagnosis of CRS.

Secondly, to prevent potential misclassification bias (i.e. incorrect diagnosis and classification of the explanatory variable), standardized guidelines were used to diagnosis CRS. However, these guidelines were developed among individuals without $\mathrm{CF}$ and it is uncertain if interpretations of symptomatology are similar between $\mathrm{CF}$ and non-CF populations. $\mathrm{CF}$ is often diagnosed at birth and individuals learn to 
cope with their symptoms, as they grow older. This limits the ability of individuals to note changes in symptoms as they constantly live at a 'baseline' or static level. There are individuals who present with nasal polyposis during their childhood and this suggests an early manifestation of CRS. ${ }^{94}$ However, CRS can present without nasal polyposis and it is unclear when this condition begins. Findings from the CF Foundation Patient Registry provide preliminary evidence that CRS is more commonly reported in older individuals. ${ }^{6}$ It is also unclear if this was a result of increased awareness of CRS in adultspecific CF centres or a progression of symptomatology. CF-specific diagnostic guidelines for CRS are unavailable and as a result, this cross-sectional study was limited by the use of guidelines specific for non-CF individuals.

Thirdly, $61 \%$ of the final study sample elected to receive nasal endoscopy. This procedure is minimally invasive and is required to be performed by a trained otorhinolaryngologist. It is promising that the majority of participants chose to receive this procedure, as this suggests it was considered safe and tolerable. However, these findings are susceptible to respondent selection bias, as the likelihood of having previously received sinus surgery or being symptomatic for CRS was greater among those choosing nasal endoscopy. Similarly, the majority of individuals choosing nasal endoscopy were diagnosed with CRS. This further suggests those most likely to have CRS were also more likely to choose the additional endoscopic assessment.

\subsection{Strengths}

There are several factors that strengthen this cross-sectional study. CRS has previously been shown to be a prevalent chronic disease among individuals with CF but this is the first study to examine its effect on HRQoL using a CF-specific questionnaire (i.e. CFQ-R 14+). This enables these findings to be generalized to those with CF because the CFQ-R 14+ is customized for the unique challenges faced by these individuals. This will allow patients, care providers and future researchers the opportunity to compare the effects of CRS and other chronic diseases on CF-specific HRQoL. Secondly, the final 
study sample recruited was an adequate representation of the total clinic population in terms of age, gender, lung function, BMI, age of CF diagnosis, pancreatic insufficiency, chronic P.aeruginosa infection and depression. This suggests that the prevalence of CRS and its effect on HRQoL can be considered representative of the total clinic population enrolled at the St. Paul's CF Clinic. Selection bias was minimized during recruitment given the high response rate (93\%) and adequate representativeness of the final study sample. This validates that participants were approached without regard to their underlying sinus symptoms or likelihood of being categorized as CRS positive. As a result, final regression estimates can be considered representative of the relationship of CRS and HRQoL in the total clinic population. Thirdly, a systematic review was performed to identify potential confounders. This outlined several socio-demographic and clinical factors that were previously shown to affect HRQoL, as measured by the CFQ-R 14+. As a result, multivariable linear regression models were constructed to control for potentially confounding effects and to yield minimally biased regression estimates. However, it is important to consider that residual confounding of unknown or unmeasured factors may have existed despite these methods. Fourthly, results from a sensitivity analysis using multiple imputations yielded regression estimates similar to the complete case analysis. This suggests that even though data were missing for several variables, the exclusion of missing participants from multivariable linear regression models did not appear to bias the regression estimates.

\subsection{Implications}

As discussed earlier, CF care providers are increasingly evaluating HRQoL given advances in age, prevalence of extra-pulmonary co-morbidities and treatment burden. These are often used to improve the delivery of care and to determine the effectiveness of interventions. It is evident in the non-CF population that CRS is associated with significantly reduced HRQoL. ${ }^{18-20,95}$ This includes negative associations with productivity, absenteeism and hospitalization. ${ }^{18-20,95} \mathrm{CRS}$ is a prevalent co-morbidity affecting adults with $\mathrm{CF}$, yet there is a paucity of evidence regarding its impact on the HRQoL. 
Individuals with CRS reported lower scores on the majority of domains of the CFQ-R 14+. This included significantly worse scores related to respiratory symptom- and digestion-related HRQoL. This consists of poor nasal congestion, trouble breathing, coughing and shortness of breath, problems with gas, diarrhea and abdominal pain. CF care providers encountering individuals with reductions in HRQoL such as these may consider investigating for CRS. This can include assessing the severity of the five major sinus symptoms and determining whether sinus surgery was previously performed. Referral may then be made to an otorhinolaryngologist for a more detailed nasal examination and possible treatment.

Bacteria colonized in the sinuses have previously been associated with an increase in the frequency of pulmonary exacerbations. ${ }^{86,96}$ Pulmonary exacerbations may require intravenous antibiotics, contribute to worse survival and reduce HRQoL. ${ }^{4}$ Current evidence remains controversial for the optimal way to manage CRS in adults with CF. ${ }^{97-99}$ Medical treatment with topical nasal steroids has been shown to improve symptoms, reduce inflammation and shrink nasal polyps. ${ }^{100}$ Alternatively, bacteria can be removed and obstructed sinus ostia can be opened with sinus surgery. This has been shown to moderately reduce the incidence of pulmonary exacerbations and improve CRS-specific HRQoL. ${ }^{88,101}$ Currently, there are few studies using the CFQ-R to measure change in HRQoL after the CRS-related treatment. When compared to preoperative scores, Aanaes et al. (2013) found that individuals receiving sinus surgery reported significant improvements in total CFQ-R scores up to six months after this procedure. Although the investigators did not stratify CFQ-R scores by domains, this suggests that CRS-related treatment may improve HRQoL yet further research is required.

CRS is also associated with other co-morbidities like depression. As individuals with CF grow older, they face increasing rates of depression and anti-depressant use. Studies using patient registries frequently rely on self-reporting that may not be reliable, as these methods are susceptible to recall and 
misclassification bias. ${ }^{4}$ Depression may be heightened by poor lung function, receiving a lung transplant or increasing treatment costs. ${ }^{4}$ Although not significant, the current study found the prevalence of depression to be higher among participants with CRS. Given this finding, CF care providers may consider investigating CRS during assessments for depression.

\subsection{Future Studies}

As the current study was focused predominantly on investigating the relationship between CRS and HRQoL, several additional topics regarding diagnosis, predictive modeling and treatment could not be addressed. The following are topics that may of interest for future studies.

\subsubsection{Diagnosis of CRS}

The findings of this thesis support previous studies indicating CRS is a prevalent chronic disease in adults with CF. Standard guidelines for the diagnosis of CRS are currently available but are not specific for the $\mathrm{CF}$ population. It may be hypothesized that individuals with $\mathrm{CF}$ may be less likely to report sinus symptoms than non-CF counterparts, given overwhelming lung-related morbidity. As symptomatology is a vital component for the diagnosis of CRS, future CF-specific guidelines may account for the differences in symptom reporting. This may yield guidelines that emphasize a unique combination of symptoms and objective findings that are different from those that currently exist for individuals without CF. This could be established by recruiting a group of senior otorhinolaryngologists with experience in $\mathrm{CF}$ and systematically reviewing relevant literature. Similar to the construction of the Canadian Clinical Practice Guidelines for Acute and Chronic Rhinosinusitis, a Delphi process can be used to establish criteria for these guidelines. Once this is complete, these can be prospectively tested and compared to existing guidelines. 


\subsubsection{Predictive Model for CRS}

As described earlier, CF care providers are increasingly concerned with the rising prevalence of extrapulmonary co-morbidities affecting adults with CF. This can result in several chronic diseases being diagnosed and managed simultaneously. Given this, CRS may be overshadowed by competing conditions like CF-related diabetes and depression. Therefore, $\mathrm{CF}$ care providers may find use in a predictive model to identify individuals who may warrant referral to an otorhinolaryngologist for investigation of CRS. This model can incorporate various socio-demographic and clinical factors that occur more frequently among those with CRS and from relevant literature. Since CRS has a significant impact on HRQoL, the predictive model may include the Respiratory symptoms and Digestion domains of the CFQ-R 14+. Currently, the Sinonasal Outcomes Test-22 (SNOT-22) is a popular instrument to measure sinus-specific HRQoL among individuals with CRS. ${ }^{102}$ This questionnaire is comprised of twenty-two sinus-specific questions that can be completed in less than five minutes. CF care providers may benefit from the development of a predictive model that includes relevant sociodemographic/clinical factors, Respiratory symptom and Digestion domains from the CFQ-R 14+ and the SNOT-22 to assist in identifying those who require further investigation from an otorhinolaryngologist. The validity of this model can be prospectively compared to diagnostic guidelines for CRS that include nasal endoscopy.

\subsection{Conclusion}

The current study investigated the effect of CRS on the HRQoL of adults with CF, using a CF-specific instrument (i.e. CFQ-R 14+). The CFQ-R 14+ is currently the gold standard instrument to measure HRQoL in adolescents and adults with $\mathrm{CF}^{74}$ Participants with or without CRS did not significantly differ in any of the socio-demographic and clinical factors recorded. However, individuals with CRS appeared to have a more severe phenotype of CF that included a greater frequency of class I to III mutations, earlier age of $\mathrm{CF}$ diagnosis, more time living with $\mathrm{CF}$ and higher rates of chronic 
P.aeruginosa infection. In terms of HRQoL, participants with CRS reported worse scores on the CFQR 14+ domains Respiratory symptoms and Digestion. These findings persisted despite adjustment for lung function and age of $\mathrm{CF}$ diagnosis. Given that data were missing for some participants, a sensitivity analysis was performed using multiple imputations. Unadjusted and adjusted linear regression estimates did not appear to differ between the complete case analysis that excluded participants with missing data and the sensitivity analysis. Consistent with findings among individuals without $\mathrm{CF}^{18-20,95}$, CRS is a prevalent chronic disease that is associated with reduced HRQoL even in adults with CF. Future endeavors are recommended to establish CF-specific CRS guidelines and predictive models to assist CF care providers to identify individuals who may warrant referral to an otorhinolaryngologist for investigation of CRS. 


\section{BIBLIOGRAPHY}

1. Strausbaugh SD, Davis PB. Cystic fibrosis: a review of epidemiology and pathobiology. Clin Chest Med. 2007;28(2):279-88. doi:10.1016/j.ccm.2007.02.011.

2. Zielenski J. Genotype and phenotype in cystic fibrosis. Respiration. 2000;67(2):117-33. doi:29497.

3. Parkins MD, Parkins VM, Rendall JC, Elborn S. Changing epidemiology and clinical issues arising in an ageing cystic fibrosis population. Ther Adv Respir Dis. 2011;5(2):105-19. doi:10.1177/1753465810386051.

4. Quon BS, Aitken ML. Cystic fibrosis: what to expect now in the early adult years. Paediatr Respir Rev. 2012;13(4):206-14. doi:10.1016/j.prrv.2012.03.005.

5. Cystic Fibrosis Canada. Annual Report.; 2012.

6. Cystic Fibrosis Foundation Patient Registry. 2012 Annual Report. Berthesda, Maryland; 2012.

7. Benninger M, Ferguson B, Hadley J, et al. Adult chronic rhinosinusitis: Definitions, diagnosis, epidemiology, and pathophysiology. Otolaryngol - Head Neck Surg. 2003;129(3):S1-S32. doi:10.1016/S0194-5998(03)01397-4.

8. Fokkens WJ, Lund VJ, Mullol J, et al. European Position Paper on Rhinosinusitis and Nasal Polyps 2012. Rhinol Suppl. 2012;(23):3 p preceding table of contents, 1-298.

9. Desrosiers M, Evans G a, Keith PK, et al. Canadian clinical practice guidelines for acute and chronic rhinosinusitis. Allergy Asthma Clin Immunol. 2011;7(1):2. doi:10.1186/1710-1492-7-2.

10. Pleis JR, Ward BW, Lucas JW. Summary Health Statistics for U.S. Adults: National Health Interview Survey, 2009. Vital Heal Stat. 2010;10(249):1-207.

11. Chen Y, Dales R, Lin M. The epidemiology of chronic rhinosinusitis in Canadians. Laryngoscope. 2003;113(7):1199-205. doi:10.1097/00005537-200307000-00016. 
12. Bhattacharyya N. Associations between obesity and inflammatory sinonasal disorders. Laryngoscope. 2013;123(8):1840-4. doi:10.1002/lary.24019.

13. Berkhout MC, van Rooden CJ, Rijntjes E, Fokkens WJ, El Bouazzaoui LH, Heijerman HGM. Sinonasal manifestations of cystic fibrosis: A correlation between genotype and phenotype? J Cyst Fibros. 2013. doi:10.1016/j.jcf.2013.10.011.

14. Kerrebijn J, Poublon R, Overbeek S. Nasal and paranasal disease in adult cystic fibrosis patients. Eur Respir J. 1992;5(10):1239-1242.

15. The WHOQOL Group. The World Health Organization quality of life assessment (WHOQOL): Position paper from the World Health Organization. Soc Sci Med. 1995;41(10):1403-1409.

16. World Health Organization. Preamble to the constitution of the World Health Organization. In: Basic Documents. 26th ed. Geneva, Switzerland; 1976:Part 1.

17. Guyatt GH, Feeny DH, Patrick DL. Measuring health-related quality of life. Ann Intern Med. $1993 ; 118(8): 622-9$.

18. Gliklich RE, Metson R. The health impact of chronic sinusitis in patients seeking otolaryngologic care. Otolaryngol Head Neck Surg. 1995;113(1):104-9.

19. Durr DG, Desrosiers MY, Dassa C. Impact of rhinosinusitis in health care delivery: the Quebec experience. J Otolaryngol. 2001;30(2):93-7.

20. Macdonald KI, McNally JD, Massoud E. The health and resource utilization of Canadians with chronic rhinosinusitis. Laryngoscope. 2009;119(1):184-9. doi:10.1002/lary.20034.

21. Goss CH, Quittner AL. Patient-reported outcomes in cystic fibrosis. Proc Am Thorac Soc. 2007;4(4):378-86. doi:10.1513/pats.200703-039BR.

22. Henry B, Aussage P, Grosskopf C, Goehrs J-M. Development of the Cystic Fibrosis Questionnaire (CFQ) for assessing quality of life in pediatric and adult patients. Qual Life Res. 2003;12(1):63-76. 
23. Quittner A., Sweeny S, Watrous M, et al. Translation and linguistic validation of a diseasespecific quality of life measure for cystic fibrosis. J Pediatr Psychol. 2000;25(6):403-14.

24. Yuksel H, Yilmaz O, Dogru D, Karadag B, Unal F, Quittner AL. Reliability and validity of the Cystic Fibrosis Questionnaire-Revised for children and parents in Turkey: cross-sectional study. Qual Life Res. 2013;22(2):409-14. doi:10.1007/s11136-012-0152-4.

25. Quittner AL, Buu A, Messer M a, Modi AC, Watrous M. Development and validation of The Cystic Fibrosis Questionnaire in the United States: a health-related quality-of-life measure for cystic fibrosis. Chest. 2005;128(4):2347-54. doi:10.1378/chest.128.4.2347.

26. Bregnballe V, Thastum M, Lund LD, Hansen CR, Preissler T, Schiøtz PO. Validation of the Danish version of the revised cystic fibrosis quality of life questionnaire in adolescents and adults (CFQ-R14+). J Cyst Fibros. 2008;7(6):531-6. doi:10.1016/j.jcf.2008.06.006.

27. Schmidt A, Wenninger K, Niemann N, Wahn U, Staab D. Health-related quality of life in children with cystic fibrosis: validation of the German CFQ-R. Health Qual Life Outcomes. 2009;7:97. doi:10.1186/1477-7525-7-97.

28. Quittner AL, Sawicki GS, McMullen A, et al. Psychometric evaluation of the Cystic Fibrosis Questionnaire-Revised in a national sample. Qual Life Res. 2012;21(7):1267-78. doi:10.1007/s11136-011-0036-z.

29. Wenninger K, Aussage P, Wahn U, Staab D. The revised German Cystic Fibrosis Questionnaire: validation of a disease-specific health-related quality of life instrument. Qual Life Res. 2003;12(1):77-85.

30. Klijn PH, van Stel HF, Quittner AL, et al. Validation of the Dutch cystic fibrosis questionnaire (CFQ) in adolescents and adults. J Cyst Fibros. 2004;3(1):29-36. doi:10.1016/j.jcf.2003.12.006.

31. Congleton J, Hodson ME, Duncan-Skingle F. Quality of life in adults with cystic fibrosis. Thorax. 1996;51(9):936-940. doi:10.1136/thx.51.9.936. 
32. DeJong W., Kaptein A.A. vanderSchans C. Quality of life in patients with cystic fibrosis. Pediatr Pulmonol. 1997;23(2):95-100. doi:10.1002/(SICI)1099-0496(199702)23:2\&lt;95::AIDPPUL4\&gt;3.0.CO;2-N.

33. Abbott J. Health-related quality of life measurement in cystic fibrosis: advances and limitations. Chron Respir Dis. 2009;6(1):31-41. doi:10.1177/1479972308098159.

34. Quittner AL, Buu A, Messer M a, Modi AC, Watrous M. Development and validation of The Cystic Fibrosis Questionnaire in the United States: a health-related quality-of-life measure for cystic fibrosis. Chest. 2005;128(4):2347-54. doi:10.1378/chest.128.4.2347.

35. Quittner AL, Sawicki GS, McMullen A, et al. Erratum to: Psychometric evaluation of the Cystic Fibrosis Questionnaire-Revised in a national, US sample. Qual Life Res. 2012;21(7):1279-90. doi:10.1007/s11136-011-0091-5.

36. Gee L. Development of a disease specific health related quality of life measure for adults and adolescents with cystic fibrosis. Thorax. 2000;55(11):946-954. doi:10.1136/thorax.55.11.946.

37. Moher D, Liberati A, Tetzlaff J, Altman DG. Preferred reporting items for systematic reviews and meta-analyses: the PRISMA statement. PLoS Med. 2009;6(7):e1000097. doi:10.1371/journal.pmed.1000097.

38. Stroup DF, Berlin JA, Morton SC, et al. Meta-analysis of Observational Studies in Epidemiology: A Proposal for Reporting. JAMA. 2000;283(15):2008-2012.

39. Von Elm E, Altman DG, Egger M, Pocock SJ, Gøtzsche PC, Vandenbroucke JP. The Strengthening the Reporting of Observational Studies in Epidemiology (STROBE) statement: guidelines for reporting observational studies. Rev Esp Salud Publica. 2007;82(3):251-9.

40. Guyatt GH, Oxman AD, Vist GE, et al. GRADE: an emerging consensus on rating quality of evidence and strength of recommendations. BMJ. 2008;336(7650):924-6. doi:10.1136/bmj.39489.470347.AD. 
41. Wenninger K, Weiss C, Wahn U, Staab D. Body image in cystic fibrosis--development of a brief diagnostic scale. J Behav Med. 2003;26(1):81-94.

42. Dobbin CJ, Bartlett D, Melehan K, Grunstein RR, Bye PTP. The effect of infective exacerbations on sleep and neurobehavioral function in cystic fibrosis. Am J Respir Crit Care Med. 2005;172(1):99-104. doi:10.1164/rccm.200409-1244OC.

43. Riekert K a, Bartlett SJ, Boyle MP, Krishnan J a, Rand CS. The association between depression, lung function, and health-related quality of life among adults with cystic fibrosis. Chest. 2007;132(1):231-7. doi:10.1378/chest.06-2474.

44. Havermans T, Colpaert K, Dupont LJ. Quality of life in patients with Cystic Fibrosis: association with anxiety and depression. J Cyst Fibros. 2008;7(6):581-4. doi:10.1016/j.jcf.2008.05.010.

45. Sawicki G., Sellers D., Robinson W. Self-Reported Physical and Psychological Symptom Burden in Adults with Cystic Fibrosis. J Pain Symptom Manag. 2008;35(4):372-380.

46. Dunnink M a, Doeleman WR, Trappenburg JC a, de Vries WR. Respiratory muscle strength in stable adolescent and adult patients with cystic fibrosis. J Cyst Fibros. 2009;8(1):31-6. doi:10.1016/j.jcf.2008.07.006.

47. Havermans T, Colpaert K, Vanharen L, Dupont LJ. Health related quality of life in cystic fibrosis: To work or not to work? J Cyst Fibros. 2009;8(3):218-23. doi:10.1016/j.jcf.2009.03.002.

48. Sawicki G., Sellers D., Robinson W. High Treatment Burden in Adults with Cystic Fibrosis: Challenges to Disease Self-Management. J Cyst Fibros. 2009;8(2):91-96. doi:10.1016/j.jcf.2008.09.007.High.

49. Quittner AL, Schechter MS, Rasouliyan L, Haselkorn T, Pasta DJ, Wagener JS. Impact of socioeconomic status, race, and ethnicity on quality of life in patients with cystic fibrosis in the United States. Chest. 2010;137(3):642-50. doi:10.1378/chest.09-0345. 
50. Casier A, Goubert L, Theunis M, et al. Acceptance and well-being in adolescents and young adults with cystic fibrosis: a prospective study. J Pediatr Psychol. 2011;36(4):476-87. doi:10.1093/jpepsy/jsq111.

51. Cohen MA, Ribeiro MA, Ribeiro AF, Ribeiro JD, Morcillo AM. Quality of life assessment in patients with cystic fibosis by means of the Cystic Fibrosis Questionniare. J Brazilian Pneumol. 2011;37(2):184-192.

52. Hayes M, Yaster M, Haythornthwaite $\mathrm{J}$ a, et al. Pain is a common problem affecting clinical outcomes in adults with cystic fibrosis. Chest. 2011;140(6):1598-603. doi:10.1378/chest.110132.

53. Sawicki GS, Sellers DE, Robinson WM. Associations between illness perceptions and healthrelated quality of life in adults with cystic fibrosis. J Psychosom Res. 2011;70(2):161-7. doi:10.1016/j.jpsychores.2010.06.005.

54. Ashish A, Shaw M, McShane J, Ledson MJ, Walshaw MJ. Health-related quality of life in Cystic Fibrosis patients infected with transmissible Pseudomonas aeruginosa strains: cohort study. JRSM Short Rep. 2012;3(2):12. doi:10.1258/shorts.2011.011119.

55. Bouka A, Tiede H, Liebich L, et al. Quality of life in clinically stable adult cystic fibrosis outpatients: associations with daytime sleepiness and sleep quality. Respir Med. 2012;106(9):12449. doi:10.1016/j.rmed.2012.06.010.

56. Bradley JM, Blume SW, Balp M-M, Honeybourne D, Elborn JS. Quality of life and healthcare utilisation in cystic fibrosis: a multicentre study. Eur Respir J. 2013;41(3):571-7. doi:10.1183/09031936.00224911.

57. Dill EJ, Dawson R, Sellers DE, Robinson WM, Sawicki GS. Longitudinal trends in healthrelated quality of life in adults with cystic fibrosis. Chest. 2013;144(3):981-9. doi:10.1378/chest.12-1404. 
58. Platten MJ, Newman E, Quayle E. Self-esteem and its relationship to mental health and quality of life in adults with cystic fibrosis. J Clin Psychol Med Settings. 2013;20(3):392-9. doi:10.1007/s10880-012-9346-8.

59. Sawicki GS, Ren CL, Konstan MW, Millar SJ, Pasta DJ, Quittner AL. Treatment complexity in cystic fibrosis: trends over time and associations with site-specific outcomes. J Cyst Fibros. 2013;12(5):461-7. doi:10.1016/j.jcf.2012.12.009.

60. Targett K, Bourke S, Nash E, Murphy E, Ayres J, Devereux G. Employment in adults with cystic fibrosis. Occup Med (Lond). 2014;64(2):87-94. doi:10.1093/occmed/kqt140.

61. Wojewodka G, De Sanctis JB, Bernier J, et al. Candidate markers associated with the probability of future pulmonary exacerbations in cystic fibrosis patients. PLoS One. 2014;9(2):e88567. doi:10.1371/journal.pone.0088567.

62. Bouka A, Tiede H, Liebich L, et al. Quality of life in clinically stable adult cystic fibrosis outpatients: associations with daytime sleepiness and sleep quality. Respir Med. 2012;106(9):12449. doi:10.1016/j.rmed.2012.06.010.

63. Havermans T, Colpaert K, Vanharen L, Dupont LJ. Health related quality of life in cystic fibrosis: To work or not to work? J Cyst Fibros. 2009;8(3):218-23. doi:10.1016/j.jcf.2009.03.002.

64. Abbott J, Conway S, Etherington C, et al. Perceived body image and eating behavior in young adults with cystic fibrosis and their healthy peers. J Behav Med. 2000;23(6):501-17.

65. Rothman, Kenneth., Greeland, Sandler., Lash T. Modern Epidemiology. Third. Lippincott Williams \& Wilkins; 2012:851.

66. Kramer, M.S., Boivin JF. Toward an "unconfounded" classification of epidemiologic study design. J Chronic Dis. 1987;40(1):683-88.

67. Gordis L. Epidemiology. 4th ed. Saunders Elsevier; 2008. 
68. Van den Broeck J, Brestoff J. Epidemiology: Principles and Practical Guidelines. 1st ed. Springer Dordrecht Heidelberg; 2013.

69. Canadan Institutes of Health Research, Natural Sciences and Engineering Research Council of Canada, Social Sciences and Humanities Research Council of Canada. Tri-Council Policy Statement: Ethical Conduct for Research Involving Humans.; 2010.

70. Vittinghoff E, Shiboski SC, Glidden D V, McCulloch CE. Regression Methods in Biostatistis: Linear, Logistic, Survival and Repeated Measures Models. 1st ed. Springer Science+Business Media, Inc.; 2005.

71. Jones J, Hunter D. Qualitative Research: Consensus methods for medical and health services research. BMJ. 1995;311(7001):376-380. doi:10.1136/bmj.311.7001.376.

72. Quittner AL, Modi AC, Wainwright C, Otto K, Kirihara J, Montgomery a B. Determination of the minimal clinically important difference scores for the Cystic Fibrosis Questionnaire-Revised respiratory symptom scale in two populations of patients with cystic fibrosis and chronic Pseudomonas aeruginosa airway infection. Chest. 2009;135(6):1610-8. doi:10.1378/chest.081190.

73. Henry B, Grosskopf C, Aussage P, Goehrs J., Launois R. Construction of a disease-specific quality of life questionnaire for cystic fibrosis. Pediatr Pulmonol. 1997;13(suppl)(1):337-338.

74. Goss CH, Quittner AL. Patient-reported outcomes in cystic fibrosis. Proc Am Thorac Soc. 2007;4(4):378-86. doi:10.1513/pats.200703-039BR.

75. Godoy JM, Godoy AN, Ribalta G, Largo I. Bacterial pattern in chronic sinusitis and cystic fibrosis. Otolaryngol Head Neck Surg. 2011;145(4):673-6. doi:10.1177/0194599811407279.

76. Donders ART, van der Heijden GJMG, Stijnen T, Moons KGM. Review: a gentle introduction to imputation of missing values. J Clin Epidemiol. 2006;59(10):1087-91. doi:10.1016/j.jclinepi.2006.01.014.

77. Kirkwood B, Sterne J. Essential Medical Statistics. 2nd ed. Blackwell Publishing; 2006. 
78. Shrier I, Platt RW. Reducing bias through directed acyclic graphs. BMC Med Res Methodol. 2008;8:70. doi:10.1186/1471-2288-8-70.

79. Babinski D, Trawinska-Bartnicka M. Rhinosinusitis in cystic fibrosis: not a simple story. Int J Pediatr Otorhinolaryngol. 2008;72(5):619-24. doi:10.1016/j.ijporl.2008.01.010.

80. Khalid, Ayesha N., Mace, Jess., Smith TL. Outcomes of Sinus Surgery in Adults with Cystic Fibrosis. Otolaryngol Head Neck Surg. 2009;141(3):358-363.

doi:10.1016/j.otohns.2009.05.034.Outcomes.

81. Henry B, Aussagel P, Grosskopf C. Development of the Cystic Fibrosis Questionnaire (CFQ) for assessing quality of life in pediatric and adult patients. Qual Life Res. 2003;12(1):63-76.

82. Gaines AD. Anosmia and hyposmia. Allergy Asthma Proc. 2010;31(3):185-189. doi:10.2500/aap.2010.31.3357.

83. Steinkamp G. Relationship between nutritional status and lung function in cystic fibrosis: cross sectional and longitudinal analyses from the German CF quality assurance (CFQA) project. Thorax. 2002;57(7):596-601. doi:10.1136/thorax.57.7.596.

84. Stallings VA, Stark LJ, Robinson KA, Feranchak AP, Quinton H. Evidence-based practice recommendations for nutrition-related management of children and adults with cystic fibrosis and pancreatic insufficiency: results of a systematic review. J Am Diet Assoc. 2008;108(5):8329. doi:10.1016/j.jada.2008.02.020.

85. Rasmussen J, Aanæs K, Norling R, Nielsen KG, Johansen HK, von Buchwald C. CT of the paranasal sinuses is not a valid indicator for sinus surgery in CF patients. J Cyst Fibros. 2012;11(2):93-9. doi:10.1016/j.jcf.2011.09.009.

86. Johansen HK, Aanaes K, Pressler T, et al. Colonisation and infection of the paranasal sinuses in cystic fibrosis patients is accompanied by a reduced PMN response. J Cyst Fibros. 2012;11(6):525-31. doi:10.1016/j.jcf.2012.04.011. 
87. Orens JB, Estenne M, Arcasoy S, et al. International guidelines for the selection of lung transplant candidates: 2006 update--a consensus report from the Pulmonary Scientific Council of the International Society for Heart and Lung Transplantation. J Heart Lung Transplant. 2006;25(7):745-55. doi:10.1016/j.healun.2006.03.011.

88. Macdonald KI, Gipsman A, Magit A, et al. Endoscopic sinus surgery in patients with cystic fibrosis $\square$ : A systematic review and meta-analysis of pulmonary function. Rhinology. 2012;50(1):360-370. doi:10.4193/Rhino.11.271.

89. Bhattacharyya N, Wasan A. Do anxiety and depression confound symptom reporting and diagnostic accuracy in chronic rhinosinusitis? Ann Otol Rhinol Laryngol. 2008;117(1):18-23.

90. Wasan A, Fernandez E, Jamison RN, Bhattacharyya N. Association of anxiety and depression with reported disease severity in patients undergoing evaluation for chronic rhinosinusitis. Ann Otol Rhinol Laryngol. 2007;116(7):491-7.

91. Hanna BC, Wormald PJ. Gastroesophageal reflux and chronic rhinosinusitis. Curr Opin Otolaryngol Head Neck Surg. 2012;20(1):15-8. doi:10.1097/MOO.0b013e32834e8f11.

92. Katle E-J, Hatlebakk JG, Steinsvåg S. Gastroesophageal reflux and rhinosinusitis. Curr Allergy Asthma Rep. 2013;13(2):218-23. doi:10.1007/s11882-013-0340-5.

93. Robinson NB, DiMango E. Prevalence of gastroesophageal reflux in cystic fibrosis and implications for lung disease. Ann Am Thorac Soc. 2014;11(6):964-8. doi:10.1513/AnnalsATS.201401-044FR.

94. Schraven SP, Wehrmann M, Wagner W, Blumenstock G, Koitschev A. Prevalence and histopathology of chronic polypoid sinusitis in pediatric patients with cystic fibrosis. $J$ Cyst Fibros. 2011;10(3):181-6. doi:10.1016/j.jcf.2011.01.003.

95. Bhattacharyya N. Functional limitations and workdays lost associated with chronic rhinosinusitis and allergic rhinitis. Am J Rhinol Allergy. 2012;26(2):120-2. doi:10.2500/ajra.2012.26.3752. 
96. Aanæs K. Bacterial sinusitis can be a focus for initial lung colonisation and chronic lung infection in patients with cystic fibrosis. J Cyst Fibros. 2013;12 Suppl 2:S1-20. doi:10.1016/S1569-1993(13)00150-1.

97. Crosby DL, Adappa ND. What is the optimal management of chronic rhinosinusitis in cystic fibrosis? Curr Opin Otolaryngol Head Neck Surg. 2014;22(1):42-6. doi:10.1097/MOO.0000000000000014.

98. Mainz JG, Koitschev A. Management of chronic rhinosinusitis in CF. J Cyst Fibros. 2009;8 Suppl 1(June 2008):S10-4. doi:10.1016/S1569-1993(09)60005-9.

99. Mainz JG, Koitschev A. Pathogenesis and management of nasal polyposis in cystic fibrosis. Curr Allergy Asthma Rep. 2012;12(2):163-74. doi:10.1007/s11882-012-0250-y.

100. Beer $\mathrm{H}, \mathrm{Kw} \mathrm{S}, \mathrm{Ac} \mathrm{S}$. Topical nasal steroids for treating nasal polyposis in people with cystic fibrosis ( Review ). 2013;(4).

101. Aanaes K, Johansen HK, Skov M, et al. Clinical effects of sinus surgery and adjuvant therapy in cystic fibrosis patients - can chronic lung infections be postponed? Rhinology. 2013;51(3):22230. doi:10.4193/Rhino12.207.

102. Hopkins C, Gillett S, Slack R, Lund VJ, Browne JP. Psychometric validity of the 22-item Sinonasal Outcome Test. Clin Otolaryngol. 2009;34(5):447-54. doi:10.1111/j.17494486.2009.01995.x. 


\section{APPENDICES}

\section{Appendix A: Additional Tables for Chapter 2: Systematic Review}

Table A.1- Description of search strategy for systematic review identifying socio-demographic factors and clinical characteristics that are associated with health-related quality of life in adults with cystic fibrosis.

\begin{tabular}{|c|c|c|}
\hline Database & Groups & Search Terms \\
\hline MEDLINE / CENTRAL & $\begin{array}{l}\text { Population } \\
\text { HRQoL } \\
\text { Keywords }\end{array}$ & 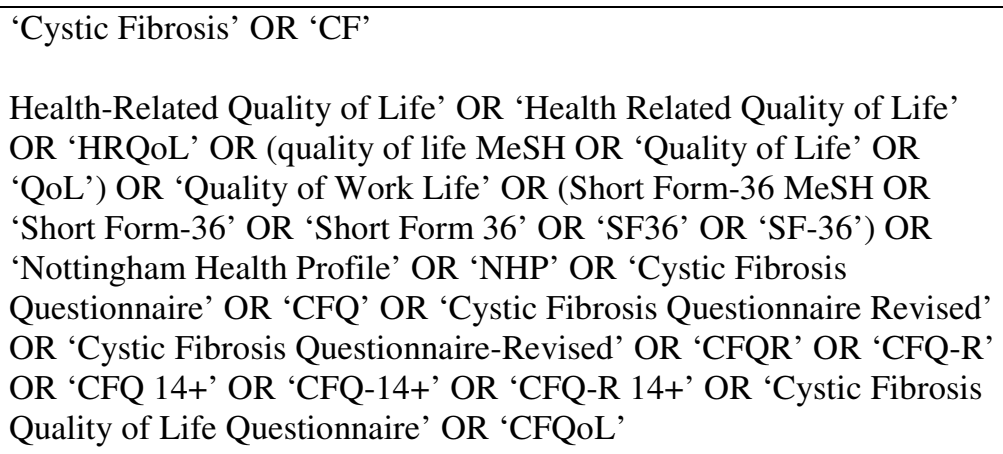 \\
\hline $\begin{array}{l}\text { EMBASE / CINAHL / } \\
\text { pyschNFO }\end{array}$ & $\begin{array}{l}\text { Population } \\
\text { HRQoL } \\
\text { Keywords }\end{array}$ & $\begin{array}{l}\text { 'Health-Related Quality of Life' OR 'Health Related Quality of Life' } \\
\text { OR 'HRQoL' OR 'Quality of Life' OR 'QoL' OR ‘Quality of Work } \\
\text { Life' OR ‘Short Form-36' OR 'Short Form 36' OR ‘SF36' OR ‘SF-36' } \\
\text { OR 'Nottingham Health Profile' OR 'NHP' OR 'Cystic Fibrosis } \\
\text { Questionnaire' OR 'CFQ' OR 'Cystic Fibrosis Questionnaire Revised' } \\
\text { OR 'Cystic Fibrosis Questionnaire-Revised' OR 'CFQR' OR 'CFQ-R' } \\
\text { OR 'CFQ 14+' OR 'CFQ-14+' OR 'CFQ-R 14+' OR ‘Cystic Fibrosis } \\
\text { Quality of Life Questionnaire' OR 'CFQoL' }\end{array}$ \\
\hline
\end{tabular}


Table A.2- Description of data collection form for systematic review identifying socio-demographic and clinical factors potentially associated with health-related quality of life in adults with cystic fibrosis.

\section{Assessment Categories \\ Characteristics Recorded From Full-Text Review of Articles Included in Final Collection}

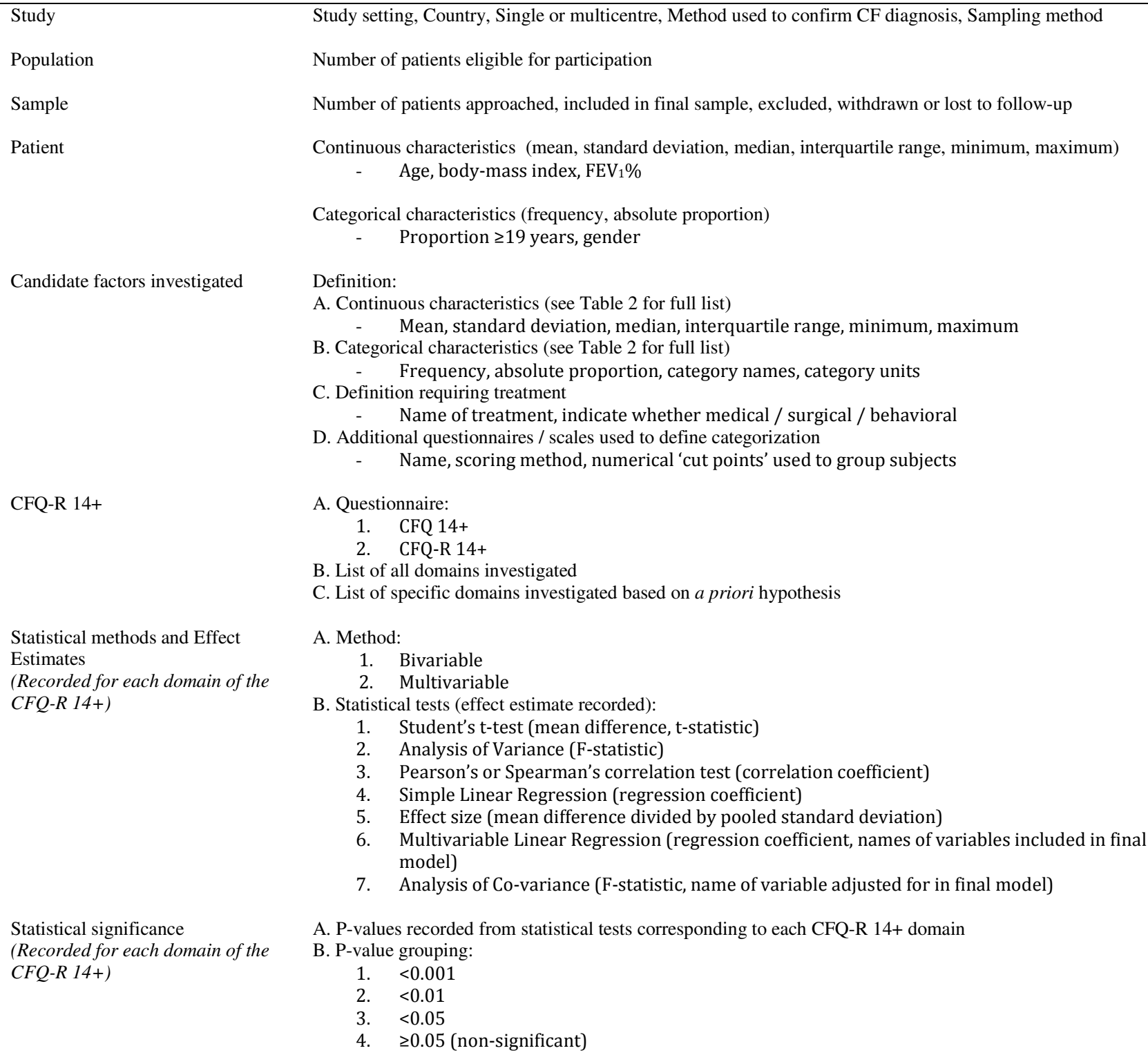

Number of patients eligible for participation

Number of patients approached, included in final sample, excluded, withdrawn or lost to follow-up

Continuous characteristics (mean, standard deviation, median, interquartile range, minimum, maximum) - $\quad$ Age, body-mass index, $\mathrm{FEV}_{1} \%$

Categorical characteristics (frequency, absolute proportion)

- $\quad$ Proportion $\geq 19$ years, gender

Definition:

A. Continuous characteristics (see Table 2 for full list)

- $\quad$ Mean, standard deviation, median, interquartile range, minimum, maximum

B. Categorical characteristics (see Table 2 for full list)

- $\quad$ Frequency, absolute proportion, category names, category units

C. Definition requiring treatment

- $\quad$ Name of treatment, indicate whether medical / surgical / behavioral

D. Additional questionnaires / scales used to define categorization

- $\quad$ Name, scoring method, numerical 'cut points' used to group subjects

A. Questionnaire

1. CFQ $14+$

2. CFQ-R $14+$

B. List of all domains investigated

C. List of specific domains investigated based on a priori hypothesis

A. Method:

1. Bivariable

2. Multivariable

B. Statistical tests (effect estimate recorded):

1. Student's t-test (mean difference, t-statistic)

2. Analysis of Variance (F-statistic)

3. Pearson's or Spearman's correlation test (correlation coefficient)

4. Simple Linear Regression (regression coefficient)

5. Effect size (mean difference divided by pooled standard deviation)

6. Multivariable Linear Regression (regression coefficient, names of variables included in final model)

7. Analysis of Co-variance (F-statistic, name of variable adjusted for in final model)

A. P-values recorded from statistical tests corresponding to each CFQ-R 14+ domain

B. P-value grouping:

1. $<0.001$

2. $<0.01$

3. $<0.05$

4. $\geq 0.05$ (non-significant)

Study quality / Risk of bias

A. STROBE checklist for complete reporting of observational studies

B. GRADE framework for assessing the quality of evidence 
Table A.3- Gender, age and lung function of subjects included in the final collection of 28 articles for systematic review identifying socio-demographic factors and clinical characteristics that are associated with health-related quality of life in adults with cystic fibrosis.

\begin{tabular}{|c|c|c|c|c|c|c|}
\hline $\begin{array}{c}\text { Primary } \\
\text { Author }\end{array}$ & Year & $\begin{array}{r}\text { Males } \\
(\%)\end{array}$ & \multicolumn{2}{|c|}{$\begin{array}{c}\text { Age } \\
\text { (years) }\end{array}$} & \multicolumn{2}{|c|}{$\begin{array}{l}\text { Lung function } \\
\left(\mathrm{FEV}_{1} \%\right)\end{array}$} \\
\hline Quittner & 2000 & 60 & 22.9 & 6.2 & 79.3 & 35.0 \\
\hline Henry & 2003 & 59 & 20.0 & 5.9 & - & - \\
\hline $\begin{array}{r}\text { Wenninger } \\
\text { (1) }\end{array}$ & 2003 & 46 & 25.5 & 9.2 & 53.1 & 23.0 \\
\hline $\begin{array}{r}\text { Wenninger } \\
\text { (2) }\end{array}$ & 2003 & 46 & 25.8 & 9.4 & 50.3 & 24.6 \\
\hline Klijn & 2004 & 52 & 21.4 & - & - & . \\
\hline Dobbin & 2005 & 36 & 26.0 & 9.0 & 59.0 & 24.0 \\
\hline Quittner & 2005 & 49 & 23.0 & 8.1 & 65.2 & 25.2 \\
\hline Fridge & 2007 & 60 & 17.0 & 6.0 & - & \\
\hline Riekert & 2007 & 45 & 30.6 & 9.6 & 62.8 & 24.6 \\
\hline Bregnballe & 2008 & 46 & 25.0 & 8.5 & 71.9 & 25.4 \\
\hline Havermans & 2008 & 51 & 26.8 & 8.2 & 65.1 & 22.2 \\
\hline Sawicki & 2008 & 42 & 32.8 & 13.2 & 69.0 & 28.0 \\
\hline Dunnick & 2009 & 48 & 26.0 & 7.0 & 63.0 & 25.0 \\
\hline Havermans & 2009 & 51 & 26.8 & 8.2 & 65.1 & 22.2 \\
\hline Sawicki & 2009 & 38 & 35.4 & 10.0 & 61.0 & 20.0 \\
\hline Quittner & 2010 & 53 & 26.7 & 8.2 & 62.8 & 27.9 \\
\hline Casier & 2011 & 58 & 18.4 & 2.9 & 83.0 & 19.7 \\
\hline Cohen & 2011 & 58 & $12.5^{1}$ & $5.1^{1}$ & 57.2 & 16.4 \\
\hline Hayes & 2011 & 43 & $29.3^{1}$ & - & - & - \\
\hline Sawicki & 2011 & 38 & 35.8 & 10.3 & 62.5 & 22.8 \\
\hline Ashish & 2012 & 60 & 23.0 & - & 70.6 & 24.0 \\
\hline Quittner & 2012 & 53 & 23.5 & 9.6 & 66.5 & 25.1 \\
\hline Bradley & 2013 & 51 & 28.5 & 8.2 & 58.7 & 26.8 \\
\hline Dill & 2013 & 45 & 32.5 & 10.7 & 59.8 & 22.4 \\
\hline Platten & 2013 & 33 & 27.8 & 9.2 & 61.7 & 25.0 \\
\hline Targett & 2014 & 54 & $26.0^{2}$ & - & 60.0 & - \\
\hline Wojewodka & 2014 & 54 & 32.8 & 1.8 & 63.0 & 3.8 \\
\hline
\end{tabular}

$\left(\mathrm{FEV}_{1} \%=\right.$ percent predicted forced expiratory volume in one second, '- " = not reported).

1. This estimate represents the entire study sample, as stratification of subjects' $\geq 14$ years was not provided in manuscript.

2. This estimate reflects the median, as the mean was not reported in the manuscript. 
Table A.4- Proportion of studies reporting statistically significant bivariable associations between candidate factors and individual CFQ-R 14+ domains.

\begin{tabular}{|c|c|c|c|c|c|c|c|c|c|c|c|c|}
\hline \multirow[b]{2}{*}{$\begin{array}{l}\text { CFQ-R 14+ } \\
\text { Domains }\end{array}$} & \multirow[b]{2}{*}{ Age } & \multirow[b]{2}{*}{ Gender } & \multirow[b]{2}{*}{ BMI } & \multirow[b]{2}{*}{$\mathrm{FEV}_{1} \%$} & \multirow[b]{2}{*}{ Employment } & \multicolumn{3}{|c|}{$\begin{array}{l}\text { Socio-Demographic and Clinical Factors } \\
\text { (Investigated in } \geq 2 \text { studies) }\end{array}$} & \multirow[b]{2}{*}{$\begin{array}{l}\text { Pseudomonas } \\
\text { aeruginosa } \\
\text { infection }\end{array}$} & \multirow[b]{2}{*}{$\begin{array}{c}\text { Symptom } \\
\text { Burden: } \\
\text { Psychological }\end{array}$} & \multirow[b]{2}{*}{$\begin{array}{l}\text { Symptom } \\
\text { Burden: } \\
\text { Gastrointestinal }\end{array}$} & \multirow[b]{2}{*}{$\begin{array}{l}\text { Symptom } \\
\text { Burden: } \\
\text { Respiratory }\end{array}$} \\
\hline & & & & & & Depression & $\begin{array}{l}\text { Pulmonary } \\
\text { exacerbation }\end{array}$ & $\begin{array}{l}\text { Frequency of } \\
\text { exacerbation }\end{array}$ & & & & \\
\hline $\begin{array}{l}\text { Physical } \\
\text { Functioning }\end{array}$ & $\begin{array}{r}3 \text { of } 3 \\
(100 \%)\end{array}$ & $\begin{array}{l}2 \text { of } 6 \\
(33 \%)\end{array}$ & $\begin{array}{l}1 \text { of } 7 \\
(14 \%)\end{array}$ & $\begin{array}{r}13 \text { of } 13 \\
(100 \%)\end{array}$ & $\begin{array}{r}1 \text { of } 1 \\
(100 \%)\end{array}$ & $\begin{array}{r}1 \text { of } 1 \\
(100 \%)\end{array}$ & $\begin{array}{r}2 \text { of } 2 \\
(100 \%)\end{array}$ & $\begin{array}{r}1 \text { of } 1 \\
(100 \%)\end{array}$ & $\begin{array}{r}1 \text { of } 1 \\
(100 \%)\end{array}$ & None & None & None \\
\hline Energy & $\begin{array}{r}2 \text { of } 2 \\
(100 \%)\end{array}$ & $\begin{array}{l}1 \text { of } 5 \\
(20 \%)\end{array}$ & $\begin{array}{l}1 \text { of } 7 \\
(14 \%)\end{array}$ & $\begin{array}{r}4 \text { of } 11 \\
(36 \%)\end{array}$ & $\begin{array}{r}1 \text { of } 1 \\
(100 \%)\end{array}$ & $\begin{array}{r}1 \text { of } 1 \\
(100 \%)\end{array}$ & $\begin{array}{l}1 \text { of } 2 \\
(50 \%)\end{array}$ & $\begin{array}{r}1 \text { of } 1 \\
(100 \%)\end{array}$ & $\begin{array}{r}1 \text { of } 1 \\
(100 \%)\end{array}$ & None & None & None \\
\hline Emotion & $\begin{array}{l}2 \text { of } 3 \\
(67 \%)\end{array}$ & $\begin{array}{l}4 \text { of } 6 \\
(67 \%)\end{array}$ & $\begin{array}{l}1 \text { of } 7 \\
(14 \%)\end{array}$ & $\begin{array}{r}5 \text { of } 13 \\
(38 \%)\end{array}$ & $\begin{array}{r}1 \text { of } 1 \\
(100 \%)\end{array}$ & $\begin{array}{r}1 \text { of } 1 \\
(100 \%)\end{array}$ & $\begin{array}{r}2 \text { of } 2 \\
(100 \%)\end{array}$ & $\begin{array}{r}0 \text { of } 1 \\
(0 \%)\end{array}$ & $\begin{array}{r}1 \text { of } 1 \\
(100 \%)\end{array}$ & $\begin{array}{r}1 \text { of } 1 \\
(100 \%)\end{array}$ & $\begin{array}{r}1 \text { of } 1 \\
(100 \%)\end{array}$ & $\begin{array}{r}1 \text { of } 1 \\
(100 \%)\end{array}$ \\
\hline $\begin{array}{l}\text { Social } \\
\text { Functioning }\end{array}$ & $\begin{array}{l}1 \text { of } 3 \\
(33 \%)\end{array}$ & $\begin{array}{l}3 \text { of } 6 \\
(50 \%)\end{array}$ & $\begin{array}{l}1 \text { of } 7 \\
(14 \%)\end{array}$ & $\begin{array}{r}6 \text { of } 13 \\
(46 \%)\end{array}$ & $\begin{array}{r}1 \text { of } 1 \\
(100 \%)\end{array}$ & $\begin{array}{r}1 \text { of } 1 \\
(100 \%)\end{array}$ & $\begin{array}{r}1 \text { of } 2 \\
(50 \%)\end{array}$ & $\begin{array}{r}0 \text { of } 1 \\
(0 \%)\end{array}$ & $\begin{array}{r}0 \text { of } 1 \\
(0 \%)\end{array}$ & None & None & None \\
\hline $\begin{array}{l}\text { Role } \\
\text { Functioning }\end{array}$ & $\begin{array}{l}1 \text { of } 3 \\
(33 \%)\end{array}$ & $\begin{array}{l}1 \text { of } 6 \\
(17 \%)\end{array}$ & $\begin{array}{l}1 \text { of } 7 \\
(14 \%)\end{array}$ & $\begin{array}{r}8 \text { of } 13 \\
(62 \%)\end{array}$ & $\begin{array}{r}1 \text { of } 1 \\
(100 \%)\end{array}$ & $\begin{array}{r}1 \text { of } 1 \\
(100 \%)\end{array}$ & $\begin{array}{r}2 \text { of } 2 \\
(100 \%)\end{array}$ & $\begin{array}{r}1 \text { of } 1 \\
(100 \%)\end{array}$ & $\begin{array}{r}1 \text { of } 1 \\
(100 \%)\end{array}$ & None & None & None \\
\hline $\begin{array}{l}\text { Eating } \\
\text { Disturbances }\end{array}$ & $\begin{array}{l}1 \text { of } 2 \\
(50 \%)\end{array}$ & $\begin{array}{l}1 \text { of } 4 \\
(25 \%)\end{array}$ & $\begin{array}{l}5 \text { of } 7 \\
(71 \%)\end{array}$ & $\begin{array}{r}6 \text { of } 11 \\
(55 \%)\end{array}$ & $\begin{array}{r}1 \text { of } 1 \\
(100 \%)\end{array}$ & $\begin{array}{r}1 \text { of } 1 \\
(100 \%)\end{array}$ & $\begin{array}{l}1 \text { of } 2 \\
(50 \%)\end{array}$ & $\begin{array}{r}0 \text { of } 1 \\
(0 \%)\end{array}$ & $\begin{array}{r}0 \text { of } 1 \\
(0 \%)\end{array}$ & None & None & None \\
\hline Body image & $\begin{array}{l}1 \text { of } 2 \\
(50 \%)\end{array}$ & $\begin{array}{l}3 \text { of } 4 \\
(75 \%)\end{array}$ & $\begin{array}{l}6 \text { of } 7 \\
(86 \%)\end{array}$ & $\begin{array}{r}8 \text { of } 11 \\
(73 \%)\end{array}$ & $\begin{array}{r}1 \text { of } 1 \\
(100 \%)\end{array}$ & $\begin{array}{r}1 \text { of } 1 \\
(100 \%)\end{array}$ & $\begin{array}{r}2 \text { of } 2 \\
(100 \%)\end{array}$ & $\begin{array}{r}0 \text { of } 1 \\
(0 \%)\end{array}$ & $\begin{array}{r}1 \text { of } 1 \\
(100 \%)\end{array}$ & None & None & None \\
\hline $\begin{array}{l}\text { Treatment } \\
\text { Burden }\end{array}$ & $\begin{array}{l}1 \text { of } 3 \\
(33 \%)\end{array}$ & $\begin{array}{l}2 \text { of } 5 \\
(40 \%)\end{array}$ & $\begin{array}{l}1 \text { of } 7 \\
(14 \%)\end{array}$ & $\begin{array}{r}5 \text { of } 12 \\
(42 \%)\end{array}$ & $\begin{array}{r}1 \text { of } 1 \\
(100 \%)\end{array}$ & $\begin{array}{r}1 \text { of } 1 \\
(100 \%)\end{array}$ & $\begin{array}{l}1 \text { of } 2 \\
(50 \%)\end{array}$ & $\begin{array}{r}0 \text { of } 1 \\
(0 \%)\end{array}$ & $\begin{array}{r}1 \text { of } 1 \\
(100 \%)\end{array}$ & None & None & None \\
\hline $\begin{array}{l}\text { Health } \\
\text { Perception }\end{array}$ & $\begin{array}{r}2 \text { of } 2 \\
(100 \%)\end{array}$ & $\begin{array}{l}1 \text { of } 4 \\
(25 \%)\end{array}$ & $\begin{array}{l}4 \text { of } 7 \\
(57 \%)\end{array}$ & $\begin{array}{r}9 \text { of } 11 \\
(82 \%)\end{array}$ & $\begin{array}{r}1 \text { of } 1 \\
(100 \%)\end{array}$ & $\begin{array}{r}1 \text { of } 1 \\
(100 \%)\end{array}$ & $\begin{array}{r}2 \text { of } 2 \\
(100 \%)\end{array}$ & $\begin{array}{r}1 \text { of } 1 \\
(100 \%)\end{array}$ & $\begin{array}{r}1 \text { of } 1 \\
(100 \%)\end{array}$ & None & None & None \\
\hline $\begin{array}{l}\text { Respiratory } \\
\text { symptoms }\end{array}$ & $\begin{array}{r}2 \text { of } 2 \\
(100 \%)\end{array}$ & $\begin{array}{l}2 \text { of } 4 \\
(50 \%)\end{array}$ & $\begin{array}{l}1 \text { of } 7 \\
(14 \%)\end{array}$ & $\begin{array}{r}7 \text { of } 11 \\
(64 \%)\end{array}$ & $\begin{array}{r}1 \text { of } 1 \\
(100 \%)\end{array}$ & $\begin{array}{r}1 \text { of } 1 \\
(100 \%)\end{array}$ & $\begin{array}{l}1 \text { of } 2 \\
(50 \%)\end{array}$ & $\begin{array}{r}1 \text { of } 1 \\
(100 \%)\end{array}$ & $\begin{array}{r}1 \text { of } 1 \\
(100 \%)\end{array}$ & $\begin{array}{r}1 \text { of } 1 \\
(100 \%)\end{array}$ & $\begin{array}{r}1 \text { of } 1 \\
(100 \%)\end{array}$ & $\begin{array}{r}1 \text { of } 1 \\
(100 \%)\end{array}$ \\
\hline Digestion & $\begin{array}{r}0 \text { of } 2 \\
(0 \%)\end{array}$ & $\begin{array}{l}1 \text { of } 4 \\
(25 \%)\end{array}$ & $\begin{array}{r}0 \text { of } 7 \\
(0 \%)\end{array}$ & $\begin{array}{r}0 \text { of } 11 \\
(0 \%)\end{array}$ & $\begin{array}{r}1 \text { of } 1 \\
(100 \%)\end{array}$ & $\begin{array}{r}1 \text { of } 1 \\
(100 \%)\end{array}$ & $\begin{array}{l}1 \text { of } 2 \\
(50 \%)\end{array}$ & $\begin{array}{r}0 \text { of } 1 \\
(0 \%)\end{array}$ & $\begin{array}{r}0 \text { of } 1 \\
(0 \%)\end{array}$ & $\begin{array}{r}1 \text { of } 1 \\
(100 \%)\end{array}$ & $\begin{array}{r}1 \text { of } 1 \\
(100 \%)\end{array}$ & $\begin{array}{r}1 \text { of } 1 \\
(100 \%)\end{array}$ \\
\hline Weight & $\begin{array}{r}0 \text { of } 2 \\
(0 \%)\end{array}$ & $\begin{array}{l}1 \text { of } 4 \\
(25 \%)\end{array}$ & $\begin{array}{l}6 \text { of } 7 \\
(86 \%)\end{array}$ & $\begin{array}{r}6 \text { of } 11 \\
(55 \%)\end{array}$ & $\begin{array}{c}1 \text { of } 1 \\
(100 \%)\end{array}$ & $\begin{array}{r}1 \text { of } 1 \\
(100 \%)\end{array}$ & $\begin{array}{r}2 \text { of } 2 \\
(100 \%)\end{array}$ & $\begin{array}{r}0 \text { of } 1 \\
(0 \%)\end{array}$ & $\begin{array}{r}1 \text { of } 1 \\
(100 \%)\end{array}$ & $\begin{array}{r}0 \text { of } 1 \\
(0 \%)\end{array}$ & $\begin{array}{c}1 \text { of } 1 \\
(100 \%)\end{array}$ & $\begin{array}{r}0 \text { of } 1 \\
(0 \%)\end{array}$ \\
\hline
\end{tabular}


Table A.5- Proportion of studies reporting statistically significant multivariable associations between candidate factors and domains of the CFQ-R 14+.

\begin{tabular}{|c|c|c|c|c|c|c|c|c|c|c|c|c|}
\hline \multirow[b]{2}{*}{$\begin{array}{l}\text { CFQ-R 14+ } \\
\text { Domains }\end{array}$} & \multirow[b]{2}{*}{ Age } & \multirow[b]{2}{*}{ Gender } & \multirow[b]{2}{*}{ BMI } & \multirow[b]{2}{*}{$\mathrm{FEV}_{1} \%$} & \multirow[b]{2}{*}{ Employment } & \multicolumn{3}{|c|}{$\begin{array}{l}\text { Socio-Demographic and Clinical Factors } \\
\text { (Investigated in } \geq 2 \text { studies) }\end{array}$} & \multirow[b]{2}{*}{$\begin{array}{l}\text { Pseudomonas } \\
\text { aeruginosa } \\
\text { infection }\end{array}$} & \multirow[b]{2}{*}{$\begin{array}{c}\text { Symptom } \\
\text { Burden: } \\
\text { Psychological }\end{array}$} & \multirow[b]{2}{*}{$\begin{array}{c}\text { Symptom } \\
\text { Burden: } \\
\text { Gastrointestinal }\end{array}$} & \multirow[b]{2}{*}{$\begin{array}{l}\text { Symptom } \\
\text { Burden: } \\
\text { Respiratory }\end{array}$} \\
\hline & & & & & & Depression & $\begin{array}{l}\text { Pulmonary } \\
\text { exacerbation }\end{array}$ & $\begin{array}{l}\text { Frequency of } \\
\text { exacerbation }\end{array}$ & & & & \\
\hline $\begin{array}{l}\text { Physical } \\
\text { functioning }\end{array}$ & $\begin{array}{l}1 \text { of } 2 \\
(50 \%)\end{array}$ & $\begin{array}{r}2 \text { of } 2 \\
(100 \%)\end{array}$ & $\begin{array}{r}0 \text { of } 1 \\
(0 \%)\end{array}$ & $\begin{array}{r}2 \text { of } 2 \\
(100 \%)\end{array}$ & $\begin{array}{r}1 \text { of } 1 \\
(100 \%)\end{array}$ & $\begin{array}{r}0 \text { of } 1 \\
(0 \%)\end{array}$ & $\begin{array}{r}1 \text { of } 1 \\
(100 \%)\end{array}$ & $\begin{array}{l}1 \text { of } 2 \\
(50 \%)\end{array}$ & $\begin{array}{r}0 \text { of } 1 \\
(0 \%)\end{array}$ & $\begin{array}{r}0 \text { of } 1 \\
(0 \%)\end{array}$ & $\begin{array}{r}0 \text { of } 1 \\
(0 \%)\end{array}$ & $\begin{array}{r}1 \text { of } 1 \\
(100 \%)\end{array}$ \\
\hline Energy & $\begin{array}{r}0 \text { of } 2 \\
(0 \%)\end{array}$ & $\begin{array}{l}1 \text { of } 2 \\
(50 \%)\end{array}$ & $\begin{array}{r}1 \text { of } 1 \\
(100 \%)\end{array}$ & $\begin{array}{l}1 \text { of } 2 \\
(50 \%)\end{array}$ & $\begin{array}{r}0 \text { of } 1 \\
(0 \%)\end{array}$ & $\begin{array}{r}0 \text { of } 1 \\
(0 \%)\end{array}$ & $\begin{array}{r}1 \text { of } 1 \\
(100 \%)\end{array}$ & $\begin{array}{l}1 \text { of } 2 \\
(50 \%)\end{array}$ & $\begin{array}{r}0 \text { of } 1 \\
(0 \%)\end{array}$ & $\begin{array}{r}1 \text { of } 1 \\
(100 \%)\end{array}$ & $\begin{array}{r}0 \text { of } 1 \\
(0 \%)\end{array}$ & $\begin{array}{r}1 \text { of } 1 \\
(100 \%)\end{array}$ \\
\hline Emotion & $\begin{array}{r}0 \text { of } 2 \\
(0 \%)\end{array}$ & $\begin{array}{l}1 \text { of } 2 \\
(50 \%)\end{array}$ & $\begin{array}{r}0 \text { of } 1 \\
(0 \%)\end{array}$ & $\begin{array}{r}0 \text { of } 2 \\
(0 \%)\end{array}$ & $\begin{array}{r}0 \text { of } 1 \\
(0 \%)\end{array}$ & $\begin{array}{r}1 \text { of } 1 \\
(100 \%)\end{array}$ & $\begin{array}{r}0 \text { of } 1 \\
(0 \%)\end{array}$ & $\begin{array}{l}1 \text { of } 2 \\
(50 \%)\end{array}$ & $\begin{array}{r}0 \text { of } 1 \\
(0 \%)\end{array}$ & $\begin{array}{r}1 \text { of } 1 \\
(100 \%)\end{array}$ & None & $\begin{array}{r}1 \text { of } 1 \\
(100 \%)\end{array}$ \\
\hline $\begin{array}{l}\text { Social } \\
\text { functioning }\end{array}$ & $\begin{array}{l}1 \text { of } 2 \\
(50 \%)\end{array}$ & $\begin{array}{l}1 \text { of } 2 \\
(50 \%)\end{array}$ & $\begin{array}{r}0 \text { of } 1 \\
(0 \%)\end{array}$ & $\begin{array}{r}0 \text { of } 2 \\
(0 \%)\end{array}$ & $\begin{array}{r}1 \text { of } 1 \\
(100 \%)\end{array}$ & $\begin{array}{r}0 \text { of } 1 \\
(0 \%)\end{array}$ & $\begin{array}{r}0 \text { of } 1 \\
(0 \%)\end{array}$ & $\begin{array}{l}1 \text { of } 2 \\
(50 \%)\end{array}$ & $\begin{array}{r}0 \text { of } 1 \\
(0 \%)\end{array}$ & $\begin{array}{r}1 \text { of } 1 \\
(100 \%)\end{array}$ & $\begin{array}{r}0 \text { of } 1 \\
(0 \%)\end{array}$ & $\begin{array}{r}1 \text { of } 1 \\
(100 \%)\end{array}$ \\
\hline $\begin{array}{l}\text { Role } \\
\text { functioning }\end{array}$ & $\begin{array}{r}0 \text { of } 2 \\
(0 \%)\end{array}$ & $\begin{array}{r}0 \text { of } 2 \\
(0 \%)\end{array}$ & $\begin{array}{r}0 \text { of } 1 \\
(0 \%)\end{array}$ & $\begin{array}{l}1 \text { of } 2 \\
(50 \%)\end{array}$ & $\begin{array}{r}1 \text { of } 1 \\
(100 \%)\end{array}$ & $\begin{array}{r}0 \text { of } 1 \\
(0 \%)\end{array}$ & $\begin{array}{r}1 \text { of } 1 \\
(100 \%)\end{array}$ & $\begin{array}{r}2 \text { of } 2 \\
(100 \%)\end{array}$ & $\begin{array}{r}0 \text { of } 1 \\
(0 \%)\end{array}$ & $\begin{array}{r}1 \text { of } 1 \\
(100 \%)\end{array}$ & $\begin{array}{r}1 \text { of } 1 \\
(100 \%)\end{array}$ & $\begin{array}{r}1 \text { of } 1 \\
(100 \%)\end{array}$ \\
\hline $\begin{array}{l}\text { Eating } \\
\text { disturbances }\end{array}$ & $\begin{array}{r}0 \text { of } 2 \\
(0 \%)\end{array}$ & $\begin{array}{r}0 \text { of } 2 \\
(0 \%)\end{array}$ & $\begin{array}{r}0 \text { of } 1 \\
(0 \%)\end{array}$ & $\begin{array}{l}1 \text { of } 2 \\
(50 \%)\end{array}$ & $\begin{array}{r}0 \text { of } 1 \\
(0 \%)\end{array}$ & $\begin{array}{r}1 \text { of } 1 \\
(100 \%)\end{array}$ & $\begin{array}{r}0 \text { of } 1 \\
(0 \%)\end{array}$ & $\begin{array}{r}2 \text { of } 2 \\
(100 \%)\end{array}$ & $\begin{array}{r}0 \text { of } 1 \\
(0 \%)\end{array}$ & $\begin{array}{r}1 \text { of } 1 \\
(100 \%)\end{array}$ & $\begin{array}{r}1 \text { of } 1 \\
(100 \%)\end{array}$ & $\begin{array}{r}0 \text { of } 1 \\
(0 \%)\end{array}$ \\
\hline Body image & $\begin{array}{r}0 \text { of } 2 \\
(0 \%)\end{array}$ & $\begin{array}{r}2 \text { of } 2 \\
(100 \%)\end{array}$ & $\begin{array}{r}1 \text { of } 1 \\
(100 \%)\end{array}$ & $\begin{array}{l}1 \text { of } 2 \\
(50 \%)\end{array}$ & $\begin{array}{r}0 \text { of } 1 \\
(0 \%)\end{array}$ & $\begin{array}{r}1 \text { of } 1 \\
(100 \%)\end{array}$ & $\begin{array}{l}0 \text { of } 1 \\
(0 \%)\end{array}$ & $\begin{array}{r}2 \text { of } 2 \\
(100 \%)\end{array}$ & $\begin{array}{r}0 \text { of } 1 \\
(0 \%)\end{array}$ & $\begin{array}{r}1 \text { of } 1 \\
(100 \%)\end{array}$ & $\begin{array}{r}1 \text { of } 1 \\
(100 \%)\end{array}$ & $\begin{array}{r}0 \text { of } 1 \\
(0 \%)\end{array}$ \\
\hline $\begin{array}{l}\text { Treatment } \\
\text { burden }\end{array}$ & $\begin{array}{r}2 \text { of } 2 \\
(100 \%)\end{array}$ & $\begin{array}{l}1 \text { of } 2 \\
(50 \%)\end{array}$ & $\begin{array}{r}0 \text { of } 1 \\
(0 \%)\end{array}$ & $\begin{array}{r}2 \text { of } 2 \\
(100 \%)\end{array}$ & $\begin{array}{r}0 \text { of } 1 \\
(0 \%)\end{array}$ & $\begin{array}{r}0 \text { of } 1 \\
(0 \%)\end{array}$ & $\begin{array}{r}0 \text { of } 1 \\
(0 \%)\end{array}$ & $\begin{array}{l}1 \text { of } 2 \\
(50 \%)\end{array}$ & $\begin{array}{r}0 \text { of } 1 \\
(0 \%)\end{array}$ & $\begin{array}{r}0 \text { of } 1 \\
(0 \%)\end{array}$ & $\begin{array}{r}0 \text { of } 1 \\
(0 \%)\end{array}$ & $\begin{array}{r}1 \text { of } 1 \\
(100 \%)\end{array}$ \\
\hline $\begin{array}{l}\text { Health } \\
\text { perception }\end{array}$ & $\begin{array}{r}0 \text { of } 2 \\
(0 \%)\end{array}$ & $\begin{array}{r}0 \text { of } 2 \\
(0 \%)\end{array}$ & $\begin{array}{r}0 \text { of } 1 \\
(0 \%)\end{array}$ & $\begin{array}{l}1 \text { of } 2 \\
(50 \%)\end{array}$ & $\begin{array}{r}0 \text { of } 1 \\
(0 \%)\end{array}$ & $\begin{array}{l}0 \text { of } 1 \\
(0 \%)\end{array}$ & $\begin{array}{r}1 \text { of } 1 \\
(100 \%)\end{array}$ & $\begin{array}{l}1 \text { of } 2 \\
(50 \%)\end{array}$ & $\begin{array}{r}0 \text { of } 1 \\
(0 \%)\end{array}$ & $\begin{array}{l}0 \text { of } 1 \\
(0 \%)\end{array}$ & $\begin{array}{r}0 \text { of } 1 \\
(0 \%)\end{array}$ & $\begin{array}{r}1 \text { of } 1 \\
(100 \%)\end{array}$ \\
\hline $\begin{array}{l}\text { Respiratory } \\
\text { symptoms }\end{array}$ & $\begin{array}{r}0 \text { of } 2 \\
(0 \%)\end{array}$ & $\begin{array}{r}0 \text { of } 2 \\
(0 \%)\end{array}$ & $\begin{array}{r}0 \text { of } 1 \\
(0 \%)\end{array}$ & $\begin{array}{l}1 \text { of } 2 \\
(50 \%)\end{array}$ & $\begin{array}{r}0 \text { of } 1 \\
(0 \%)\end{array}$ & $\begin{array}{r}0 \text { of } 1 \\
(0 \%)\end{array}$ & $\begin{array}{r}1 \text { of } 1 \\
(100 \%)\end{array}$ & $\begin{array}{r}2 \text { of } 2 \\
(100 \%)\end{array}$ & $\begin{array}{r}0 \text { of } 1 \\
(0 \%)\end{array}$ & $\begin{array}{r}0 \text { of } 1 \\
(0 \%)\end{array}$ & $\begin{array}{r}0 \text { of } 1 \\
(0 \%)\end{array}$ & $\begin{array}{r}1 \text { of } 1 \\
(100 \%)\end{array}$ \\
\hline Digestion & $\begin{array}{r}0 \text { of } 2 \\
(0 \%)\end{array}$ & $\begin{array}{r}0 \text { of } 2 \\
(0 \%)\end{array}$ & $\begin{array}{r}0 \text { of } 1 \\
(0 \%)\end{array}$ & $\begin{array}{r}0 \text { of } 2 \\
(0 \%)\end{array}$ & $\begin{array}{r}0 \text { of } 1 \\
(0 \%)\end{array}$ & $\begin{array}{r}0 \text { of } 1 \\
(0 \%)\end{array}$ & $\begin{array}{r}0 \text { of } 1 \\
(0 \%)\end{array}$ & $\begin{array}{r}0 \text { of } 2 \\
(0 \%)\end{array}$ & $\begin{array}{r}0 \text { of } 1 \\
(0 \%)\end{array}$ & $\begin{array}{r}0 \text { of } 1 \\
(0 \%)\end{array}$ & $\begin{array}{r}0 \text { of } 1 \\
(0 \%)\end{array}$ & $\begin{array}{r}1 \text { of } 1 \\
(100 \%)\end{array}$ \\
\hline Weight & $\begin{array}{r}0 \text { of } 2 \\
(0 \%)\end{array}$ & $\begin{array}{l}1 \text { of } 2 \\
(50 \%)\end{array}$ & $\begin{array}{r}1 \text { of } 1 \\
(100 \%)\end{array}$ & $\begin{array}{l}1 \text { of } 2 \\
(50 \%)\end{array}$ & $\begin{array}{r}0 \text { of } 1 \\
(0 \%)\end{array}$ & $\begin{array}{r}0 \text { of } 1 \\
(0 \%)\end{array}$ & $\begin{array}{r}0 \text { of } 1 \\
(0 \%)\end{array}$ & $\begin{array}{r}2 \text { of } 2 \\
(100 \%)\end{array}$ & $\begin{array}{r}0 \text { of } 1 \\
(0 \%)\end{array}$ & $\begin{array}{r}1 \text { of } 1 \\
(100 \%)\end{array}$ & $\begin{array}{r}1 \text { of } 1 \\
(100 \%)\end{array}$ & $\begin{array}{r}1 \text { of } 1 \\
(100 \%)\end{array}$ \\
\hline
\end{tabular}




\section{Appendix B: Data Collection Form for Sinus Symptoms and Nasal Endoscopy}

CYSTIC FIBROSIS AND SINUSITS OBSERVATIONAL STUDY - SINUS DATA

DATE:

SUBJECT ID:

1. PREVIOUSLY VISITED AN ENT SPECIALIST?

FREQUENCY:

YEARS AGO:

2. CURRENT TREATMENT?

\begin{tabular}{|c|c|c|l|l|}
\hline TREATMENTS & YES & NO & FREQUENCY & COMMENTS \\
\hline INCS & $\square$ & $\square$ & & \\
\hline ANTIBIOTICS & $\square$ & $\square$ & & \\
\hline ORAL STEROIDS & $\square$ & $\square$ & & \\
\hline SALINE IRRIGATION & $\square$ & $\square$ & & \\
\hline
\end{tabular}

3. HISTORY OF SINUS SURGERY?

FREQUENCY:

YEARS AGO:

4. HISTORY OF POLYPECTOMY?

FREQUENCY:

YEARS AGO:

YES $\square \quad$ NO $\square$

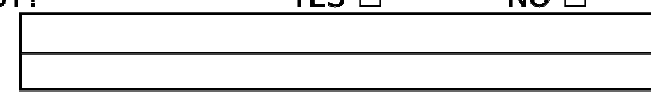

5. SUBJECTIVE SYMPTOMS PRESENTING GREATER THAN 12 WEEKS

\begin{tabular}{|c|c|c|c|c|}
\hline SYMPTOMS & NONE & MILD & MODERATE & SEVERE \\
\hline CONGESTION & $\square$ & $\square$ & $\square$ & $\square$ \\
\hline PAIN/PRESSURE & $\square$ & $\square$ & $\square$ & $\square$ \\
\hline OBSTRUCTION & $\square$ & $\square$ & $\square$ & $\square$ \\
\hline PURULENT DISCHARGE & $\square$ & $\square$ & $\square$ & $\square$ \\
\hline HYPOSMIA/ANOSMIA & $\square$ & $\square$ & $\square$ & $\square$ \\
\hline
\end{tabular}

6. OBJECTIVE FINDINGS

\begin{tabular}{|c|c|c|l|}
\hline FINDINGS & YES & NO & COMMENTS: \\
\hline NASAL POLYPOSIS & $\square$ & $\square$ & \\
\hline DISCOLORED MUCUS & $\square$ & $\square$ & \\
\hline MM/ ETH EDEMA & $\square$ & $\square$ & \\
\hline PUS FROM OMC & $\square$ & $\square$ & \\
\hline
\end{tabular}

7. DIAGNOSIS?

\begin{tabular}{|l|c|c|l|}
\cline { 2 - 4 } \multicolumn{1}{c|}{} & YES & NO & COMMENTS: \\
\hline CHRONIC RHINOSINUSITIS & $\square$ & $\square$ & \\
\hline OTHER: & $\square$ & $\square$ & \\
\hline
\end{tabular}
8. DOES PATIENT WARRENT SINUS-REALATED CARE?
YES $\square$
NO $\square$
COMMENTS:

9. ADDITIONAL COMMENTS: 


\section{Appendix C: Comparing Participants With or Without Missing Data}

Table C.1- Comparison of participants with or without missing data regarding CRS status.

\begin{tabular}{|c|c|c|c|c|}
\hline \multirow{5}{*}{\begin{tabular}{|l} 
Continuous \\
Socio-demographic Factors \\
Age $^{1}$ \\
(years $)$ \\
Body-mass index \\
$\left(\mathrm{kg} / \mathrm{m}^{2}\right)$
\end{tabular}} & \multicolumn{2}{|c|}{$\begin{array}{c}\text { Missing } \\
\text { CRS Status } \\
(n=7)\end{array}$} & \multicolumn{2}{|c|}{$\begin{array}{c}\text { Not Missing } \\
\text { CRS Status } \\
(n=106)\end{array}$} \\
\hline & Mean & Standard & Mean & Standard \\
\hline & & Deviation & & Deviation \\
\hline & 39.0 & 11.3 & 36.0 & 13.0 \\
\hline & 23.8 & 3.4 & 23.3 & 3.5 \\
\hline Categorical & $\mathrm{n}$ & Absolute & $\mathrm{n}$ & Absolute \\
\hline Socio-demographic Factors & & $\begin{array}{r}\text { Frequency } \\
(\%)\end{array}$ & & $\begin{array}{r}\text { Frequency } \\
(\%)\end{array}$ \\
\hline Males & 5 & 71.4 & 70 & 66.0 \\
\hline $\begin{array}{l}\text { Current employment or } \\
\text { school status }\end{array}$ & 3 & 42.9 & 64 & 61.5 \\
\hline Continuous & Mean & Standard & Mean & Standard \\
\hline Clinical Characteristics & & Deviation & & Deviation \\
\hline $\begin{array}{l}\text { Lung Function } \\
\left(\mathrm{FEV}_{1} \% \text { predicted }\right)\end{array}$ & 77.9 & 27.2 & 73.1 & 25.8 \\
\hline $\begin{array}{l}\text { Age of CF diagnosis } \\
\text { (years) }\end{array}$ & 15.5 & 20.9 & 9.3 & 13.4 \\
\hline $\begin{array}{l}\text { Time since CF diagnosis } \\
\text { (years) }\end{array}$ & 21.0 & 14.2 & 26.5 & 12.3 \\
\hline Categorical & $\mathrm{n}$ & Absolute & $\mathrm{n}$ & Absolute \\
\hline Clinical Characteristics & & $\begin{array}{r}\text { Frequency } \\
(\%)\end{array}$ & & $\begin{array}{r}\text { Frequency } \\
(\%)\end{array}$ \\
\hline $\begin{array}{l}\text { Class I to III Genotype } \\
\text { Mutations }\end{array}$ & 4 & 57.1 & 75 & 75.8 \\
\hline Pancreatic Insufficiency & 6 & 85.7 & 78 & 73.6 \\
\hline $\begin{array}{l}\text { Chronic P.aeruginosa } \\
\text { Infection }\end{array}$ & 1 & 14.3 & 43 & 43.0 \\
\hline Depression $^{2}$ & 0 & 0 & 20 & 18.9 \\
\hline History of Lung Transplant ${ }^{2}$ & 3 & 42.9 & 13 & 12.3 \\
\hline
\end{tabular}


Table C.2- Comparison of sinus-related characteristics, socio-demographics and clinical characteristics between participants with or without missing CFQ-R 14+ domain scores.

\begin{tabular}{|c|c|c|c|c|}
\hline \multirow{2}{*}{ Sinus-related Characteristics } & \multicolumn{2}{|c|}{$\begin{array}{c}\text { Missing } \\
\text { CFQ-R 14+ Domain Scores } \\
(n=6)\end{array}$} & \multicolumn{2}{|c|}{$\begin{array}{c}\text { Not Missing } \\
\text { CFQ-R 14+ Domain Scores } \\
(\mathrm{n}=107)\end{array}$} \\
\hline & $\mathrm{n}$ & $\begin{array}{r}\text { Absolute } \\
\text { Frequency } \\
(\%)\end{array}$ & $\mathrm{n}$ & $\begin{array}{r}\text { Absolute } \\
\text { Frequency } \\
(\%)\end{array}$ \\
\hline CRS Positive & 2 & 33.3 & 66 & 61.7 \\
\hline Missing & 3 & 50.0 & 4 & 3.7 \\
\hline Symptomatic & 1 & 16.7 & 75 & 70.1 \\
\hline Missing & 3 & 50.0 & 5 & 4.7 \\
\hline History of Sinus Surgery & 1 & 16.7 & 44 & 41.9 \\
\hline Missing & 3 & 50.0 & 4 & 3.7 \\
\hline Continuous & Mean & Standard & Mean & Standard \\
\hline Socio-demographic Factors & & Deviation & & Deviation \\
\hline $\begin{array}{l}\text { Age } \\
\text { (years) }\end{array}$ & 40.2 & 11.9 & 35.9 & 12.9 \\
\hline $\begin{array}{l}\text { Body-mass index } \\
\left(\mathrm{kg} / \mathrm{m}^{2}\right)\end{array}$ & 23.9 & 3.7 & 23.3 & 3.5 \\
\hline Categorical & $\mathrm{n}$ & Absolute & $\mathrm{n}$ & Absolute \\
\hline Socio-demographic Factors & & $\begin{array}{r}\text { Frequency } \\
(\%)\end{array}$ & & $\begin{array}{r}\text { Frequency } \\
(\%)\end{array}$ \\
\hline Males & 4 & 66.7 & 71 & 66.4 \\
\hline $\begin{array}{l}\text { Current employment or } \\
\text { school status }\end{array}$ & 0 & 0 & 67 & 62.6 \\
\hline Missing & 5 & 83.3 & 0 & 0 \\
\hline Continuous & Mean & Standard & Mean & Standard \\
\hline Clinical Characteristics & & Deviation & & Deviation \\
\hline $\begin{array}{l}\text { Lung Function } \\
\text { (FEV } \text { FE predicted) }^{\circ} \%\end{array}$ & 66.5 & 26.4 & 73.8 & 25.9 \\
\hline $\begin{array}{l}\text { Age of CF diagnosis } \\
\text { (years) }\end{array}$ & 15.5 & 17.7 & 9.4 & 13.7 \\
\hline $\begin{array}{l}\text { Time since CF diagnosis } \\
\text { (years) }\end{array}$ & 22.0 & 12.3 & 26.4 & 12.4 \\
\hline Categorical & $\mathrm{n}$ & Absolute & $\mathrm{n}$ & Absolute \\
\hline Clinical Characteristics & & $\begin{array}{r}\text { Frequency } \\
(\%)\end{array}$ & & $\begin{array}{r}\text { Frequency } \\
(\%)\end{array}$ \\
\hline $\begin{array}{l}\text { Class I to III Genotype } \\
\text { Mutations }\end{array}$ & 3 & 50.0 & 76 & 71.0 \\
\hline Missing & 1 & 16.7 & 7 & 6.5 \\
\hline Pancreatic Insufficiency & 4 & 66.7 & 80 & 74.8 \\
\hline $\begin{array}{l}\text { Chronic P.aeruginosa } \\
\text { Infection }\end{array}$ & 2 & 33.3 & 42 & 39.3 \\
\hline Missing & 2 & 33.3 & 7 & 6.5 \\
\hline Depression & 1 & 16.7 & 19 & 17.8 \\
\hline History of Lung Transplant & 2 & 33.3 & 14 & 13.1 \\
\hline
\end{tabular}




\section{Appendix D: Associations Between Covariates and CFQ-R 14+ Domains}

Table D.1- Bivariate associations between socio-demographic factors and CFQ-R 14+ domains.

\begin{tabular}{|c|c|c|c|c|c|c|c|c|}
\hline $\begin{array}{l}\text { CFQ-R 14+ } \\
\text { Domains }\end{array}$ & \multicolumn{2}{|c|}{$\begin{array}{c}\text { Age } \\
(\mathbf{n}=107)\end{array}$} & \multicolumn{2}{|c|}{$\begin{array}{c}\begin{array}{c}\text { Gender } \\
(\mathbf{n}=\mathbf{1 0 7})\end{array} \\
(\text { Males vs. Females })\end{array}$} & \multicolumn{2}{|c|}{$\begin{array}{c}\text { Body-mass index } \\
(n=107)\end{array}$} & \multicolumn{2}{|c|}{$\begin{array}{c}\text { Current } \\
\text { employment or } \\
\text { school status } \\
(\mathbf{n}=\mathbf{1 0 7}) \\
(\text { Yes vs. No })\end{array}$} \\
\hline Physical functioning $^{1}$ & -0.39 & $<0.001$ & 13.06 & 0.02 & 0.16 & 0.10 & 22.56 & $<0.001$ \\
\hline Energy & -0.11 & 0.28 & 8.54 & 0.06 & 0.05 & 0.62 & 6.39 & 0.15 \\
\hline Emotion & -0.06 & 0.55 & 3.99 & 0.27 & 0.07 & 0.49 & 7.36 & 0.04 \\
\hline Social functioning & -0.29 & 0.002 & 2.51 & 0.52 & 0.01 & 0.98 & 8.91 & 0.02 \\
\hline Role functioning ${ }^{1}$ & 0.16 & 0.10 & 1.91 & 0.41 & 0.15 & 0.13 & 16.78 & $<0.001$ \\
\hline Eating disturbances ${ }^{1}$ & -0.13 & 0.18 & -5.14 & 0.16 & 0.24 & 0.01 & 12.04 & 0.008 \\
\hline Body image $^{1}$ & -0.06 & 0.52 & -9.31 & 0.11 & 0.42 & $<0.0001$ & 11.27 & 0.04 \\
\hline Treatment burden & -0.01 & 0.93 & 1.67 & 0.72 & 0.09 & 0.33 & 6.89 & 0.14 \\
\hline Health perception & -0.27 & 0.01 & -1.51 & 0.75 & 0.11 & 0.27 & 11.34 & 0.01 \\
\hline Respiratory symptoms & 0.004 & 0.96 & 2.17 & 0.62 & 0.08 & 0.44 & 5.17 & 0.22 \\
\hline Digestion $^{1}$ & -0.09 & 0.38 & 3.28 & 0.91 & -0.07 & 0.49 & -1.49 & 0.38 \\
\hline Weight ${ }^{1}$ & 0.12 & 0.22 & -24.68 & 0.001 & 0.61 & $<0.0001$ & 11.96 & 0.15 \\
\hline
\end{tabular}

1. Non-parametric Spearman's correlation or Wilcoxon Rank-sum test performed. 
Table D.2- Bivariate associations between continuous clinical characteristics and CFQ-R 14+ domains.

\begin{tabular}{|c|c|c|c|c|c|c|}
\hline \multirow[b]{2}{*}{$\begin{array}{l}\text { CFQ-R 14+ } \\
\text { Domains }\end{array}$} & \multicolumn{2}{|c|}{$\begin{array}{l}\text { Lung function } \\
(\mathbf{n}=107)\end{array}$} & \multicolumn{2}{|c|}{$\begin{array}{c}\text { Age of CF } \\
\text { diagnosis } \\
(n=105)\end{array}$} & \multicolumn{2}{|c|}{$\begin{array}{c}\text { Time since } \\
\text { CF diagnosis } \\
(n=105)\end{array}$} \\
\hline & $\begin{array}{l}\text { Correlation } \\
\text { Coefficient }\end{array}$ & $\mathrm{p}$ & $\begin{array}{l}\text { Correlation } \\
\text { Coefficient }\end{array}$ & $\mathrm{p}$ & $\begin{array}{l}\text { Correlation } \\
\text { Coefficient }\end{array}$ & $\mathrm{p}$ \\
\hline Physical functioning & 0.42 & $<0.001$ & -0.19 & 0.04 & -0.14 & 0.17 \\
\hline Energy & 0.01 & 0.89 & -0.17 & 0.08 & 0.09 & 0.36 \\
\hline Emotion & 0.21 & 0.04 & -0.11 & 0.24 & 0.07 & 0.45 \\
\hline Social functioning & 0.26 & 0.01 & -0.35 & $<0.001$ & 0.09 & 0.35 \\
\hline Role functioning $^{1}$ & 0.30 & 0.002 & -0.04 & 0.71 & -0.08 & 0.39 \\
\hline Eating disturbances ${ }^{1}$ & 0.16 & 0.11 & -0.0006 & 0.99 & -0.12 & 0.23 \\
\hline Body image $^{1}$ & 0.25 & 0.01 & 0.16 & 0.11 & -0.13 & 0.19 \\
\hline Treatment burden & 0.36 & $<0.001$ & 0.04 & 0.71 & -0.05 & 0.61 \\
\hline Health perception & 0.34 & $<0.001$ & -0.25 & 0.01 & 0.01 & 0.91 \\
\hline Respiratory symptoms & 0.17 & 0.08 & -0.22 & 0.02 & 0.27 & 0.005 \\
\hline Digestion $^{1}$ & -0.29 & 0.002 & 0.03 & 0.73 & -0.05 & 0.61 \\
\hline Weight $^{1}$ & 0.14 & 0.15 & 0.16 & 0.10 & -0.02 & 0.82 \\
\hline
\end{tabular}


Table D.3- Bivariate associations between categorical clinical characteristics and CFQ-R 14+ domains.

\begin{tabular}{|c|c|c|c|c|c|c|c|c|}
\hline $\begin{array}{l}\text { CFQ-R 14+ } \\
\text { Domains }\end{array}$ & \multicolumn{2}{|c|}{$\begin{array}{c}\text { Class I to III } \\
\text { genotype } \\
\text { mutations } \\
(\text { Yes vs. No })\end{array}$} & \multicolumn{2}{|c|}{ 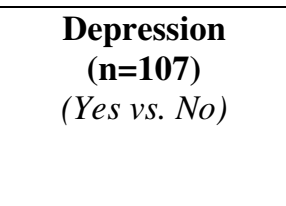 } & \multicolumn{2}{|c|}{$\begin{array}{c}\text { Chronic } \\
\text { P.aeruginosa } \\
\text { infection } \\
(\mathbf{n}=\mathbf{1 0 0}) \\
(\text { Yes vs. No })\end{array}$} & \multicolumn{2}{|c|}{$\begin{array}{c}\text { History of lung } \\
\text { transplant } \\
(\mathbf{n}=\mathbf{1 0 7}) \\
(\text { Yes vs. No })\end{array}$} \\
\hline Physical functioning $^{1}$ & 7.19 & 0.37 & -24.35 & 0.001 & -9.41 & 0.06 & 6.35 & 0.50 \\
\hline Energy & 5.14 & 0.31 & -16.09 & 0.004 & -3.48 & 0.44 & 7.52 & 0.24 \\
\hline Emotion & 3.36 & 0.38 & -10.66 & 0.02 & 2.41 & 0.51 & 4.50 & 0.38 \\
\hline Social functioning & 11.04 & 0.01 & -14.31 & 0.005 & 1.03 & 0.79 & 9.60 & 0.08 \\
\hline Role functioning ${ }^{1}$ & -1.53 & 0.74 & -11.69 & 0.01 & -7.86 & 0.02 & 1.42 & 0.94 \\
\hline Eating disturbances ${ }^{1}$ & -0.34 & 0.57 & -13.69 & 0.005 & -3.03 & 0.21 & 2.50 & 0.83 \\
\hline Body image $^{1}$ & -12.37 & 0.06 & -1.42 & 0.84 & 3.97 & 0.49 & -7.87 & 0.20 \\
\hline Treatment burden & -5.3 & 0.33 & -14.96 & 0.01 & -9.29 & 0.04 & 21.62 & 0.001 \\
\hline Health perception & 8.38 & 0.12 & -17.93 & 0.003 & -4.47 & 0.32 & 16.09 & 0.01 \\
\hline Respiratory symptoms & 7.49 & 0.12 & -9.73 & 0.07 & -2.56 & 0.54 & 28.94 & 0.001 \\
\hline Digestion $^{1}$ & -0.07 & 0.99 & -3.32 & 0.54 & -0.36 & 0.83 & -7.28 & 0.56 \\
\hline Weight ${ }^{1}$ & -16.3 & 0.07 & -3.93 & 0.67 & 11.33 & 0.15 & -8.48 & 0.43 \\
\hline
\end{tabular}




\section{Appendix E: Directed Acyclic Graphs Illustrating the Relationship Between CRS and CFQ-R 14+ Domains}

Figure E.1- Schematic illustrating the relationship between CRS and CFQ-R 14+ Physical Functioning.

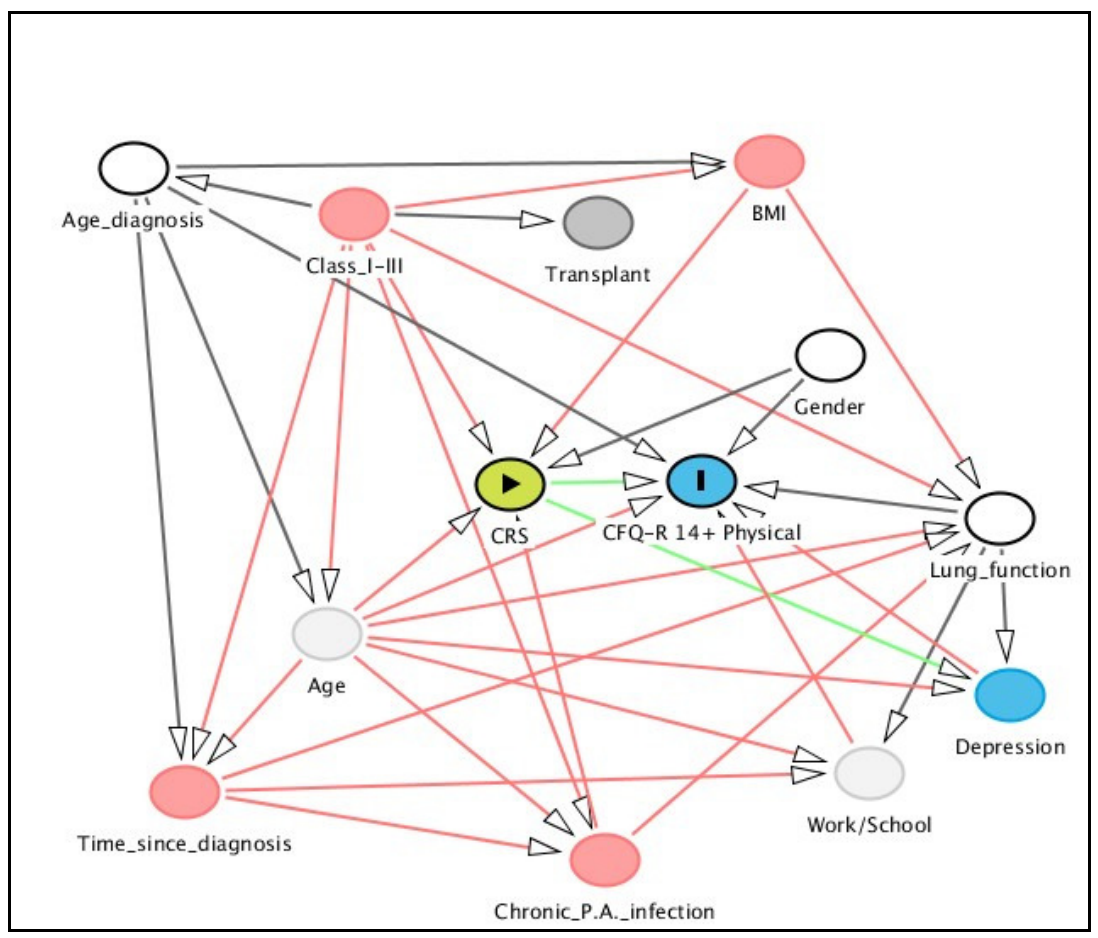


Figure E.2- Schematic illustrating the relationship between CRS and CFQ-R 14+ Energy.

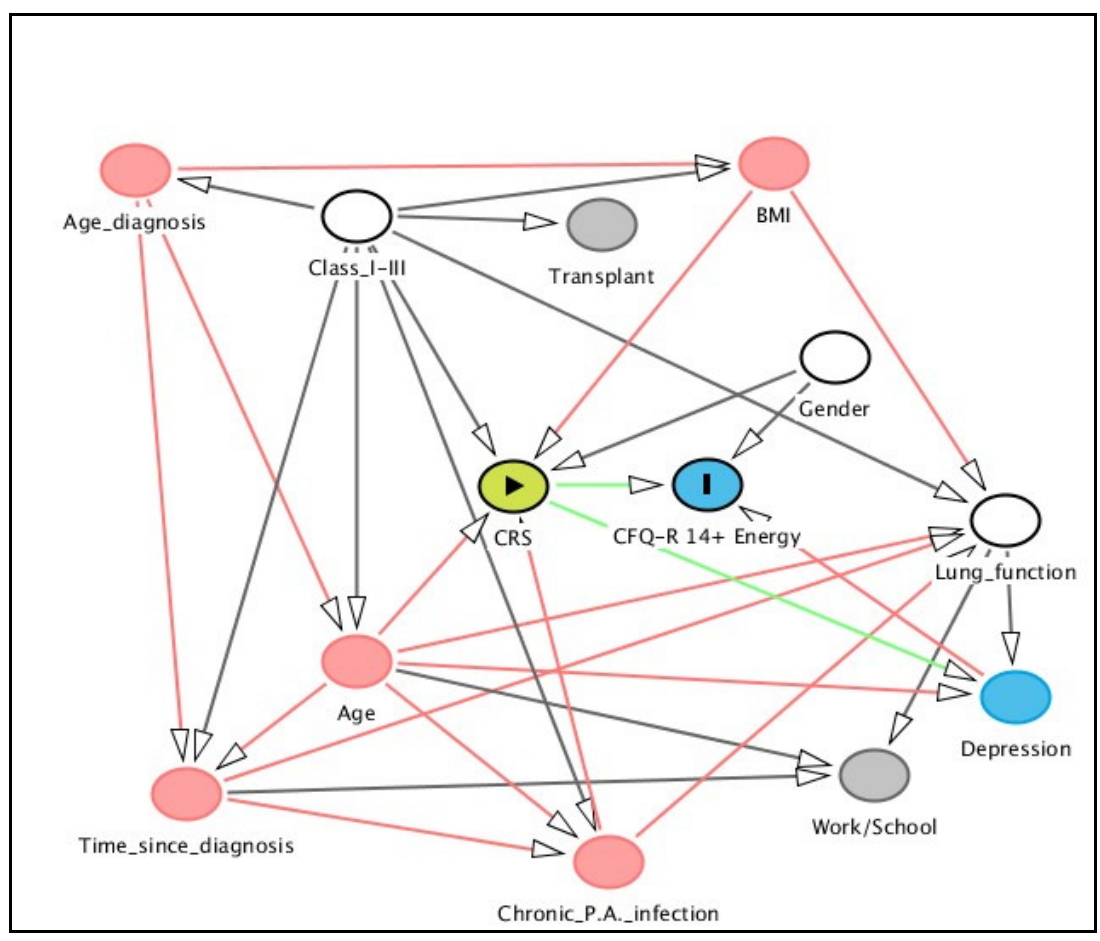


Figure E.3- Schematic illustrating the relationship between CRS and CFQ-R 14+ Emotion.

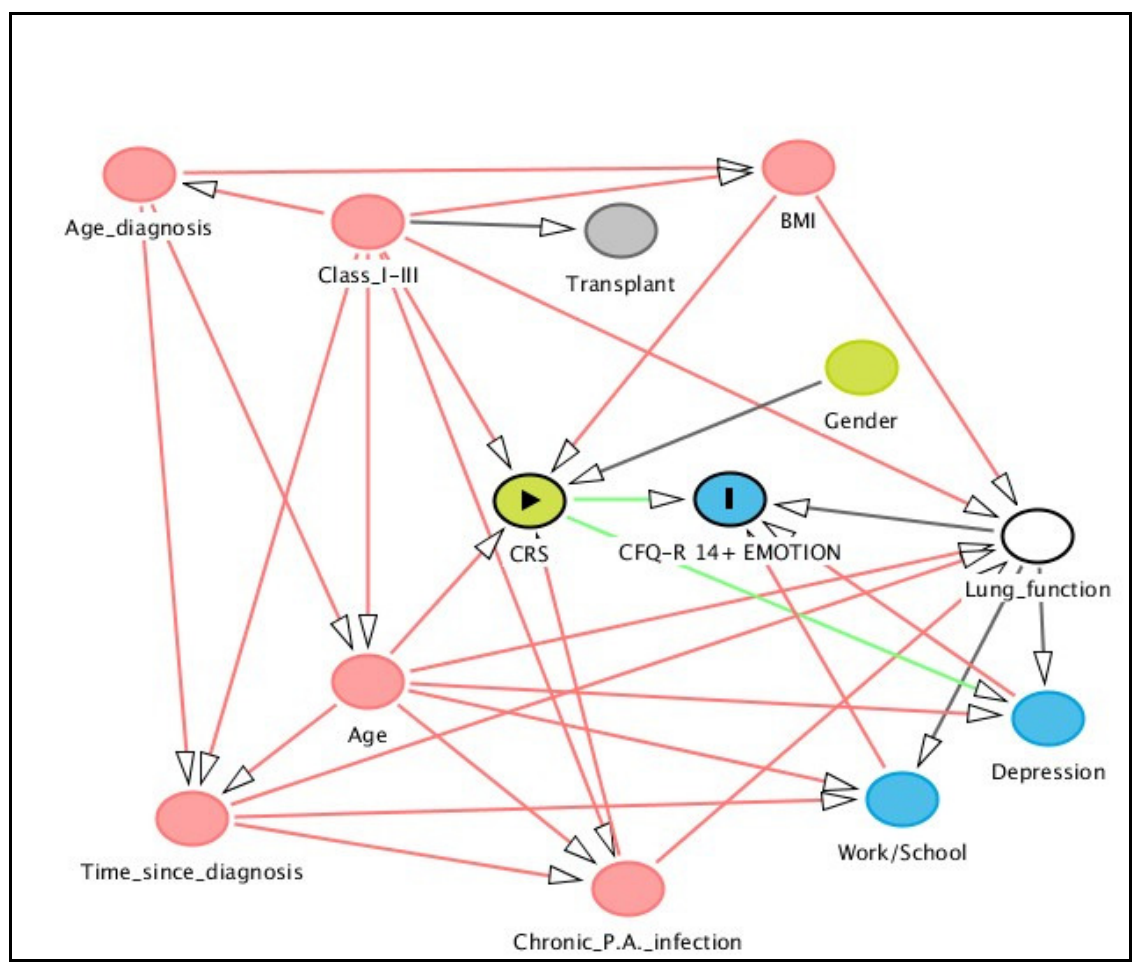

Figure E.4- Schematic illustrating the relationship between CRS and CFQ-R 14+ Social Functioning.

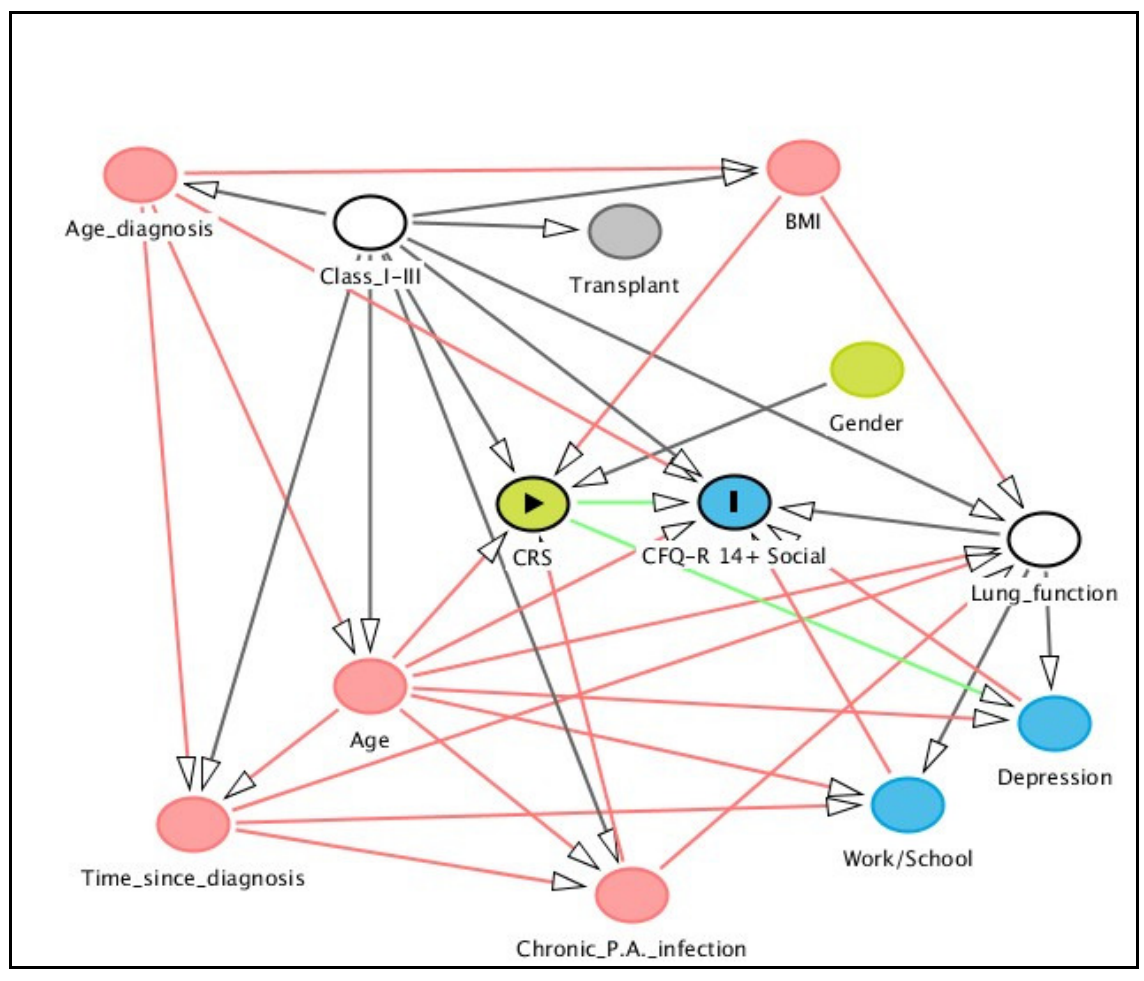


Figure E.5- Schematic illustrating the relationship between CRS and CFQ-R 14+ Role Functioning.

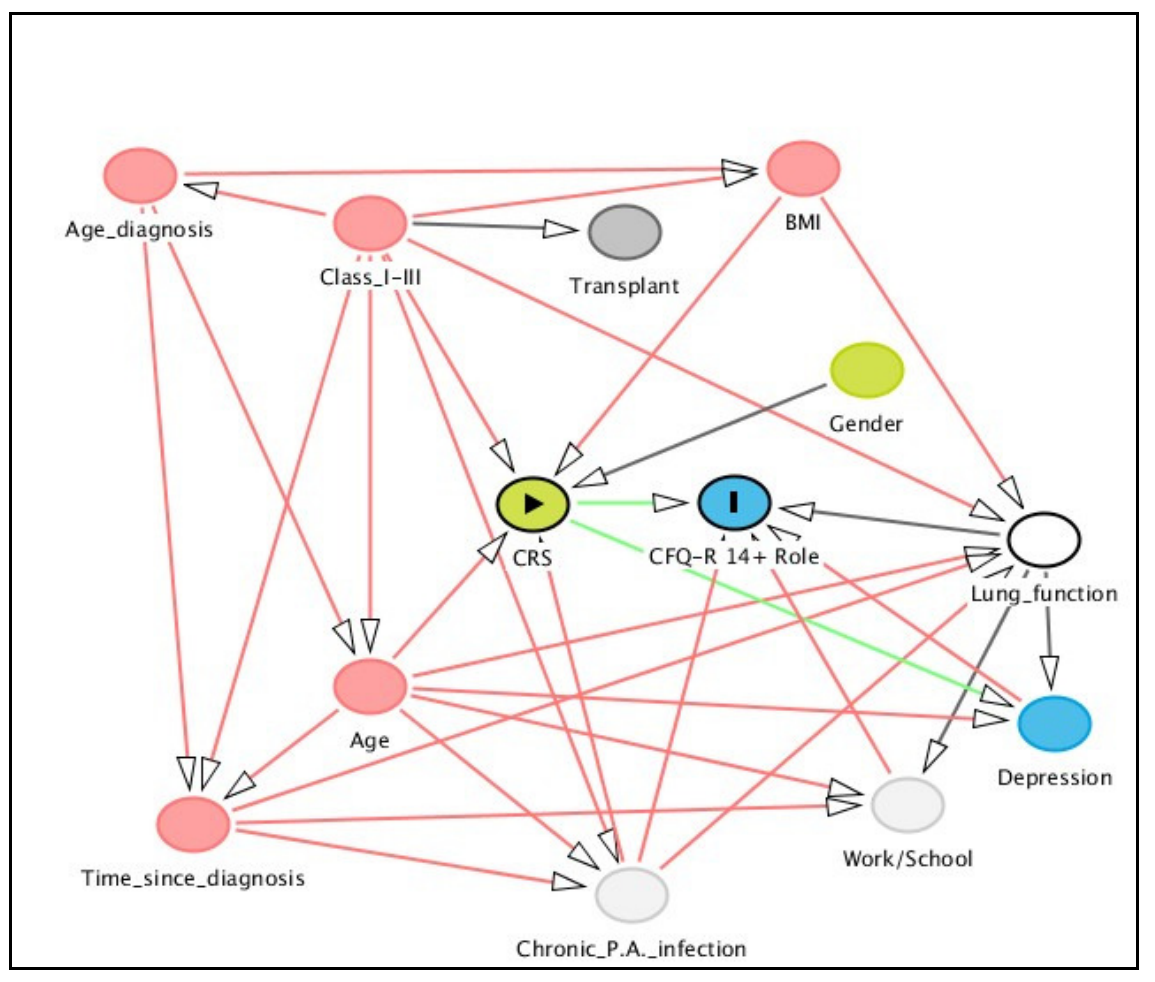

Figure E.6- Schematic illustrating the relationship between CRS and CFQ-R 14+ Eating Disturbances.

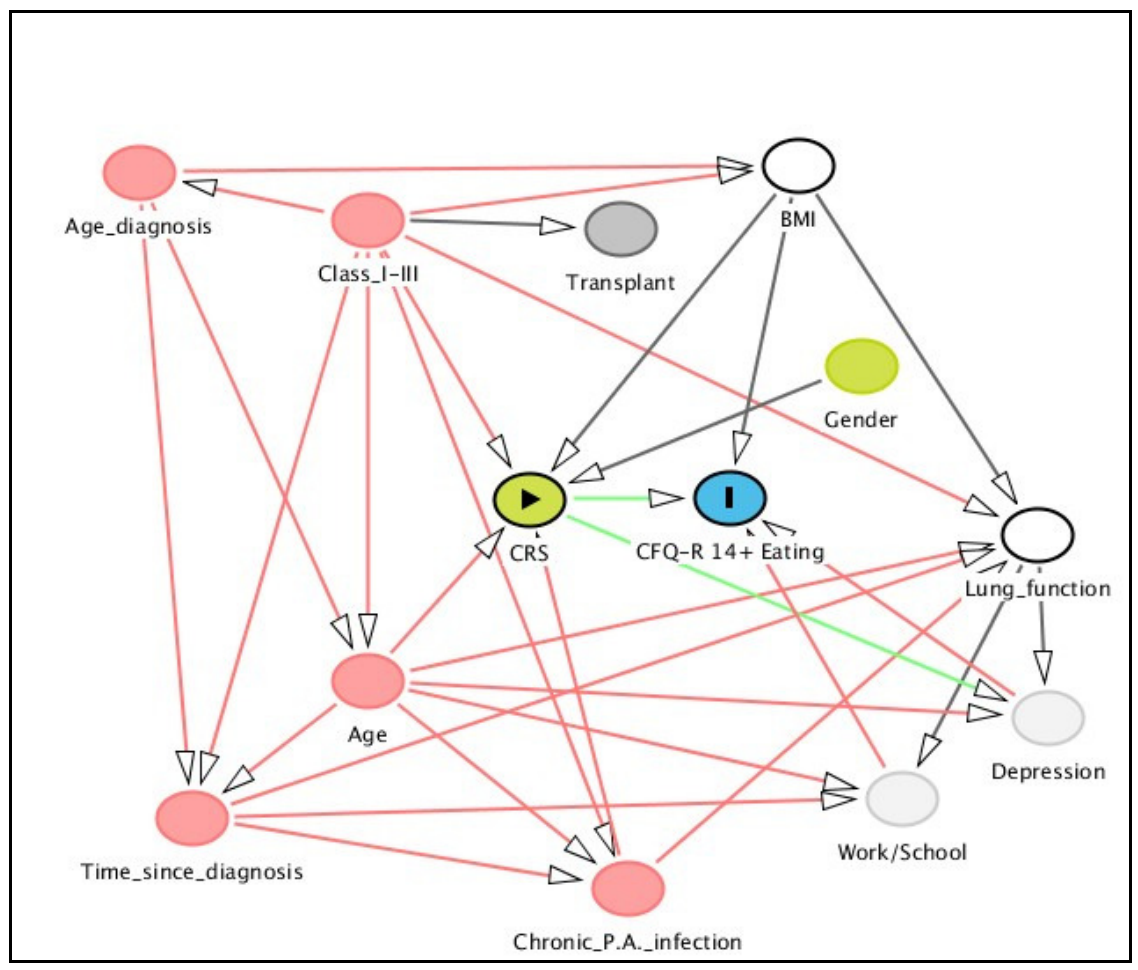


Figure E.7- Schematic illustrating the relationship between CRS and CFQ-R 14+ Body Image.

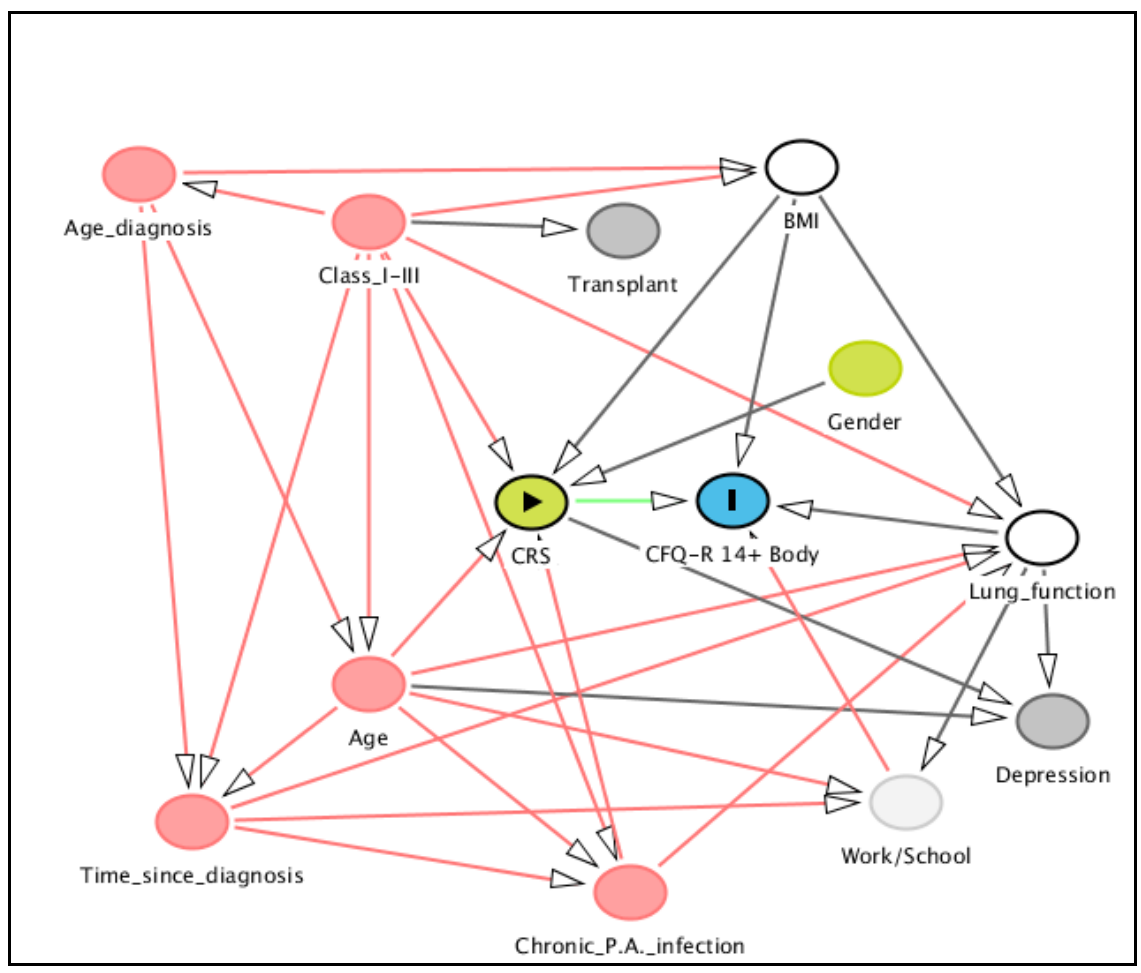


Figure E.8- Schematic illustrating the relationship between CRS and CFQ-R 14+ Treatment Burden.

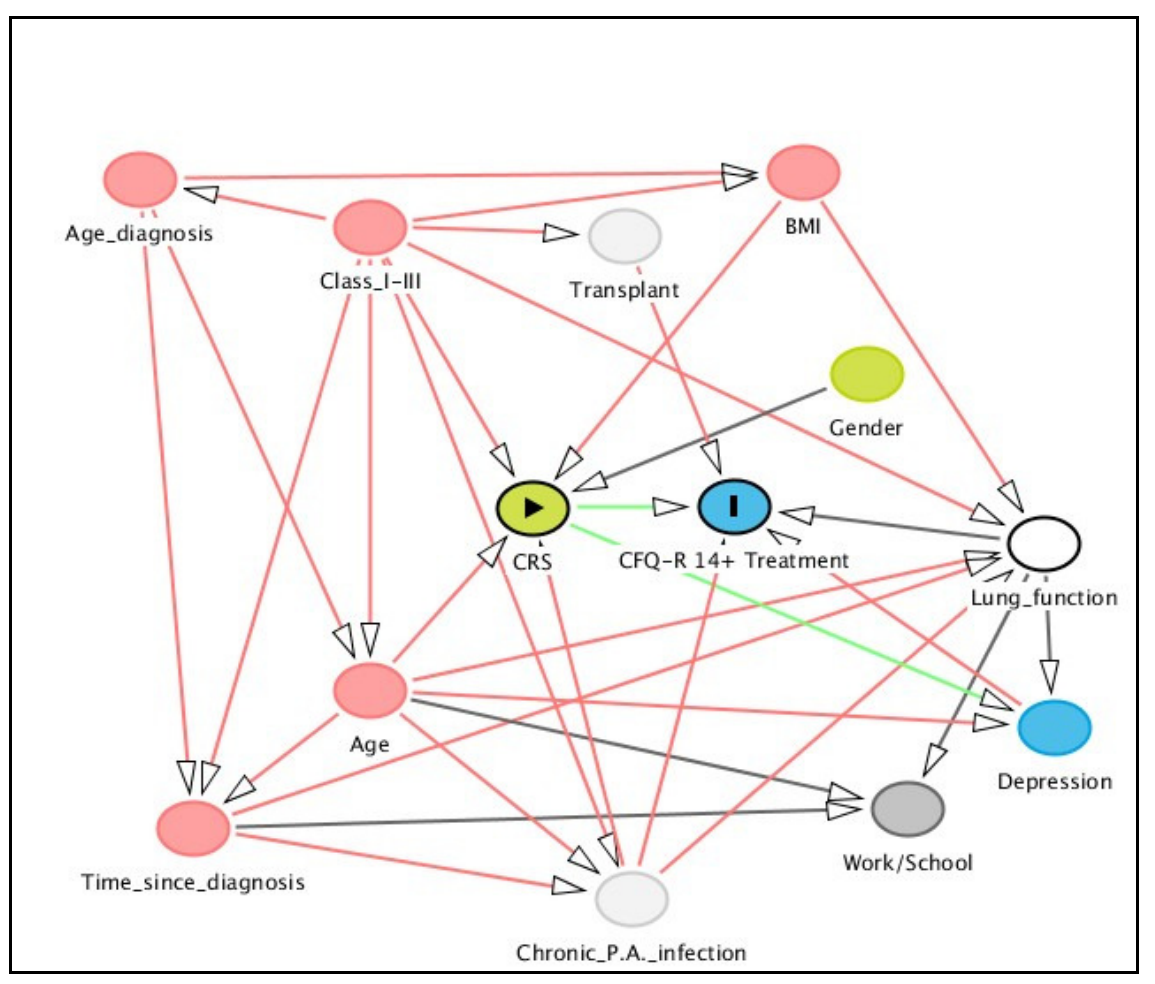


Figure E.9- Schematic illustrating the relationship between CRS and CFQ-R 14+ Health Perception.

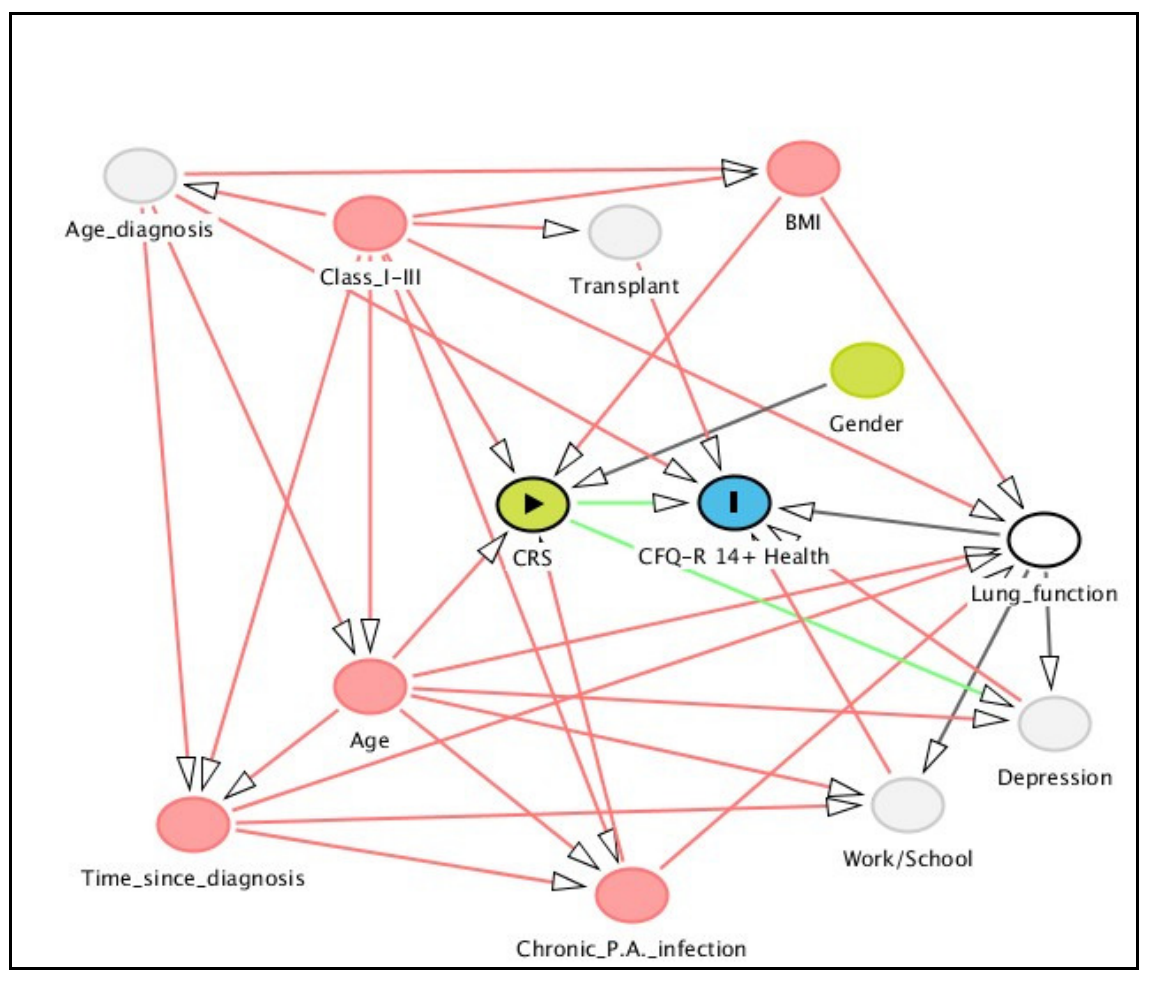

Figure E.10- Schematic illustrating the relationship between CRS and CFQ-R 14+ Respiratory Symptoms.

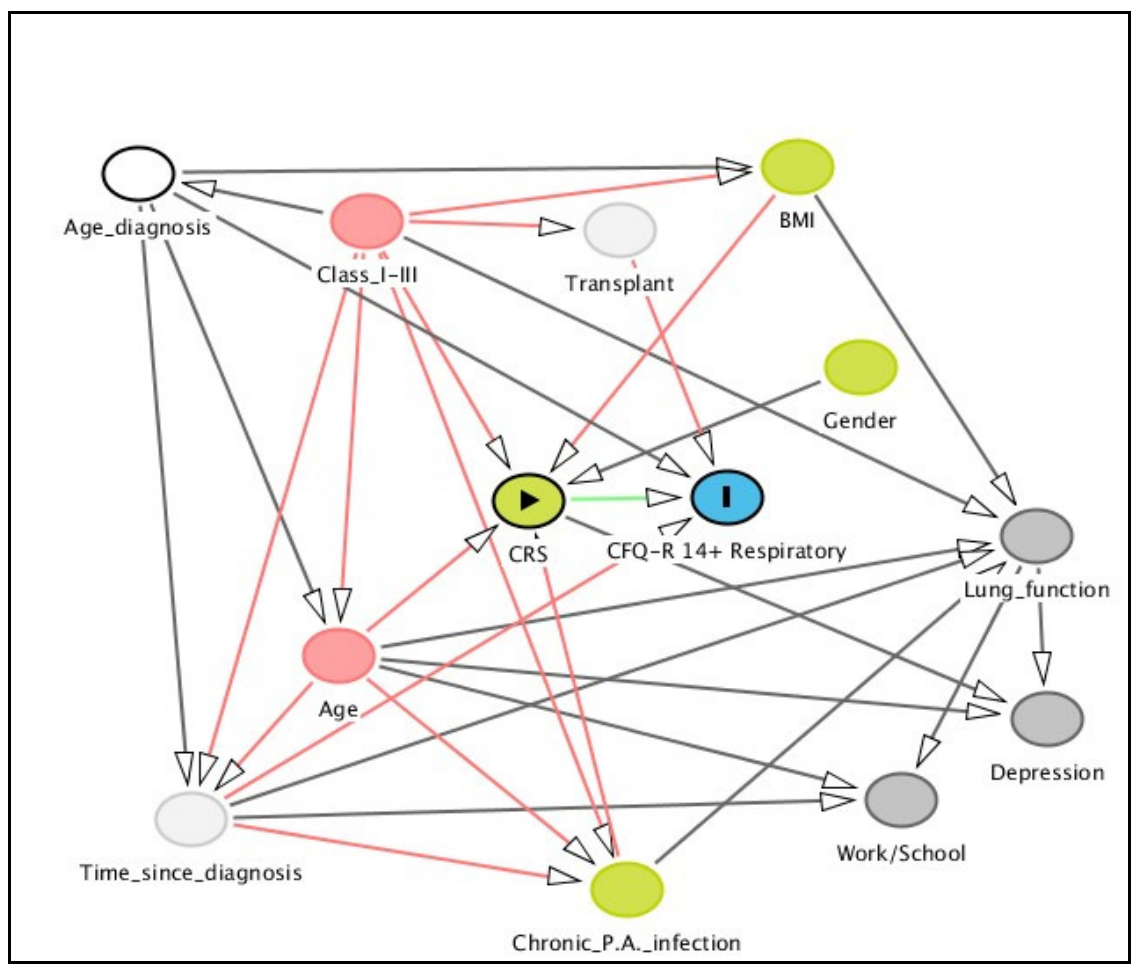


Figure E.11- Schematic illustrating the relationship between CRS and CFQ-R 14+ Digestion.

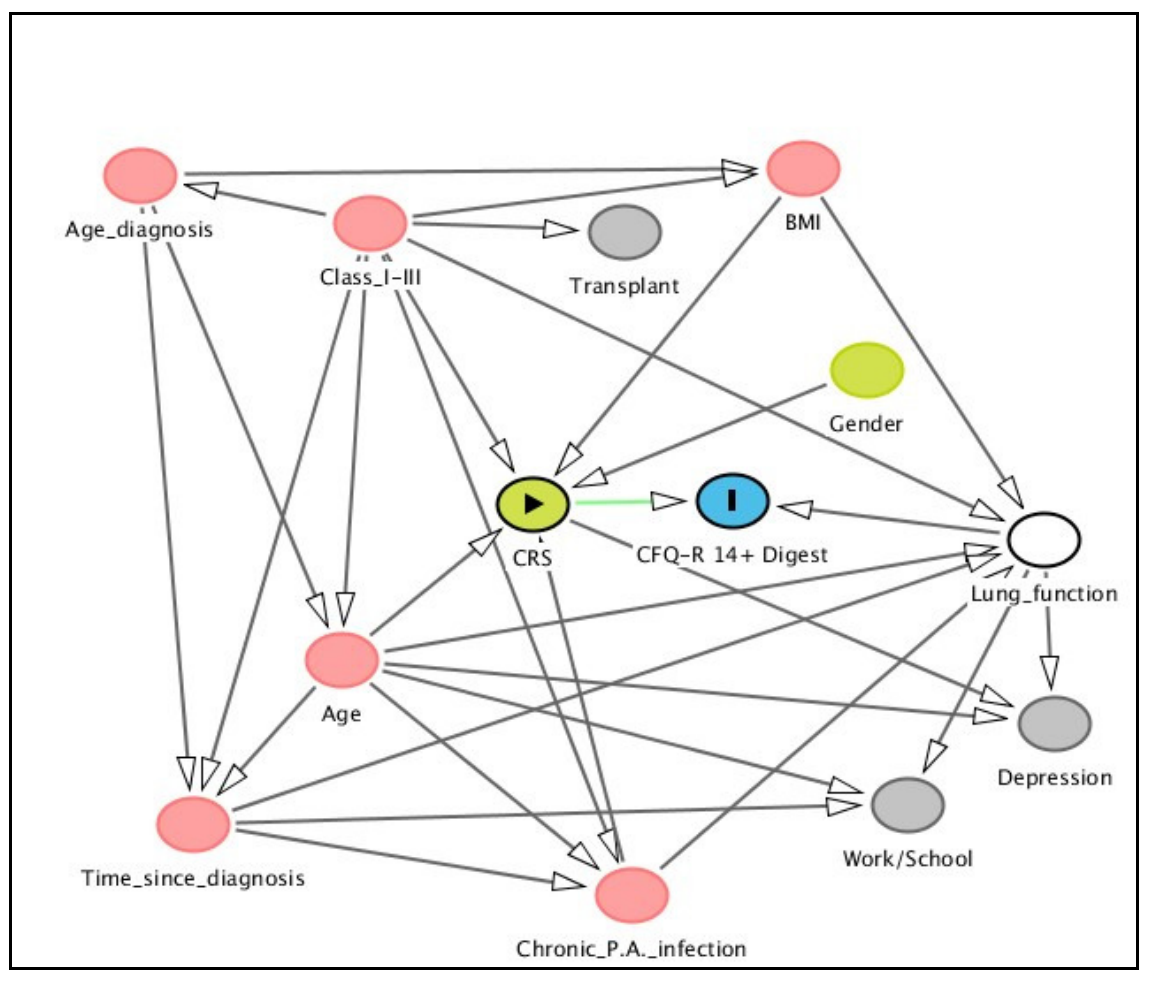

Figure E.12- Schematic illustrating the relationship between CRS and CFQ-R 14+ Weight.

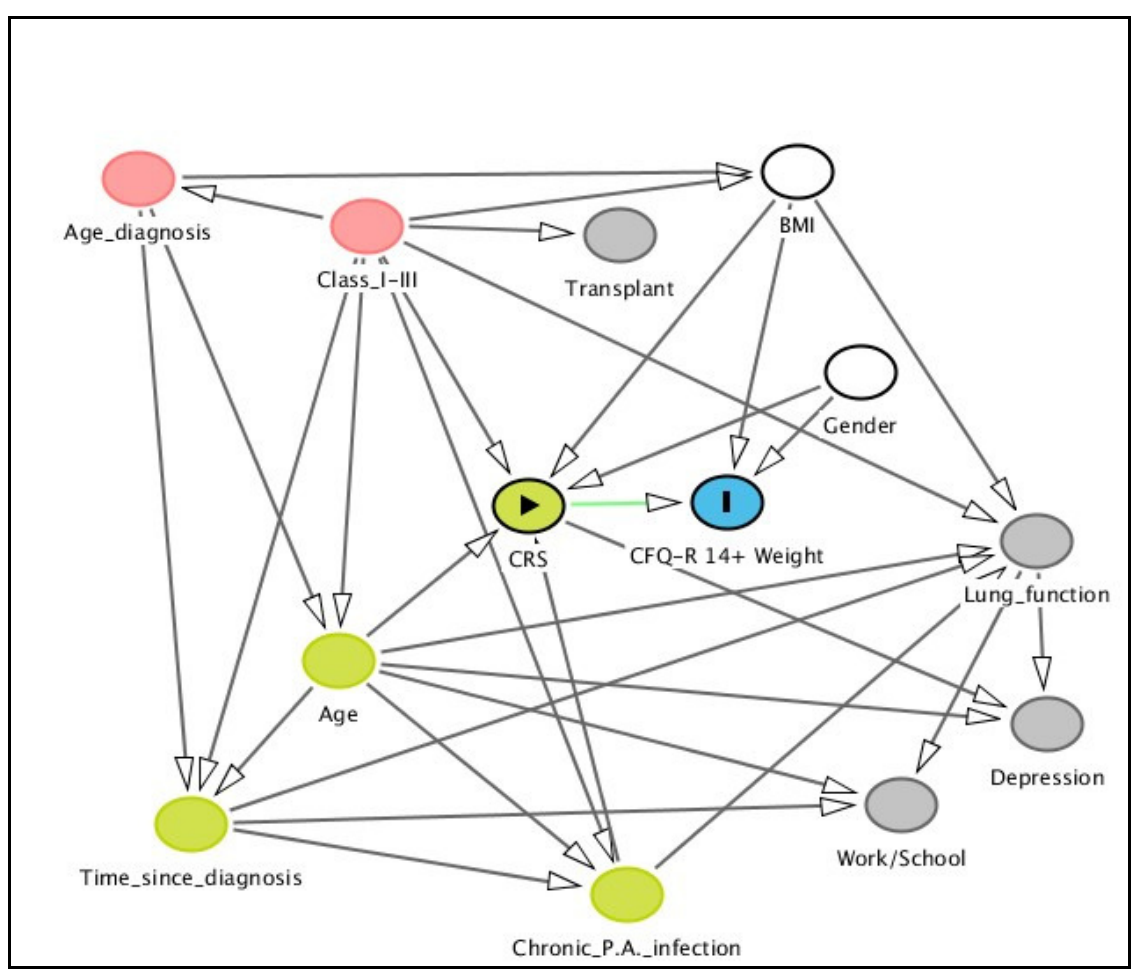

